\title{
STRUCTURAL DYNAMICS OF FREE MOLECULES AND CONDENSED STATE OF MATTER. Part II. TRANSIENT STRUCTURES IN CHEMICAL REACTIONS
}

\author{
Anatoly A. Ischenko, ${ }^{1,}$, Yury I. Tarasov ${ }^{1}$, Lothar Schäfer ${ }^{2}$ \\ ${ }^{1}$ Moscow Technological University (M.V. Lomonosov Institute of Fine Chemical Technologies), \\ Moscow 119571, Russia \\ ${ }^{2}$ Department of Chemistry and Biochemistry, University of Arkansas, Fayetteville, AR, U.S.A., AR72701 \\ ${ }^{\circledR}$ Corresponding author e-mail: aischenko@yasenevo.ru
}

Dedicated to the memory of John David Ewbank (23.12.1947-13.10.2002)

\begin{abstract}
Basic knowledge of mankind so far relates to the description of electrons and atoms in the material in a state of equilibrium, where the behavior changes slowly over time. The electron diffraction with a high temporal and space resolution has opened the possibility of direct observation of the processes occurring in the transient state of the substance (molecular movie). Here it is necessary to provide a temporary resolution of the order of $100 \mathrm{fs}$, which corresponds to the transition of the system through the energy barrier of the potential surface, which describes the chemical reaction - the process of the breaking and the formation of new bonds between the interacting agents. Thus, the possibility of the investigation of the coherent nuclear dynamics of molecular systems and the condensed matter can be opened. In the past two decades, it has been possible to observe the nuclear motion in the temporal interval corresponding to the period of the nuclear oscillation. The observed coherent changes in the nuclear system at such temporal intervals determine the fundamental shift from the standard kinetics of chemical reactions to the dynamics of the phase trajectory of a single molecule, the molecular quantum state tomography.
\end{abstract}

Keywords: transient structures, chemical reaction dynamics, conical intersections, coherent nuclear dynamics, adiabatic potential energy surface, time-resolved electron diffraction, time-resolved X-ray liquidography, ultrafast spectroscopy, pump-probe experiments.

УДК 537.533/534

\section{СТРУКТУРНАЯ ДИНАМИКА СВОБОДНЫХ МОЛЕКУЛ И КОНДЕНСИРОВАННОГО СОСТОЯНИЯ ВЕЩЕСТВА. Часть ІІ. ПЕРЕХОДНЫЕ СТРУКТУРЫ В ХИМИЧЕСКИХ РЕАКЦИЯХ}

\author{
А.А. Ищенко ${ }^{1,}$, Ю.И. Тарасов ${ }^{1}$, М. Шефер ${ }^{2}$ \\ ${ }^{1}$ Московский технологический университет (Институт тонких химических технологий \\ им. М.В. Аомоносова), Москва 119571 , Россия \\ ${ }^{2}$ Факультет химии и биохимии, Университет итата Арканзас, \\ Фэйтвилл, 72701, Арканзас, США \\ ${ }^{\circledR}$ Aвтор для переписки, e-mail: aischenko@yasenevo.ru
}

Посвящается памяти Джона Дэвида юбэнка (23.12.1947-13.10.2002) Базовые знания человечества до сих пор относятся $\kappa$ описанию электронов и атомов в вешестве, находящемся в состоянии равновесия, или близком к равновесию и медленно изменяюшемуся во времени. В то же время известно, ито химические реакции носят динамический характер, а элементарный акт химической реакиии происходит в фемтосекундном временном интервале. Дифракиия электронов с высоким временным и пространственнъм разрешением открыла возможность прямого наблюдения проиессов, происходяших в переходном состоянии вещества (молекулярный фильм). Здесь необходимо обеспечить 
временное разрешение порядка 100 фр, ито соответствует переходу системы через энергетический барьер поверхности потенииальной энергии, который описывает химическую реакиию - проиесс разрушения и образования новых связей взаимодействуюших реагентов. Таким образом, может быть раскрыта возможность исследования когерентной ядерной динамики молекулярных систем и конденсированного состояния вешества, включая его экстремальные состояния. За последние два десятилетия было возможно наблюдать движение ядер в молекулах во временном интервале, соответствуюшем периоду их колебаний. Наблюдаемые когерентные изменения в ядерной системе в такие временные интерваль определяют фундаментальный переход от стандартной кинетики химических реакиий к динамике фазовой траектории отдельной молекулы, томографии молекулярного квантового состояния.

ключевые слова: переходные структуры, динамика химической реакиии, конические пересечения, когерентная ядерная динамика, поверхность потенииальной энергии, дифракиия электронов с временньм разрешением, временная релаксаиия, сверхбыстрая дифракиия рентгеновского излучения, сверхбыстрая спектроскопия.

\section{CONTENTS}

Introduction

1. Dynamics of spectrally invisible structures

2. The Jahn-Teller effect in the photodissociation and ultrafast relaxation of $\mathrm{Fe}(\mathrm{CO})_{5}$

3. Structure and nuclear dynamics in free radicals: the Jahn-Teller effect and pseudorotation in cyclopentadienyl radicals

4. Unimolecular photodissociation of 1,2-diiodtetrafluoroethane

4.1. Structural dynamics of the elimination reaction of iodine atoms from the free $\mathrm{C}_{2} \mathrm{~F}_{4} \mathrm{I}_{2}$ molecules under collisionless conditions

4.2. Structural dynamics of iodine cleavage reaction in $\mathrm{C}_{2} \mathrm{H}_{4} \mathrm{I}_{2}$ and $\mathrm{C}_{2} \mathrm{~F}_{4} \mathrm{I}_{2}$ molecules in solution

Concluding remarks

Acknowledgements

References

\section{Introduction}

The direct observation of chemical transformations, i.e. the motions of atoms and functional groups within molecules just while they undergo chemical reactions, has been a long-standing goal. Time-resolved spectroscopy has made considerable advances, especially in the context of small molecules with few atoms. But for larger molecules the density of vibrational states in the vicinity of transition states is often so large that spectra cannot be resolved or interpreted. It is the hope that a structural method, i.e. a diffraction method, provides a fundamentally more promising path, because the number of atomic coordinates is much smaller than the number of vibrational states potentially involved in the chemical transformation. Further, unlike a spectroscopy, there is no uncertainty limitation that would limit the simultaneous measurement of atomic positions and the time resolution of the observation.
To study time-evolving molecular structures, both electron diffraction and X-ray diffraction could be attractive. The cross sections for scattering electrons are much larger than those of X-rays. Consequently, experiments on low-density vapors, where chemical dynamics of isolated molecules unaffected by their surroundings can be observed, are preferentially done using electrons. The feasibility of gas electron diffraction to probe molecular structures has been demonstrated already in 1926 by the experiments of [1, $2]$. By the 1980's, gas electron diffraction as a tool to study molecular structures had become a mature and well established field [3, 4].

To expand diffraction to the time domain, a pumpprobe scheme is implemented where the chemical dynamics is initiated by a laser pulse and the structural evolution of the photo-excited molecules is probed by an electron pulse. The technique is varyingly called time resolved electron diffraction, TRED [5-12], or Ultrafast Electron Diffraction, UED [13-17].

The development of electron diffraction techniques using picosecond [9, 10, 12, 13, 16, 18] and femtosecond $[19,20]$ electron pulses contributed to the development of ultrafast X-ray diffraction (UXD) [21-28], ultrafast electron microscopy (UEM) [9, 17, 29-34], and the dynamic transmission electron microscope (DTEM) [9, 31].

The introduction of time resolved diffraction techniques $[5,6,11,35,36]$ and the development of the principles of investigation of coherent nuclear motions of isolated molecules also aided the observations of molecular dynamics in condensed phases (please, see, e.g. reviews $[37,38]$ ). On the whole, this led to the development of a new way to study matter - coherent structural dynamics [17, 31, 32, 36, 39, 40] or coherent chemistry [41]. They represent a set of spectroscopic and diffraction techniques that are complementary to each other even though they are based on different physical phenomena. 
Studying the coherent dynamics of the nuclear subsystem of a molecule, i.e. the time-evolution of a vibrational wave-packet (see, e.g., $[17,36]$ and references therein) as a chemical reaction unfolds, requires electron pulses with a duration in the sub-picosecond range. This requirement is given by the typical lifetimes of the electronic states involved and the characteristic timescales of dephasing processes. Performing ultrafast studies with picosecond or better time resolution raises numerous questions related to the concept of the dynamic parameters of the molecular system as determined from the analysis of the time-dependent intensity of scattering electrons $[42,43]$.

On the technical side, pump-probe electron diffraction experiments pose high demands on the signal-to-noise ratio. While this could be achieved by increasing the number of electrons per pulse, ultrashort electron pulses are affected by the Coulomb repulsions between the electrons within each pulse. These spacecharge interactions can lead to a distortion of diffraction patterns and/or to an increase in the electron pulse duration. Alternative approaches take advantage of high repetition rate electron sources producing electron pulses containing only a few electrons per pulse [17, 30, 31], electron gun and interaction geometries that minimize path lengths [37], or electrons with relativistic velocities where space-charge effects are diminished [44].

\section{DYNAMICS OF SPECTRALLY INVISIBLE STRUCTURES}

Radiationless transitions take place in chemical, physical and biological systems, leading to such diverse phenomena as the conversion of radiation into heat and photoaging, and photocarcinogenesis of DNA [45-47]. Following absorption of light, the molecules can undergo two main types of non-radiative processes: (1) photochemical, including breaking bonds or isomerization, (2) photophysical, including transitions between electronic states with spin conservation (internal conversion) or with spin change (intersystem crossing). For more than eight decades ([48] and references therein), our understanding of these non-radiative processes stems from indirect observations based on measuring the rates with which the populations of electronic states change. In turn, theoretical studies have introduced the concept of "thermostat" in the molecule and the conical intersection in the energy landscape [49-51], Fig. 1.

Experimentally, the presence of non-radiative electronic relaxation processes was first determined from the steady reduction of quantum yield of molecules at low pressures [52]. With the development of pulsed laser systems it became possible to study nonradiative processes directly. Even so, the structural dynamics of the molecular system, which accompanies these processes, remained inaccessible. These "dark" structures cannot be

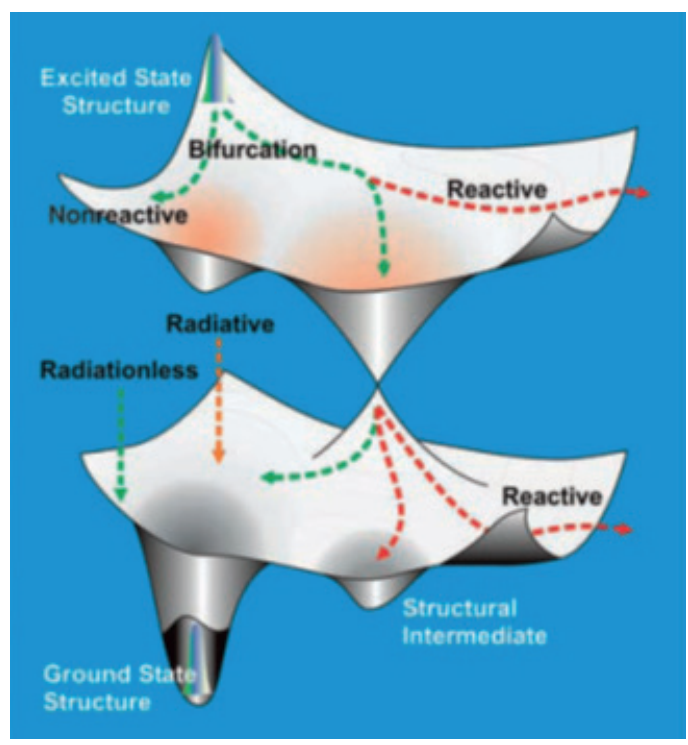

Fig. 1. The landscape of the potential surface of the ground and excited states in complex molecular systems.

The equilibrium structure of the ground state determines the initial wave packet produced by a femtosecond pulsed excitation. The excited state evolves either along a radiative or a nonradiative channel. Radiationless transitions may result in the bifurcation of a chemical reaction or physical process (internal/intersystem crossing) [17].

detected via light absorption or emission, even though they can be probed by ionization spectroscopy. Using electron diffraction or X-ray diffraction, structures of molecules in optically "dark" states can be probed (please, see review article [17]).

Ihee [et al.] [53] and Srinivasan [et al.] [17] studied the molecular structures involved in radiationless transitions that are accelerated by vibrational excitation of the molecules in the so-called "channel-three region" [54] and/or the proximity of electronic states [55]. They investigated fourprototypical heteroaromatic compounds: pyridine, 2-methylpyridine, 2,6-dimethylpyridine and benzaldehyde. The cleavage and formation of new bonds in the transition states of the molecules of pyridine and 2-methylpyridine, the formation of highly vibrationally excited structures of 2,6-dimethylpyridine and of the triplet state of quinoid form benzaldehyde allowed them to clarify the effect of the original structure on the dynamic evolution of the molecules, Fig. 2.

Pyridine, 2-methylpyridineand2,6-dimethylpyridine. Photoexcited molecules can react in several ways: the valence isomerization, fragmentation, ring opening, as shown in scheme at the top of Fig. 2 for pyridine molecule. Using TRED the dominant isomerization pathway and the structure of the intermediates were determined [17].

For registration of structural changes as a chemical reaction unfolds there were acquired diffraction patterns for several time delays from -90 ps to 185 ps for pyridine and from $-90 \mathrm{ps}$ to $215 \mathrm{ps}$ for the 2,6-dimethylpyridine. 

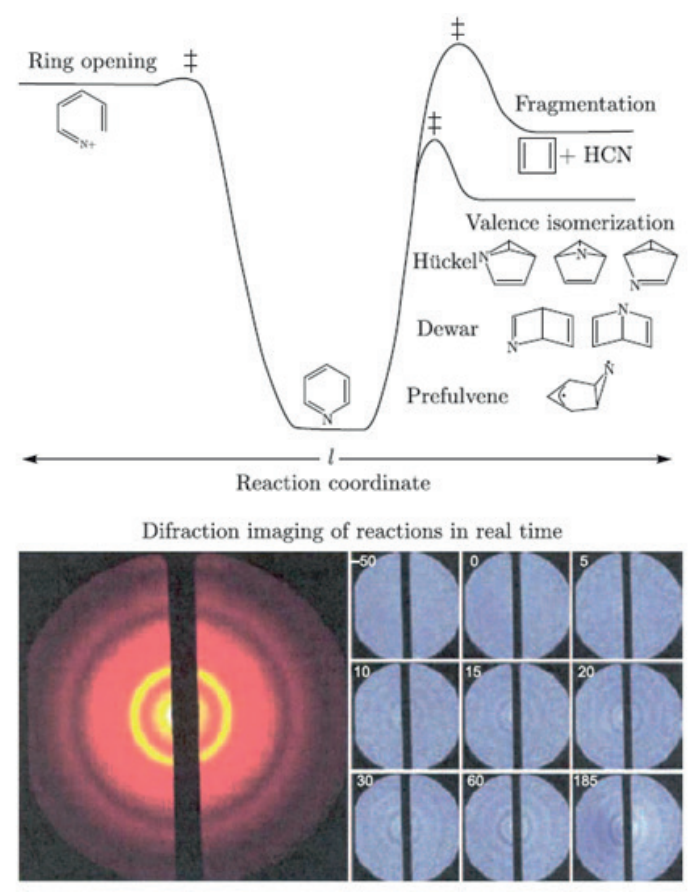

Fig. 2. Possible pathways of photochemical transformations of pyridine (top panel). TRED diffraction patterns of pyridine (lower panel). The left side - the diffraction pattern of the ground electronic state, the right one $-2 \mathrm{D}$ difference diffraction patterns obtained for different time delays between pump and probe (in ps) [17].

2D difference diffraction patterns (image at a negative delay, $-90 \mathrm{ps}$ is chosen as the reference) clearly demonstrate the change in the diffraction pattern, which is increasing with time. These rings in the difference diffraction patterns directly reflect the changes in the molecular structure. The corresponding difference radial

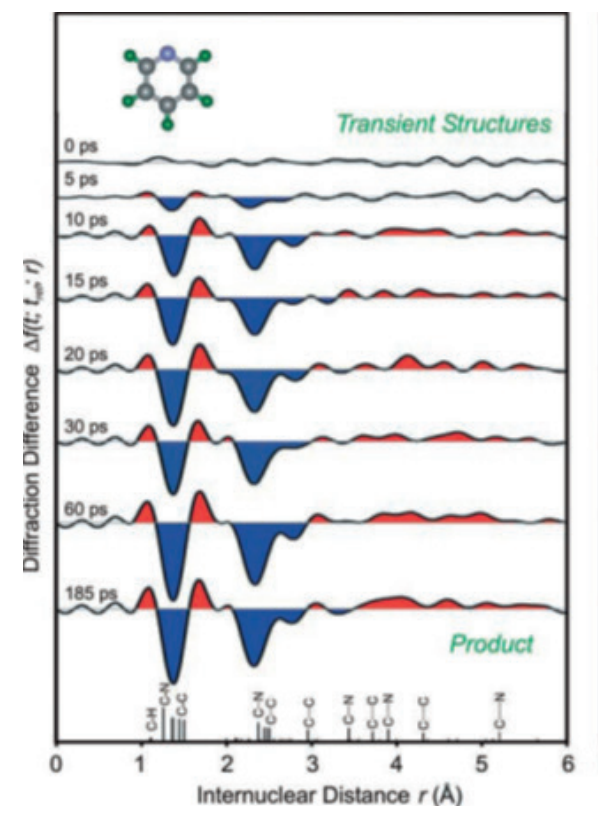

distribution curves $-f\left(t ; t_{r e f} ; r\right)$ shown in Fig. 3 contain peaks with positive and negative amplitude: negative amplitude (highlighted in blue) is positioned near $1.3 \AA$ and $2.5 \AA$, which is attributed to breakage of bonds. Peaks with positive amplitude (in red) correspond to the formation of new bonds.

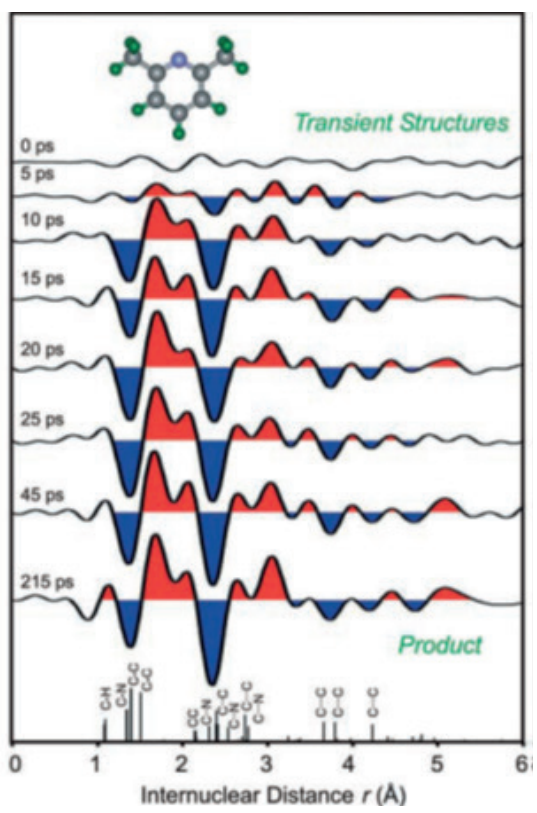

Fig. 3. Structural dynamics of pyridine and 2,6-dimethylpyridine. The radial distribution of the ground state (upper panel) and difference curves $\Delta f\left(t ; t_{r e f} ; r\right)$ (lower panel). Vertical lines on the scale of interatomic distances $r$ indicate the relative contribution of the different pairs of nuclei (ij), which amplitude is normalized to produce the nuclear charges $(Z)$ devoted by the value of internuclear distance $Z_{i} Z_{j} / r_{i j}$, multiplied by the multiplicity of the corresponding term. Peaks with positive and negative amplitudes: negative amplitude (highlighted in blue) represents the breakage of the bonds. Peaks with positive amplitudes (in red) correspond to the formation of new bonds [56]. 
For pyridine a more pronounced dynamics of the reduction of the contributions of the covalently-bonded atoms is observed, whereas for 2,6-dimethylpyridine the contribution of the unbound atoms decreases. In addition, for pyridine an increase in the contribution of unbound atoms at the distances of more than $3.5 \AA$ it is registered, which are absent for the pyridine molecule in the ground state. Please note that at these large distances, at $t=0$ only slight noises can be seen, and

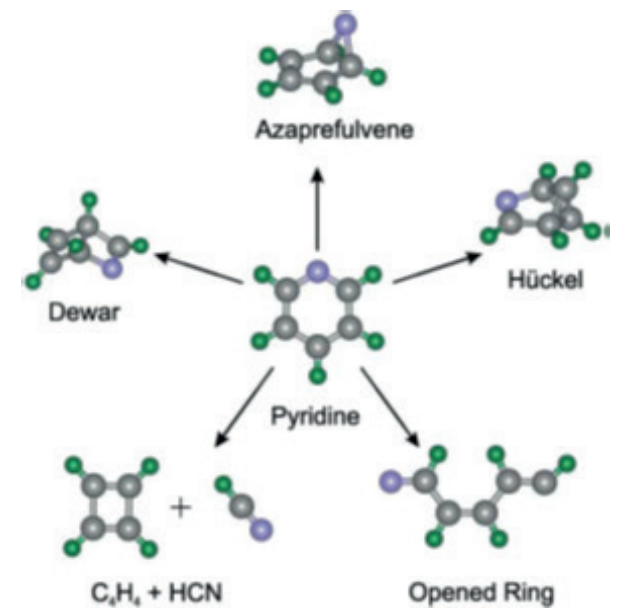

Fig. 4. Possible pyridine phototransformation pathways (please, see Fig. 1) [17].

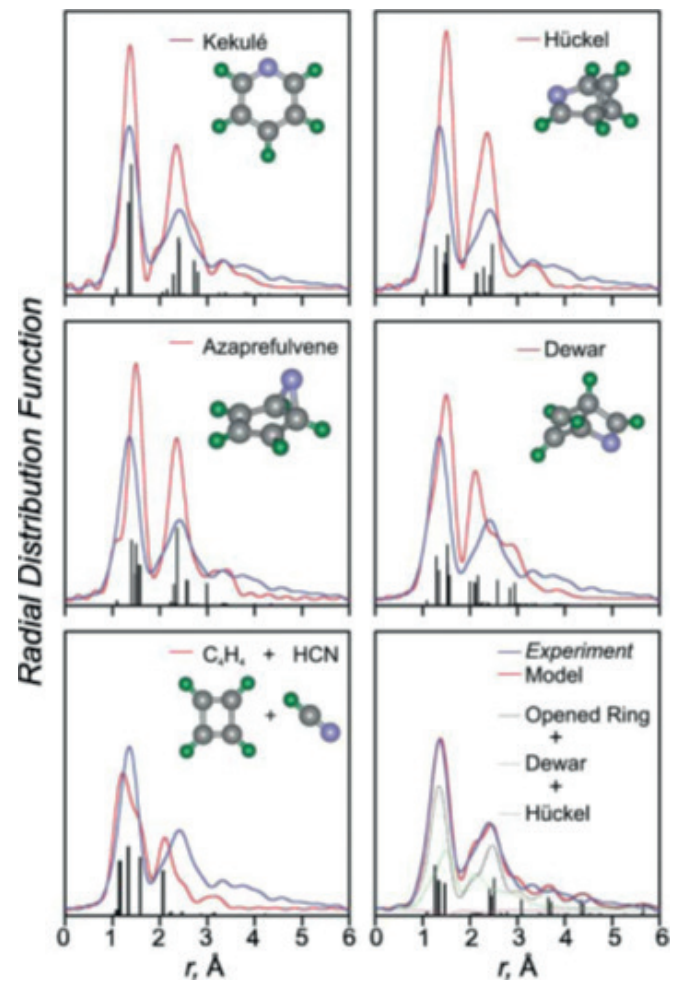

Fig. 5. Determination of the reaction pathway. Comparison of experimental (blue) and calculated (red) normalized radial distribution curves for the isolated transition structures. There is a strong mismatch for all proposed reaction channels except for the ring opening reaction with little contribution of isomeric structures of pyridine (please, see text). From ref. [17]. they transform into a sharp signal at longer time. For 2,6-dimethylpyridine the positive and the negative peaks occur as a result of the dispersion contribution from hot molecule of the relatively cold structure of the original ground state [56]. In order to distinguish between the possible reactions channels, UED data were processed for a number of structural models. Fig. 4 shows some of the structures proposed in the literature for these aromatic molecules [56].

Fig. 5 shows the experimental radial distribution curves $f(r)$ for the isolated transition structures corresponding to four time slices (from 60 to 185 ps for pyridine and theoretical curves for different models (with account of an excess internal energy). Curves were calculated for the vibrationally excited molecules - Kekulé, Dewar, Hückel isomer formation and fragmentation to $\left(\mathrm{C}_{4} \mathrm{H}_{4}+\mathrm{HCN}\right)$ are in poor agreement with experiment. It was therefore concluded that, in the time scale of the UED experiment, those reaction channels cannot be dominant. A mixture of Dewar and Hückel isomers and vibrationally "cold" (403 K) structures with an open ring shows good agreement with the experimental data. Therefore, the ring opening reaction it the main channel. Isomerization of the intermediate into the Dewar structure is not a major channel; Hückel isomer contribution is negligible.

The best agreement was reached for the ring-opening reaction of pyridine and 2-methylpyridine. The average values for amplitudes of vibrations of transition structures are $70-100 \%$ higher compared with the calculated values for the "cold" molecules $(403 \mathrm{~K})$. Perhaps this is due to non-thermal (non-Boltzmann) distribution of vibrational energy in the molecule. Contribution of Kekulé and Dewar structures is extremely small. Thus, the ring opening reaction leading to formation of vibrationally excited acyclic transition structures [17] is the primary reaction pathway.

Fig. 6 illustrates the results of a least-squares refinement of internuclear distances and mean vibrational amplitudes for the molecular component of the scattering intensity $s M(s)$ and the radial distribution function $f(r)$ for the acyclic structure of the transition state of laserinduced pyridine ring-opening reaction. The obtained structural parameters match the observed structural dynamics of the reaction. For example, the appearance of large internuclear distances $r_{a}[\mathrm{C}(1)-\mathrm{N}]=5.23 \AA$ and $r_{a}[\mathrm{C}(1)-\mathrm{C}(5)]=4.33 \AA$.

The satisfactory agreement between all structural parameters and calculated quantum-chemical values was obtained except for the nuclear separation $r_{a}[\mathrm{C}(1)-\mathrm{C}(2)]$ $=1.366$ (11) $\AA$ (the corresponding value from the quantumchemical DFT calculations is $1.318 \AA$ ), as well as one of skeletal torsion angles. The experimental data correspond to the value of the torsion angle $\phi[\mathrm{NC}(5)-\mathrm{C}(4) \mathrm{C}(3)]=123^{\circ}$, while the quantum-chemical calculation gives a value of $180^{\circ}$. This discrepancy may be due to the fact that quantumchemical calculation gives the equilibrium geometric 

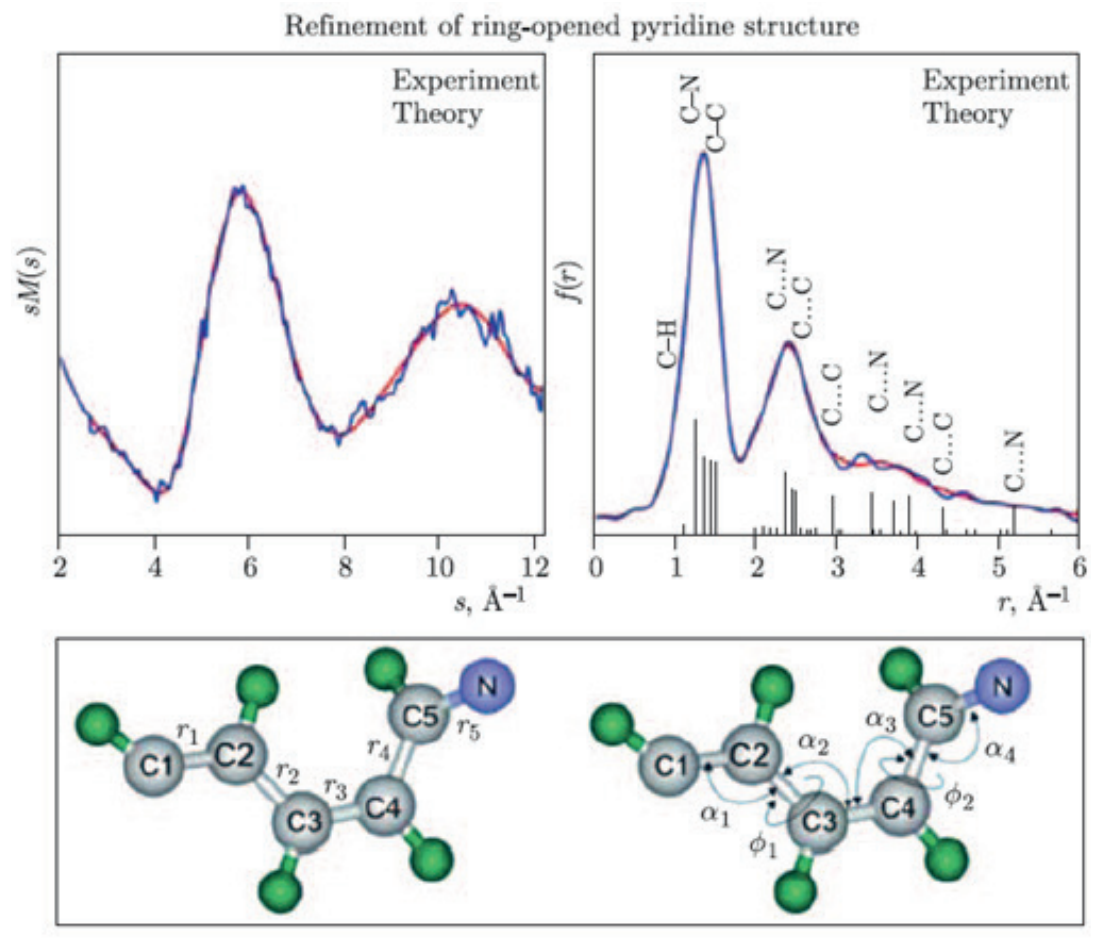

\begin{tabular}{|c|c|c|c|c|c|}
\hline \multicolumn{3}{|c|}{ Distance } & \multicolumn{3}{|c|}{ Angles } \\
\hline & Experiment & DFT & & Experiment & DFT \\
\hline$r_{1}(\mathrm{C} 1-\mathrm{C} 2)$ & $1.366 \pm 0.011$ & 1.318 & $\alpha_{1}(\mathrm{C} 1-\mathrm{C} 2-\mathrm{C} 3)$ & $127.7 \pm 4.3$ & 124.4 \\
\hline$r_{2}(\mathrm{C} 2-\mathrm{C} 3)$ & $1.433 \pm 0.012$ & 1.456 & $\alpha_{2}(\mathrm{C} 2-\mathrm{C} 3-\mathrm{C} 4)$ & $124.3 \pm 3.3$ & 127.0 \\
\hline$r_{3}(\mathrm{C} 3-\mathrm{C} 4)$ & $1.342 \pm 0.033$ & 1.348 & $\alpha_{3}(\mathrm{C} 3-\mathrm{C} 4-\mathrm{C} 5)$ & $123.4 \pm 3.6$ & 125.7 \\
\hline$r_{4}(\mathrm{C} 4-\mathrm{C} 5)$ & $1.487 \pm 0.018$ & 1.466 & $\alpha_{4}(\mathrm{C} 4-\mathrm{C} 5-\mathrm{N})$ & $121.1 \pm 2.7$ & 124.4 \\
\hline \multirow[t]{2}{*}{$r_{5}(\mathrm{C} 5-\mathrm{N})$} & $1.244 \pm 0.014$ & 1.256 & $\phi_{1}(\mathrm{C} 1 \mathrm{C} 2-\mathrm{C} 3 \mathrm{C} 4$ & ) $185 \pm 36$ & 180 \\
\hline & & & $\phi_{1}(\mathrm{NC} 5-\mathrm{C} 4 \mathrm{C} 3)$ & $-123 \pm 4$ & -180 \\
\hline
\end{tabular}

Fig. 6. Structure of acyclic transition state, which is formed by photoexcitation of pyridine molecules with $266 \mathrm{~nm}$ photons in the gas phase in collisionless environment. The experimental (blue) and theoretical (red) molecular scattering intensity curves $s M(s)$ and the radial distribution $f(r)$ for the isolated transition state are shown. The values of interatomic distances (in $\AA$ ) and angles (in degrees) obtained using Ultrafast Electron Diffraction and quantum-chemical calculations using DFT [17] are given. Possible causes of mismatch are discussed in the text.

parameters of the molecule, while the data of the ultrafast electron diffraction demonstrate the vibrational effects, the nonequilibrium distribution of vibrational energy among the various vibrational modes of the transient state, which is essentially manifested in the diffraction data. Neglecting this factor can lead to the significant distortions of the parameters of the studied transient structure. Similar results, showing a ring opening and the formation of acyclic transient state, were obtained for the molecules of 2-methylpyridine. For a molecule of 2,6-dimethylpyridine it was shown with time resolution of $\sim 1$ ps that the ring opening didn't occur in the temporal interval of up to $215 \mathrm{ps}$. The transient state corresponds to the highly vibrationally-excited cyclic structure [17].

Further, the data on the structural evolution of the isolated transient state was obtained as shown in the time-dependent radial distribution curves in Fig. 7. Except for their relative intensities, the forms of the radial distribution $\mathrm{f}(\mathrm{r})$ are almost unchanged over time.
It means that the structure of the transient state remains essentially constant on the timescale of the experiment. Only the value of the population of this state changes. When elaborating the value of the population by the least squares method, the time constant of 17(1) ps was determined (Fig. 7). These results combined with the analysis of the difference intensity curves, show that the ring-opening leads to the disruption of its aromaticity, and the subsequent increase in the population of the acyclic transient state occurs with the time constant of $17(1)$ ps. In this condition, the internuclear distance $\mathrm{C}-\mathrm{C}$ of the aromatic ring of pyridine should transform into the distance of $\mathrm{C}=\mathrm{C}$ characteristic for aliphatic compounds.

The corresponding time constants were determined for 2-methylpyridine and 2,6-dimethylpyridine as 28(7) ps and 16(2) ps, respectively [56]. Thus, for the molecules of pyridine and 2-methylpyridine there is a formation of so-called "three-channel" [55] due to the ring opening and the formation of acyclic biradical 


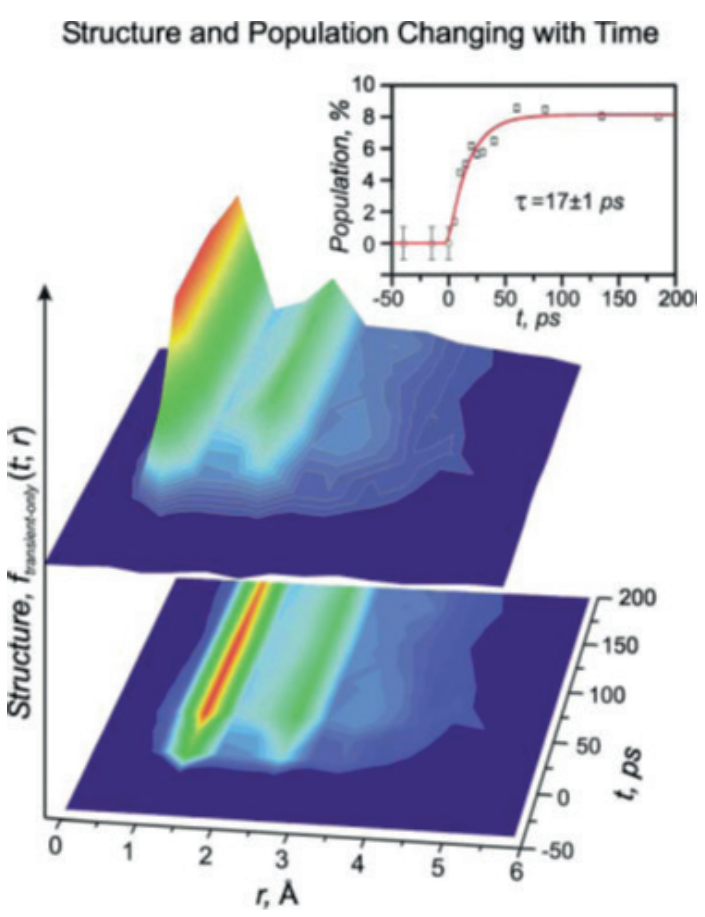

Fig. 7. The structure of pyridine and the population of acyclic transition state as a function of time. Radial distribution curve $f(t, r)$ shows the formation of an acyclic transition state. The inset shows the time dependence of the population of the transition state that corresponds to the time of 17 (1) ps. 2D images indicate the range of interatomic distances $(0-6 \AA)$, and their changes over time (see text). From ref. [17].

structure, while for 2,6-dimethylpyridine a highly excited cyclic transition state is observed. This explains the significant differences observed in the study of this group of molecules by transition-state spectroscopy with femtosecond time resolution [57].

\section{THE JAHN-TELLER EFFECT IN THE PHOTODISSOCIATION AND ULTRAFAST RELAXATION OF Fe(CO)}

It has long been known that metal carbonyl compounds eliminate a CO group upon photolysis in the UV $[58,59]$. It was not known however, whether this reaction proceeds as a simple bond breaking on a directly repulsive potential energy surface, such as is the case in some organic iodides, for instance. Some of the unsaturated reaction products are formed as triplets, raising the question where intersystem crossing occurs [60]. The dissociation was believed to occur via a directly repulsive potential energy curve [58, 59] to produce the ground state of an unsaturated carbonyl (sometimes a triplet). It has also been claimed that several CO groups can be more or less synchronously eliminated [61]. Modern femtosecond spectroscopy [60] and UED can investigate the dynamics during the photodissociation and provide information about the potential energy surfaces [62].
Among the transition metal carbonyls, $\mathrm{Fe}(\mathrm{CO})_{5}$ is one of the most extensively studied molecular systems (please, see refs. [63, 64] and references therein). $\mathrm{Fe}(\mathrm{CO})_{5}$ can dissociate into five different products $\mathrm{Fe}(\mathrm{CO})_{\mathrm{x}}, \mathrm{x}=4,3,2,1,0$, depending on the excitation wavelength $[60,65,66]$. In these reactions, $\mathrm{Fe}(\mathrm{CO})_{4}$ is the primary intermediate and serves as a doorway molecule for various subsequent reactions, such as decomposition, recombination with the carbonyl ligand, and coordination with solvent molecules [67].

The first GED study of $\mathrm{Fe}(\mathrm{CO})_{5}$ was performed by Ewens and Lister in 1939 [68], but numerous further studies followed [69-73]. In the GED study of Beagley and Schmidling [72] at $303 \mathrm{~K}$ the average distances for the trigonal bypiramidal $\left(\mathrm{TBP}, \mathrm{D}_{3 \mathrm{~h}}\right)$ structure of the $\mathrm{Fe}(\mathrm{CO})_{5}$ were determined to be: $r_{g}(\mathrm{Fe}-\mathrm{C})_{\text {average }}=$ $182.1(3) \mathrm{pm} ; r_{g}(\mathrm{C}-\mathrm{O})_{\text {average }}=115.3(3) \mathrm{pm}$. It was also shown that equatorial distances $r_{g}(\mathrm{Fe}-\mathrm{C})_{\mathrm{eq}}$ are longer than axial ones, $r_{g}(\mathrm{Fe}-\mathrm{C})_{\mathrm{ax}}$ with the difference being $\Delta\left(\mathrm{FeC}_{\mathrm{eq}}-\mathrm{FeC}_{\mathrm{ax}}\right)=2.0(6) \mathrm{pm}$.

In $2001 \mathrm{Fe}(\mathrm{CO})_{5}$ was reinvestigated in $\mathrm{K}$. Hedberg's laboratory with a focus on the question: "Are the axial or the equatorial Iron-Carbon Bonds Longer in the Gaseous Molecule?" [73]. The structure of iron pentacarbonyl, $\mathrm{Fe}(\mathrm{CO})_{5}$, was studied at 295-298 K using an experimental rotational constant available from the literature as a constraint on the structural parameters. The study utilized a B3LYP/6-311+G(d) $a b$ initio quadratic force field, scaled to fit the observed infrared wavenumbers, from which corrections were calculated for the effects of vibrational averaging. The Hedberg results confirmed that the equatorial $\mathrm{Fe}-\mathrm{C}$ bonds are longer than the axial ones, an important difference to the structure in crystalline phases where the equatorial $\mathrm{Fe}-\mathrm{C}$ bonds are shorter. Some distance $\left(r_{g} / \mathrm{pm}\right)$ and vibrational amplitude $(l \alpha / \mathrm{pm})$ parameter values (with estimated $2 \sigma$ uncertainties) based on the assumption of $\mathrm{D}_{3 \mathrm{~h}}$ symmetry are: $[r(\mathrm{Fe}-\mathrm{C})]_{\text {average }}=182.9(2),\left[r(\mathrm{Fe}-\mathrm{C})_{\mathrm{eq}}-r(\mathrm{Fe}-\mathrm{C})_{\mathrm{ax}}\right]$ $=3.2(2.0),[r(\mathrm{C}-\mathrm{O})]_{\text {average }} 114.6(2), r(\mathrm{C}-\mathrm{O})_{\mathrm{eq}}-r(\mathrm{C}-\mathrm{O})_{\mathrm{ax}}$ $=6(27), r(\mathrm{Fe}-\mathrm{C})_{\mathrm{ax}}=181.0(1.6), r(\mathrm{Fe}-\mathrm{C})_{\mathrm{eq}}=184.2(1.1)$, $r(\mathrm{C}-\mathrm{O})_{\mathrm{ax}}=114.2(2.3), r(\mathrm{C}-\mathrm{O})_{\mathrm{eq}}=114.9(1.6), l(\mathrm{Fe}-\mathrm{C})_{\mathrm{ax}}$ $=l(\mathrm{Fe}-\mathrm{C})_{\mathrm{eq}}=4.7(5)$, and $l(\mathrm{C}-\mathrm{O})_{\mathrm{ax}}=l(\mathrm{C}-\mathrm{O})_{\mathrm{eq}}=3.6(3)$.

Pseudorotation in $\mathrm{Fe}(\mathrm{CO})_{5}$ was not studied by GED. In 1998 Jang [et al.] [74] calculated the barrier to pseudoratation suggesting a Berry mechanism (i.e., a $\mathrm{C}_{4 \mathrm{v}}$ transient state). The results give the energy difference between $\mathrm{D}_{3 \mathrm{~h}}$ and $\mathrm{C}_{4 \mathrm{v}}$ configurations of the $\mathrm{Fe}(\mathrm{CO})_{5}$ equal to: 2.25 (DZ B3LYP), 2.28 (DZP BP86), 2.33(DZP B3LYP) $\mathrm{kcal} / \mathrm{mol}$.

The electronic structure of $\mathrm{Fe}(\mathrm{CO})_{5}$, was studied with quantum-chemical calculations at different levels by a number of groups (please, see [75] and references therein). They found that $\mathrm{Fe}(\mathrm{CO})_{5}$ is a $\mathrm{D}_{3 \mathrm{~h}}$ symmetry with a closed-shell ${ }^{1} \mathrm{~A}$ ' ground state corresponding to a formal $\mathrm{Fe}^{3} \mathrm{~d}_{8}$ occupation. 
In 1998 Hoffmann and co-workers calculated decomposition energies, fragment orbital overlaps, and fragment orbital populations for $\mathrm{Fe}(\mathrm{CO})_{4} \mathrm{AB}\left(\mathrm{AB}=\mathrm{N}_{2}\right.$, $\mathrm{CO}, \mathrm{BF}, \mathrm{SiO}$ ), at the NL-SCF/TZ(2P) computational level [76]. Arguably, the main reason for the special character of $\mathrm{CO}$ (especially important to the experimentalist) is the excellent balance within this diatomic between its internal stability and its excellent binding. $\mathrm{CO}$ has an intermediate HOMO-LUMO gap, which makes it stable (one can handle the stable gas easily in a laboratory) yet moderately reactive [76]. The HOMO of $\mathrm{CO}, 5 \sigma$, is an orbital relatively high in energy that is most suitable for $\mathrm{M}-\mathrm{CO}$ bonding. But, as shown in the case of $\mathrm{Fe}(\mathrm{CO})_{5}$, back-bonding into $2 \pi(\mathrm{CO})$ orbitals is in many cases even more important than $\sigma$-donation. It is this balance between donating and accepting capabilities that makes $\mathrm{CO}$ a special ligand for transition metal chemistry. $\mathrm{CO}$ is in many cases strongly bound and inert, a good spectator ligand, but not so inert as to never react. The $2 \pi$ acceptor orbital is low enough in energy to enable reactions at the CO ligand, depending on the metal and the ligand environment involved [76].

Two types of covalent interactions between $\mathrm{Fe} 3 \mathrm{~d}$ and $\mathrm{CO}$ are important for the bonding in this organometallic complex: a $\sigma$ donation from the $\mathrm{CO} \sigma$ into the formally empty $\mathrm{Fe} 3 \mathrm{~d}_{\mathrm{z2}}$ orbital of $a^{\prime}$ symmetry, and a concomitant $\pi$ back-donation from the four doubly occupied $\mathrm{Fe} 3 \mathrm{~d}$ orbitals of symmetry e' and e" into the $\mathrm{CO} \pi^{*}$ orbitals [75] (Pierloot, 2003). A qualitative MO scheme representing both bonding types is shown in Fig. 8.

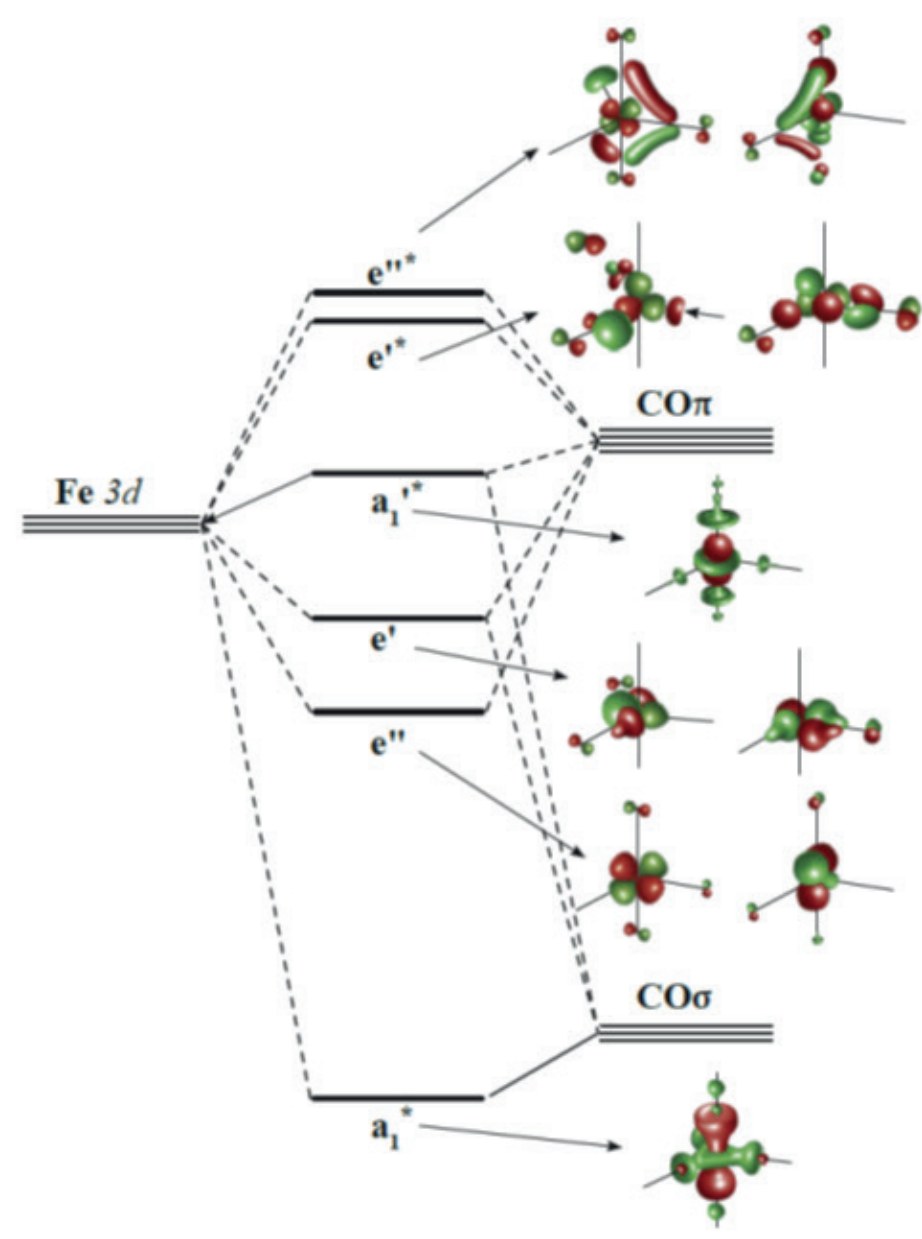

Fig. 8. Qualitative $\mathrm{MO}$ energy-level scheme for $\mathrm{Fe}(\mathrm{CO})_{5}$, showing the ten orbitals involved in covalent $\sigma$-donation from $\mathrm{CO} \sigma$ to $\mathrm{Fe} 3 \mathrm{~d}$ and $\pi$-back-donation from $\mathrm{Fe} 3 \mathrm{~d}$ to $\mathrm{CO} \pi^{*}$ [75].

Excitations from the bonding orbitals e' and e" into the antibonding $a_{1}$ ' orbital give rise to four LF excited states ${ }^{3} \mathrm{E}^{\prime},{ }^{3} \mathrm{E} ",{ }^{1} \mathrm{E}^{\prime}$ and ${ }^{1} \mathrm{E}$ ", with CASPT2 excitation energies ranging between 28,000 and $42,000 \mathrm{~cm}^{-1}$. The qualitative $\mathrm{MO}$ energy-level scheme for $\mathrm{Fe}(\mathrm{CO})_{5}$ shows the ten orbitals involved in covalent $\sigma$-donation from $\mathrm{CO}$ $\sigma$ to $\mathrm{Fe} 3 \mathrm{~d}$ and $\pi$-back-donation from $\mathrm{Fe} 3 \mathrm{~d}$ to $\mathrm{CO} \pi^{*}[75]$.
In a UED study of the photodecomposition of $\mathrm{Fe}(\mathrm{CO})_{5}$ published in 2001 [77] the determination of the molecular structure of transient $\mathrm{Fe}(\mathrm{CO})_{4}$ was reported, and the primary photodecomposition reaction pathway was identified. The major issue resolved in the UED study of the photodissociation of $\mathrm{Fe}(\mathrm{CO})_{5}[77]$ was indeed the dissociation pathway problem. Based on the evidence of 
UED experimental data, Ihee [et al.] concluded that the gas-phase structure of the transient $\mathrm{Fe}(\mathrm{CO})_{4}$ was in good agreement with that predicted for $\mathrm{Fe}(\mathrm{CO})_{4}\left({ }^{1} \mathrm{~A}_{1}, \mathrm{C}_{2 \mathrm{v}}\right)$. Moreover, Ihee [et al.] stated that "the $\left[\mathrm{Fe}(\mathrm{CO})_{4}\right]$ structure in the ${ }^{1} \mathrm{~A}_{1}$ state is very similar to that of $\mathrm{Fe}(\mathrm{CO})_{5}$, with one equatorial carbonyl group removed, while the structure of $\mathrm{Fe}(\mathrm{CO})_{4}$ in the ${ }^{3} \mathrm{~B}_{2}$ state is significantly distorted" [77]. This also supports the equatorial $\mathrm{CO}$ elimination. The diffraction-difference curves $\Delta \mathrm{sM}(+200 \mathrm{ps} ;-180 \mathrm{ps} ; \mathrm{s})$ and $\Delta \mathrm{f}(+200 \mathrm{ps} ;-180 \mathrm{ps} ; \mathrm{r})$, Fig. 9, and GED patterns of isolated $\mathrm{Fe}(\mathrm{CO})_{5}\left({ }^{1} \mathrm{~A}_{1}, \mathrm{D}_{3 \mathrm{~h}}\right), \mathrm{Fe}(\mathrm{CO})_{4}\left({ }^{1} \mathrm{~A}_{1}, \mathrm{C}_{2 \mathrm{v}}\right)$, and $\mathrm{Fe}(\mathrm{CO})_{4}\left({ }^{3} \mathrm{~B}_{2}, \mathrm{C}_{2 \mathrm{v}}\right)$, Fig. 9, were simulated at $\mathrm{T}=341 \mathrm{~K}$ using different codes for the diffraction fitting [77]. The fraction of $\mathrm{Fe}(\mathrm{CO})_{5}\left(1 \mathrm{~A}_{1}, \mathrm{D}_{3 \mathrm{~h}}\right)$ was set equal to 1.0 and 0.86 at -180 and $+200 \mathrm{ps}$, respectively [77], which scales the amplitude of the difference signal. In agreement with what was stated in ref. [77], the diffraction-difference curves characterizing $\mathrm{Fe}(\mathrm{CO})_{4}\left({ }^{1} \mathrm{~A}_{1}, \mathrm{C}_{2 \mathrm{v}}\right)$ and $\mathrm{Fe}(\mathrm{CO})_{4}$ $\left({ }^{3} \mathrm{~B}_{2}, \mathrm{C}_{2 \mathrm{v}}\right)$ turned out to be very different (Figs. 9e and $9 \mathrm{f}$ ).
Though the singlet-triplet diffraction difference obtained using the UED approach decreased significantly upon the inclusion of more realistic vibrational amplitudes (Figs. 9c and 9d), there was hardly any change in the inner $r-$ and s-regions of the diffraction-difference curves where it could be detected experimentally with a sufficient degree of reliability. In the UED study, the exact temperature of reactants and products can only be roughly estimated. Though the temperature change of $\sim 200 \mathrm{~K}$ appears to have a certain impact on the molecular intensity and radial distribution curves, the overall shape of the diffraction pattern does not seem to be significantly affected within the framework of the model (Fig. 9).

On the basis of an extensive testing and analyses of both UED models and software, it was concluded [77] that the challenging task of distinguishing between the singlet and the triplet states of transient $\mathrm{Fe}(\mathrm{CO})_{4}$ in an electron diffraction experiment has been successfully resolved.
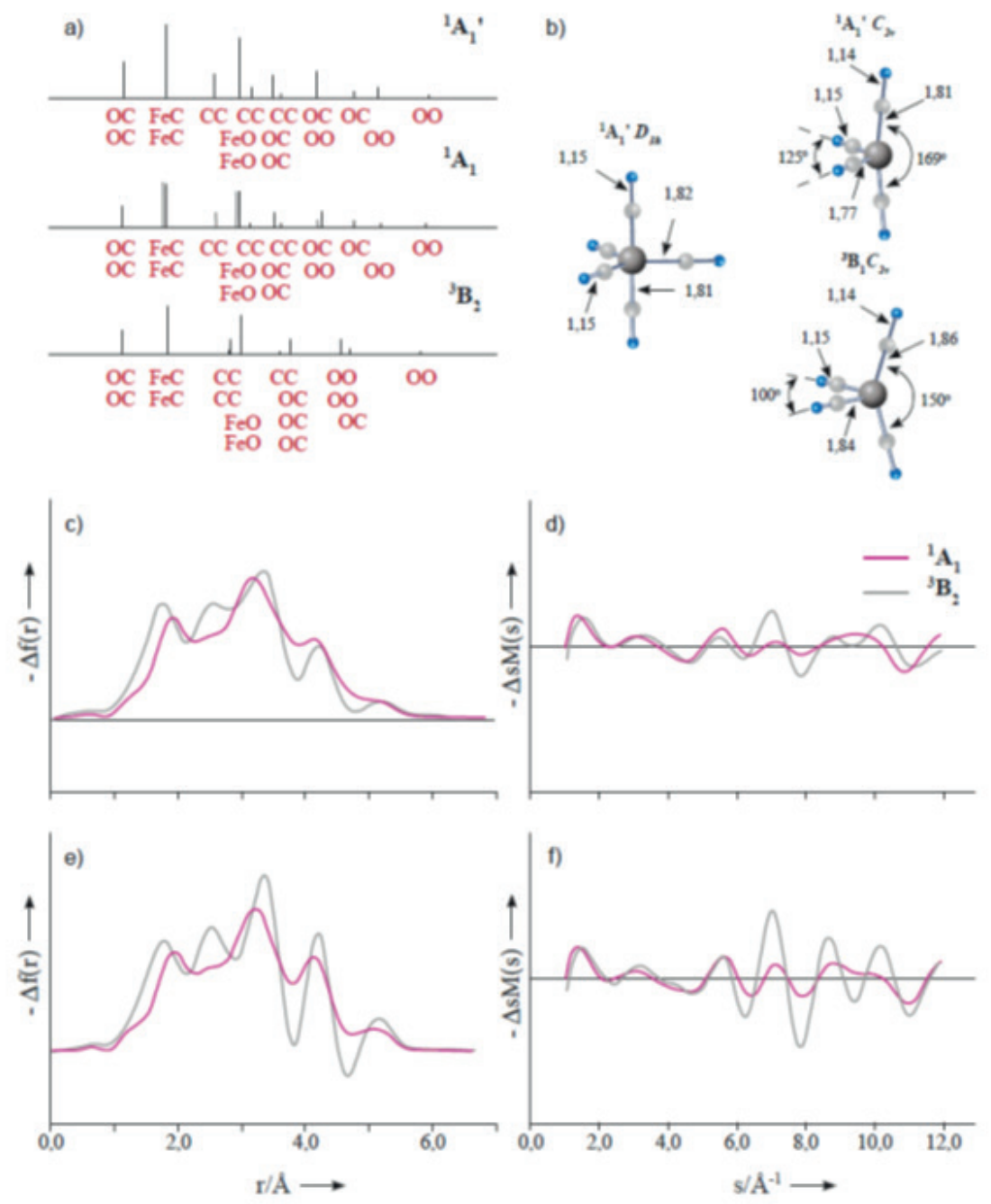

Fig. 9. a) Schematically represented scattering terms of the gas-phase structures (b) of Fe(CO) ${ }_{5}\left({ }^{1} \mathrm{~A}_{1}, \mathrm{D}_{3 \mathrm{~h}}\right), \mathrm{Fe}(\mathrm{CO}){ }_{4}\left({ }^{1} \mathrm{~A}_{1}, \mathrm{C}_{2 \mathrm{v}}\right)$, and $\mathrm{Fe}(\mathrm{CO})_{4}\left({ }^{3} \mathrm{~B}_{2}, \mathrm{C}_{2 \mathrm{v}}\right)$; bond distances in Angstroms, valence angles in degrees. c)-f) Diffraction-difference curves $\Delta \mathrm{sM}(+200$ ps; $-180 \mathrm{ps} ; \mathrm{s})$, (right) and $\Delta \mathrm{f}\left(+200 \mathrm{ps} ;-180 \mathrm{ps}\right.$; r) (left) for ${ }^{1} \mathrm{~A}_{1}$ and ${ }^{3} \mathrm{~B}_{2}$ states of $\mathrm{Fe}(\mathrm{CO})_{4}$ using $l_{\mathrm{ij}}$ obtained from ASYM99 (c, d), and estimated empirically (e, f). Please, see text from ref. [66]. 
Photochemical reactions may involve many electronic states, each of different character, and they may be coupled strongly at certain geometrical arrangements of the nuclei. In these regions, the vibronic coupling allows vibrational motion of nuclei to change the nature of the electronic wavefunctions. Such regions therefore involve a breakdown of the BornOppenheimer approximation, a cornerstone of modern computational chemistry [78]. Experimental advances using femtosecond laser pulses have seen detailed studies of fundamental molecular processes occurring on an ultrafast (sub-picosecond) timescale [60, 62, 65, 77, 79-82]. Concomitant with experimental spectroscopic advances have been the development of computational methods to explore the nature of the electronic states involved [83, 84], and the subsequent dynamical motion of nuclei across multiple potential energy surfaces [85].

The development of experimental techniques such as time-resolved femtosecond spectroscopy allows [82, 83] to follow photochemical reactions in "real time", resulting in greater insight into the mechanisms of light-induced chemistry. However, the chemistry investigated can be very complex, and the analysis of data sets can be very challenging [83]. After photodissociation of a single carbonyl ligand, the resulting unsaturated complex may be capable of achieving geometry of nonabelian symmetry (and degenerate irreducible representations of the point group) [86]. Such degenerate states are Jahn-Teller active, the geometry being on a conical intersection seam as discussed above. Two aspects need to be considered: (i) Are there Jahn-Teller geometries that connect the excited and ground electronic states? (ii) If there are, are they accessible on the excited reaction path following the photodissociation? [87].

Multiconfigurational methods are required to describe different geometries with partial orbital occupancies and possible degenerate states. CASSCF is the method of choice to model reactive potential energy surfaces as degeneracies and quasi-degeneracies are automatically accounted for, and by virtue of the orbital optimization, the mixing of metal and ligand orbitals as the geometry changes is also included [86]. In considering what orbitals are needed in the CASSCF active space, the metal $3 \mathrm{~d}$ orbitals are perhaps the most obvious choice, as the different arrangements of electrons in these orbitals gives rise to the textbook examples of Jahn-Teller instabilities [87]. This gives an active space $(8,5)$ for the $\mathrm{Fe}(\mathrm{CO})_{4}$ unsaturated complex. However, such active space does not converge well, and the wavefunctions obtained are prone to spurious symmetry breaking, which can cause inaccurate energetics and geometries. It is important to realize that metal carbonyls are paradigm systems for dative bonding involving electron pair donation from the ligand
[87]. Thus, if an active space only includes a single set of orbitals, the electrons are unable to dynamically correlate their respective motions and are on average too close together. A successful technique to handle this is to augment the active space with a set of empty orbitals with an extra node in the internuclear $\mathrm{M}-\mathrm{L}$ region. These orbitals are notionally the $4 \mathrm{~d}$ counterparts of the occupied $3 \mathrm{~d}$ orbitals. For example, for $\mathrm{Cr}(\mathrm{CO})_{5}$, the active space would increase from $(6,5)$ to $(6,10)$. Such active spaces now give accurate barrier heights relative to correlated single-configuration methods [78], but crucially are also capable of treating excited states and degeneracies as well in a balanced manner. A related active-space augmentation has been successfully used in CASPT2 calculations of metal carbonyl bonding in the ground state [88] and for the electronic spectroscopy of metal carbonyls [89]. From the optimized CASSCF wavefunctions it is found that the occupancy of the $4 d$ orbitals (as obtained from the diagonal elements of the one electron-density matrix) is non-negligible: about 0.1 in the ground electronic state relative to their occupied counterparts $(\sim 1.9)$. For $\mathrm{Cr}(\mathrm{CO})_{5}$, a smaller active space is actually possible by dropping both a $3 \mathrm{~d}$ orbital and its $4 \mathrm{~d}$ counterpart. This is because there is one unoccupied $3 \mathrm{~d}$ orbital at all geometries for $\mathrm{Cr}(\mathrm{CO})_{5}$ in the ground and lowest electronic excited states $[90,91]$. For further discussion please, see ref. [78]. The work of Fuss and co-workers [60] has shown that $\mathrm{Cr}(\mathrm{CO})_{5}, \mathrm{Mn}(\mathrm{CO})_{5}$, and $\mathrm{Fe}(\mathrm{CO})_{4}$ return to the lowest electronic states of the initially excited multiplicity within several hundred femtoseconds of the photodissociation of the parent carbonyl. This timescale precludes a spinorbit induced change from the low-spin manifold and anticipates the accessibility of a conical intersection seam to facilitate radiationless population transfer to the ground state [86].

Trushin [et al.] studied the femtosecond dynamics of $\mathrm{Fe}(\mathrm{CO})_{5}$ photodissociation at $267 \mathrm{~nm}$ by transient ionization [65]. The photodissociation of the trigonal bipyramidal $\mathrm{Fe}(\mathrm{CO})_{5}$, whose photochemistry is one of the most investigated of the binary transition metal carbonyls [92], forms $\mathrm{Fe}(\mathrm{CO})_{4}$. This photoproduct has been found to be generated on an ultrafast timescale (Fig. 10) with a Jahn-Teller conical intersection inferred to be at a tetrahedral geometry [65].

Five consecutive processes with time constants $21,15,30,47$, and 3300 fs were found in the photodissociation of $\mathrm{Fe}(\mathrm{CO})_{5}$ after excitation at 267 $\mathrm{nm}$ in the gas phase [65]. The first four represent a continuous pathway of the molecule from the FranckCondon region down to the lowest singlet state $\left(\mathrm{S}_{0}\right)$ of $\mathrm{Fe}(\mathrm{CO})_{4}$ through a chain of Jahn-Teller-induced conical intersections. The motion before dissociation initially involves more than one of the equatorial ligands, but it eliminates only one $\mathrm{CO}$. The product 
$\mathrm{Fe}(\mathrm{CO})_{4}$ is initially generated in its first excited singlet state $S_{1}$, but subsequently relaxes to $S_{0}$ in $47 \mathrm{fs}$ via a triply degenerate conical intersection at tetrahedral geometry. The pathway for this process involves pseudorotation of the ligands. The fifth step is assigned to the thermal elimination of a second $\mathrm{CO}$. Intersystem crossing to the triplet ground states of $\mathrm{Fe}(\mathrm{CO})_{4}$ and $\mathrm{Fe}(\mathrm{CO})_{2}$ takes more than 500 ps (Fig. 11).

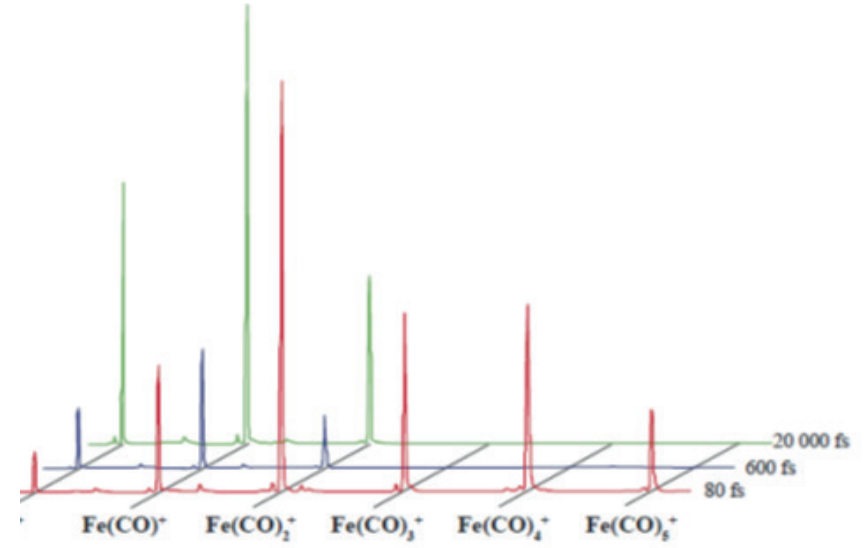

Fig. 10. Transient time-of-flight spectra obtained after irradiation of $\mathrm{Fe}(\mathrm{CO})_{5}$ with $267 \mathrm{~nm}$ pump pulses and $800 \mathrm{~nm}$ probe pulses delayed by 80,600 , and 20,000 fs. The background, which is due to ionization by the probe pulses alone, is subtracted [65].

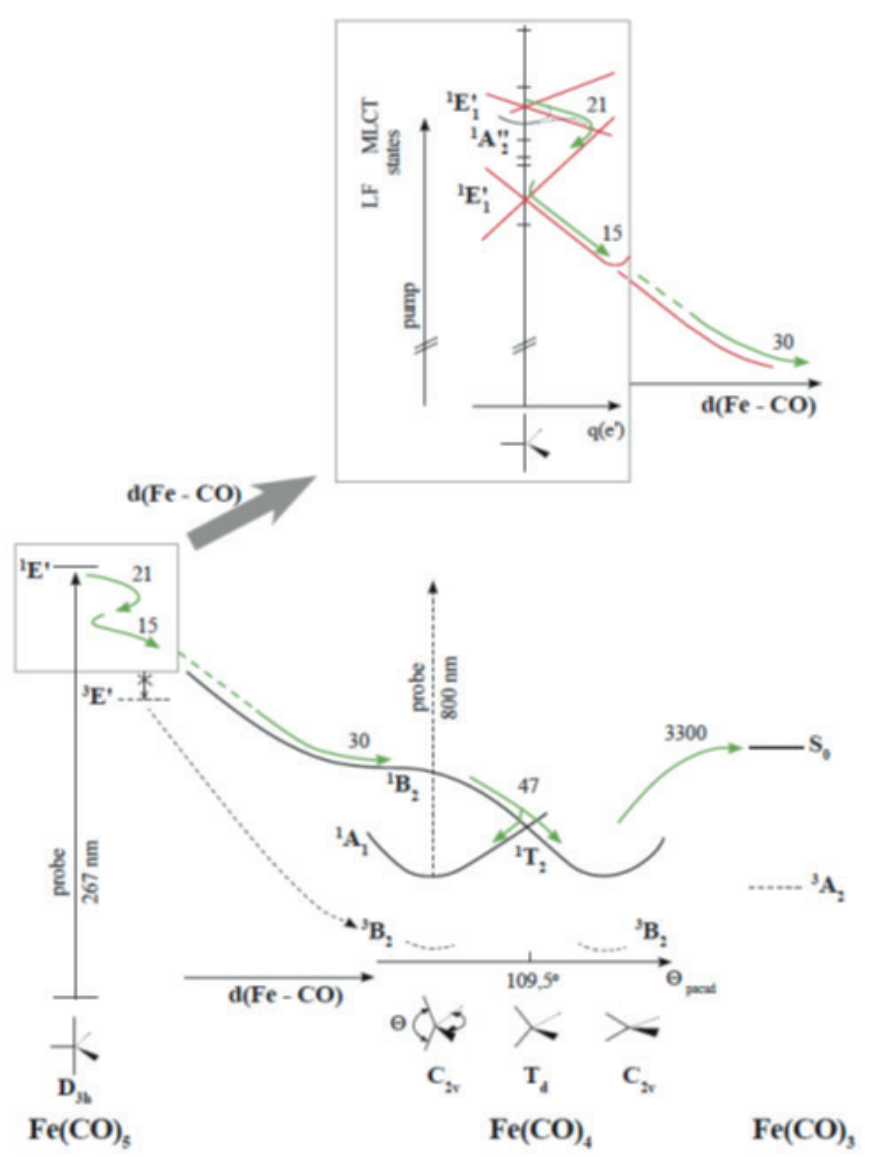

Fig. 11. The potential energy surfaces and pathways (times indicated near the arrows in femtoseconds) of the UV photodecomposition of $\mathrm{Fe}(\mathrm{CO})_{5}$. Excited levels of the parent molecule, which are probably not involved in the process, are only indicated by short lines. The inset shows details of the processes in the parent molecule. The symmetry species ${ }^{1} \mathrm{E}^{\prime}$ in the inset designates the states before Jahn-Teller splitting, i.e., on the axis $q$ ). The broken line in the inset indicates an $\mathrm{A}_{2}^{\prime \prime} \rightarrow \mathrm{E}^{\prime}$ pathway displaced along an e" direction outside the drawing plane. The drawing is not to scale. The following energies (in electronvolts) of the product levels relative to the ground state of $\mathrm{Fe}(\mathrm{CO})_{5}$ are derived from experimental dissociation energies and, for the excited states, from calculations: $\left(\mathrm{Fe}(\mathrm{CO})_{4}\right){ }^{3} \mathrm{~B}_{2}, 1.8 ;{ }^{1} \mathrm{~A}_{1}, 2.56 ;{ }^{1} \mathrm{~B}_{2}, 3.08 ;\left(\mathrm{Fe}(\mathrm{CO})_{3}\right){ }^{3} \mathrm{~A}_{2}, 2.3 ; \mathrm{S}_{0}, 3.5$. MLCT: metal to ligand charge transfer; $\mathrm{LF}$ : ligand field. From ref. [65]. 
The dissociation of the first $\mathrm{CO}$ of $\mathrm{Fe}(\mathrm{CO})_{5}$ with its individual steps is remarkably fast. The sum of the first three time constants $(21+15+30 \mathrm{fs})$ is below $100 \mathrm{fs}$. As argued in [65] this implies that the acceleration already begins in the Franck-Condon region, a statement that is not self-evident. If the excited state were nondegenerate, the potential energy curve along $\mathrm{Fe}-\mathrm{CO}$ dissociation coordinate would begin with zero slope, since there are symmetry-equivalent ligands. JahnTeller splitting of a degenerate state, however, gives rise to a nonvanishing slope. It thus explains the initial fast acceleration and predicts that it involves more than one CO ligand. (Superposition with a totally symmetric stretch coordinate, which involves several ligands, is not excluded.) Such a degenerate (2E') state is available in the right wavelength region; due to its metal-to-ligand charge transfer character the corresponding absorption is intense and, due to its short lifetime (steep slope), also broad so that it can overlap with the pump wavelength [65] On the other hand, a nondegenerate ${ }^{1} \mathrm{~A}_{2}$ " MLCT state has also been predicted in this region [93]. To explain the lack of anisotropy, Trushin [et al.] also assumed an intermediate population of the ${ }^{1} \mathrm{~A}_{2}$ " state (via the $2 \mathrm{E}^{\prime} /{ }^{1} \mathrm{~A}_{2}$ " conical intersection), which then rapidly returns to the main relaxation path [65].

In previous experiments with high-intensity nanosecond UV laser pulses, it has been suggested that resonant two-photon excitation could populate states with energies above the ionization limit and that the neutral molecule subsequently loses all its ligands explosively [94]. However, the ultrafast dissociation found in [65] hardly leaves time for absorption of a second photon with the pulses employed. Possibly further excitation took place after the dissociation. The observed fast rates imply not only real crossings, but also that they are accessible without barriers. In view of the closely spaced upper states, an absence of barriers is natural. As for the dissociation product, it was concluded [65] from the easy accessibility, that the singlet $T_{2}$ state of tetrahedral $\mathrm{Fe}(\mathrm{CO})_{4}$ lies energetically between the $\mathrm{S}_{0}$ and $\mathrm{S}_{1}$ states of the molecule in the equilibrium $\mathrm{C}_{2 \mathrm{v}}$ geometry. The fast rate through this conical intersection is also remarkable for another reason. As in all cases with a triply degenerate state, the intersection space is only $(f-5)$-dimensional [95], where $f=23$ is the number of internal coordinates. The branching space is then 5-dimensional and is spanned by two e and three $\mathrm{t}_{2}$ coordinates. The common case is a 2 -fold degeneracy with an $(f-2)$-dimensional intersection space. Although it has been shown that a conical intersection presents no bottleneck for the molecular trajectories [96], it is often asked whether the molecule can find such a small "point" $((f-2)$-dimensional space $)$ as the tip of the cone. The results show that even an $(f-5)$-dimensional space presents no problem. The reason is, of course, that the wave packet has a nonzero extension in $f$ dimensions and can already cross over in the surrounding of the "point" [65].

The work of Fuss and co-workers [60] has shown that $\mathrm{Cr}(\mathrm{CO})_{5}, \mathrm{Mn}(\mathrm{CO})_{5}$, and $\mathrm{Fe}(\mathrm{CO})_{4}$ return to the lowest electronic states of the initially excited multiplicity within several hundred femtoseconds of the photodissociation of the parent carbonyl. This timescale precludes a spin - orbit induced change from the low-spin manifold and anticipates the accessibility of a conical intersection seam to facilitate radiationless population transfer to the ground state.

A very useful tool to predict suitable stable geometries around the point of a Jahn-Teller conical intersection is the epikernel principle of Ceulemans and Vanquickenbourne [97]. This states that the highest-ranking epikernels are the point groups of minima, and that lower-ranking epikernels, and kernels will be point groups for saddle points for any Jahn-Teller distortion. Kernels are the groups of symmetry elements that are preserved when distorting along a vector spanning an irreducible representation of a given point group. Epikernels are groups of higher symmetry that are selectively preserved in part of the distortion space $[78,97,98]$.

The $\mathrm{Fe}(\mathrm{CO})_{5}$ molecule presents further challenges: either an axial or an equatorial ligand may be initially ejected. Although the axial path is likely to be favored, both need to be considered and modeled. The tetrahedral geometry has triply degenerate irreducible representations leading to possible three-state Jahn-Teller conical intersections and associated five-dimensional branching spaces [99]. Roos [84] has studied the $\mathrm{Fe}(\mathrm{CO})_{4}$ JahnTeller surface using CASSCF with an $(8,10)$ active space. $\mathrm{Fe}(\mathrm{CO})_{4}$ at tetrahedral geometries is $\mathrm{d}^{8}\left(\mathrm{e}^{4} \mathrm{t}_{2}{ }^{4}\right)$, which leads to the following electronic states: $t_{2} \otimes t_{2}=$ ${ }^{1} \mathrm{~A}_{1} \oplus{ }^{1} \mathrm{E} \oplus{ }^{1} \mathrm{~T}_{2} \oplus^{3} \mathrm{~T}_{1}$. The ${ }^{3} \mathrm{~T}_{1}$ state can be discarded due to the timescales involved in the radiationless relaxation [65]. The only way to determine the energetic ordering of the singlet states is via a high-level computation. In their spectroscopic analysis, Fuss [et al.] [60, 65] proposed a pathway through a Jahn-Teller conical intersection imposed by the ${ }^{1} \mathrm{~T}_{2}$ state. Furthermore, this intersection explains the nature of the photoproduct, which was previously determined using ultrafast electron diffraction by Zewail [et al.] [77, 100] $\mathrm{C}_{2 \mathrm{v}} \mathrm{Fe}(\mathrm{CO})_{4}$ in a singlet electronic state. Geometrically, they find that one of the pair of $(\mathrm{CFeC})$ angles is $169^{\circ} \pm 2^{\circ}$, and the other $125^{\circ} \pm 3^{\circ}$ (see Fig. 9 and Fig. 12). CASSCF calculations have found Jahn-Teller geometries present in the photodissociation pathways for these systems, with tetrahedral symmetry for singlet $\mathrm{Fe}(\mathrm{CO})_{4}$, and a $\mathrm{D}_{3 \mathrm{~h}}$ trigonal bipyramid for singlet $\mathrm{Cr}(\mathrm{CO})_{5}$ and doublet $\mathrm{Mn}(\mathrm{CO})_{5}$. The topology on the lower surface around the point of intersection has a number of symmetry-equivalent minima separated by equivalent transition states (see Fig. 12). In the 
case of $\mathrm{Cr}(\mathrm{CO})_{5}$ and $\mathrm{Mn}(\mathrm{CO})_{5}$ the surfaces are very similar, involving three $\mathrm{C}_{4 \mathrm{v}}$ square pyramidal minima separated by three $\mathrm{C}_{2 \mathrm{v}}$ transition states. For $\mathrm{Fe}(\mathrm{CO})_{4}$ this has six equivalent $\mathrm{C}_{2 \mathrm{v}}$ symmetry minima separated by 12 equivalent $\mathrm{C}_{\mathrm{s}}$ symmetry transition states (shown schematically in Fig. 12).

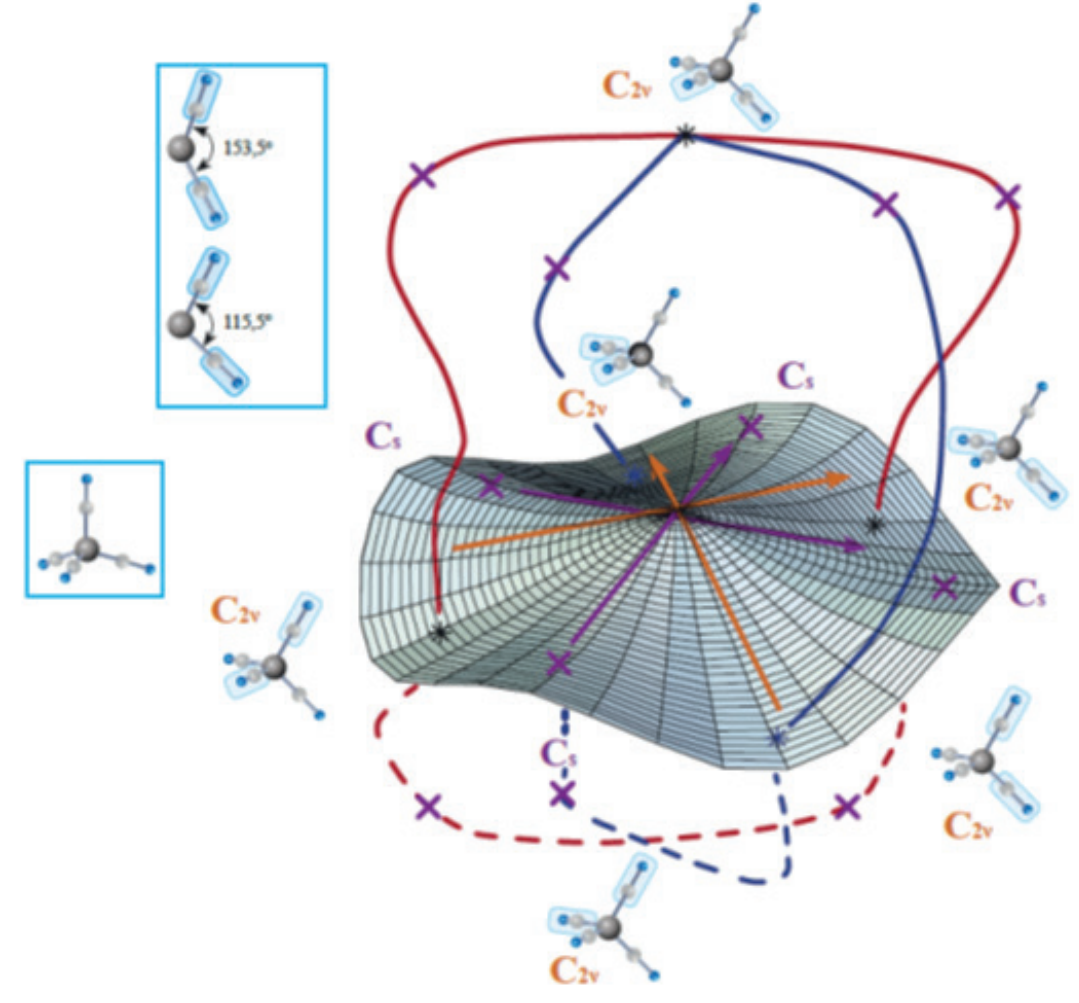

Fig. 12. Surface topology around triply degenerate Jahn-Teller conical intersections for $\mathrm{Fe}(\mathrm{CO})_{4}$. Colours indicate pathways connecting minima and transition states. The $\mathrm{Fe}(\mathrm{CO})_{4}$ cross section is for the Jahn-Teller surface around a tetrahedral geometry $\left(\mathrm{T}_{\mathrm{d}}\right.$ ), which has a triply degenerate singlet electronic state. The surface is a two-dimensional cross section through the three-dimensional Jahn-Teller surface. There are four equivalent $\mathrm{C}_{2 \mathrm{v}}$ minima connected via four equivalent $\mathrm{C}_{\mathrm{s}}$ transition structures. The CASSCF $(\mathrm{CFeC})$ angles are given to the left. Further $\mathrm{C}_{2 \mathrm{v}}$ minima and $\mathrm{C}_{\mathrm{s}}$ transition structures exist in the remaining orthogonal coordinate [78].

The $\mathrm{C}_{4 \mathrm{v}}$ square pyramidal minima are separated by three $\mathrm{C}_{2 \mathrm{v}}$ transition states. For $\mathrm{Fe}(\mathrm{CO})_{4}$ this has six equivalent $\mathrm{C}_{2 \mathrm{v}}$ symmetry minima separated by 12 equivalent $\mathrm{C}_{\mathrm{s}}$ symmetry transition states (shown schematically in Fig. 12). The barrier height for $\mathrm{Fe}(\mathrm{CO})_{4}$ is less than $2 \mathrm{kcal} \cdot \mathrm{mol}^{-1}$, indicating effectively free pseudorotation in the vibrational hot photoproducts. For $\mathrm{Cr}(\mathrm{CO})_{5}$ there is a more substantial barrier $\sim 12 \mathrm{kcal} \cdot \mathrm{mol}^{-1}$, and dynamics simulations indicate that the pseudorotation may become trapped around a single minimum. This is consistent with experimental observation of coherent oscillations with a frequency of a magnitude that matches an $\mathrm{OC}-\mathrm{M}-\mathrm{CO}$ bending vibration (which is a linear combination of the branching modes).

Further information on each surface and how they were calculated can be found elsewhere [78, 86]. An important point to note is that this type of behaviour appears common to binary carbonyls and it is suggested that such a photodissociation scheme should be applicable to most binary carbonyls (with an unfilled d-shell, thus excluding $\left.\mathrm{Ni}(\mathrm{CO})_{4}\right)$.
The simplest Jahn-Teller intersection is of $\mathrm{T} \otimes \mathrm{t}_{2}$ type (i.e., a triply degenerate electronic state whose components are coupled via a triply-degenerate vibration). Optimization of a triply degenerate conical intersection is not routinely possible at present. The vibrational modes of $\mathrm{T}_{\mathrm{d}} \mathrm{Fe}(\mathrm{CO})_{4}$ span $\mathrm{Q}_{3 \mathrm{~N}-6} \in 2 \mathrm{~A}_{1} \oplus 2 \mathrm{E} \oplus \mathrm{T}_{1} \oplus 4 \mathrm{~T}_{2}$, so, there are clearly several candidate vibrations. This $\mathrm{T} \otimes \mathrm{t}$ type of intersection has received much attention in the triplet manifold $\left(\mathrm{T} \oplus \mathrm{t}_{1}\right.$ in this case) $[63,101,102]$, as this corresponds to the global minimum of $\mathrm{Fe}(\mathrm{CO})_{4}$.

Bending of the $\mathrm{CO}$ ligands in a pairwise fashion leads from $\mathrm{T}_{\mathrm{d}}$ to $\mathrm{C}_{2 \mathrm{v}}$, and both the triplet and singlet JahnTeller surfaces are similar. The epikernel principle [97] predicts that the number of equivalent $\mathrm{C}_{2 \mathrm{v}}$ minima will be given by the quotient of the size of the $\mathrm{T}_{\mathrm{d}}$ group and the $\mathrm{C}_{2 \mathrm{v}}$ group $\left(\mathrm{nT}_{\mathrm{d}} / \mathrm{nC}_{2 \mathrm{v}}=24 / 4=6\right)$. Fig. 12 shows a twodimensional cross section of the full three-dimensional surface, using a pair of orthogonal bending coordinates, each obtained as a linear combination of the three triply degenerate $(\mathrm{CFeC})$ bending modes. Note that the full triply degenerate Jahn-Teller problem is $\mathrm{T} \otimes\left(\mathrm{t}_{2} \oplus \mathrm{e}\right)$, where the branching space is five dimensional in keeping 
with the von Neumann-Wigner theorem [103]. Only the $\mathrm{T} \otimes \mathrm{t}$ interaction has been considered in any detail for $\mathrm{Fe}(\mathrm{CO})_{4}$ in either the singlet or triplet manifolds. In the $2 \mathrm{D}$ cross section shown in Fig. 12 there are four $\mathrm{C}_{2 \mathrm{v}}$ minima (two per bending coordinate), connected by four $\mathrm{C}_{\mathrm{s}}$ transition structures. The total number of $\mathrm{C}_{2 \mathrm{v}}$ minima is given by the quotient of the size of the $\mathrm{T}_{d}$ group and the $\mathrm{C}_{\mathrm{s}}$ group $\left(\mathrm{nT}_{\mathrm{d}} / \mathrm{nC}_{\mathrm{s}}=24 / 2=12\right)$. An attractive visual representation of this is given by the octahedral model of Poliakoff [et al.] [103], in which each minimum is placed at the vertex of an octahedron. As depicted in Fig. 12, the barrier to pseudo-rotation between $\mathrm{C}_{2 \mathrm{v}}$ minima is quite small (about $4 \mathrm{kcal} \cdot \mathrm{mol}^{-1}$ ).

Although the CASSCF Jahn-Teller surface in the singlet manifold helps to explain the experimental data relating to the ultrafast relaxation of $\mathrm{Fe}(\mathrm{CO})_{4}$, there is a remaining issue that reminds us of the complexity of this system. CASSCF and MRCI predict that the ${ }^{1} \mathrm{~T}_{2}$ state is, in fact, not the lowest singlet electronic state at $\mathrm{T}_{\mathrm{d}}$ geometries. For example, CASSCF predicts that the ${ }^{1} \mathrm{E}$ state is $5 \mathrm{kcal} \cdot \mathrm{mol}^{-1}$ below the ${ }^{1} \mathrm{~T}_{2}$ state. However, an $\mathrm{E} \otimes \mathrm{e}$ Jahn-Teller intersection does not correctly give the observed photoproduct. A complete Jahn-Teller model will involve both Jahn-Teller and pseudo-Jahn-Teller coupling: $(\mathrm{T} \oplus \mathrm{E}) \otimes\left(\mathrm{t}_{2} \oplus \mathrm{e}\right)-\mathrm{a}$ five-state, five-mode model $[63,101,102]$. This is due to the proximity of the ${ }^{1} \mathrm{E}$ and ${ }^{1} \mathrm{~T}_{2}$ states; the components of these states can strongly pseudo-Jahn-Teller couple via the same vibrations that are separately Jahn-Teller active within each degenerate manifold.

Having established that conical intersections are accessible to connect excited state with ground-state potential energy surfaces, the next stage in modeling the reactive photochemistry is to simulate the dynamical motion of the nuclei on those coupled potential energy surfaces. Guillaumont [et al.] [104] performed a large number of dynamics simulations in inorganic photochemistry using quantum wave packet approaches [104-106]. The majority of these studies used one- or twodimensional simulations that are appropriate for studying phenomena such as direct photodissociation [78].

Fuss [et al.] [60] investigated $\mathrm{M}(\mathrm{CO})_{6}(\mathrm{M}=\mathrm{Cr}$, $\mathrm{Mo}, \mathrm{W}), \mathrm{Fe}(\mathrm{CO})_{5}, \mathrm{Ni}(\mathrm{CO})_{4}$ and $\mathrm{M}_{2}(\mathrm{CO})_{10}(\mathrm{M}=\mathrm{Mn}$, $\mathrm{Re}$ ) by femtosecond spectroscopy. The molecules were pumped by one photon at $267 \mathrm{~nm}$ and then probed by multiphoton ionization at $800 \mathrm{~nm}$ and mass selective detection of the resulting parent and fragment ions. Whereas it was previously believed that such metal carbonyls are excited to a repulsive potential, leading to elimination of one or several CO, it was concluded [60] that only one $\mathrm{CO}$ is photochemically split off at times below $100 \mathrm{fs}$ and that this is already a multistep process involving relaxation between excited-state surfaces. The elimination of the second $\mathrm{CO}$ takes place in the ground state of the unsaturated carbonyl and requires a much longer time ( $>1$ ps with a pump wavelength of $267 \mathrm{~nm}$ ).
The unsaturated carbonyl is initially generated in its first excited singlet state $S_{1}$. If this molecule has four-fold coordination, it can relax from this $\mathrm{S}_{1}$ state to $\mathrm{S}_{0}$ within about $50 \mathrm{fs}$, the pathway leading through a symmetryinduced conical intersection involving pseudorotation of the ligands. Coherent oscillations along such coordinates were observed in several molecules. In the case of threefold coordination $\left(\mathrm{Ni}(\mathrm{CO})_{3}\right)$, however, there is no such relaxation pathway. Therefore, this photofragment shows a beautiful luminescence with $>10$ ps lifetime. All the described processes only involve the singlet manifold.

Fuss [et al.] also observed oscillations with periods of 400 to $700 \mathrm{fs}$, which is in the range of bending vibrations [60]. The authors assign them to pseudorotation, since along this coordinate the $\mathrm{S}_{0} \rightarrow \mathrm{S}_{1}$ transition is tuned from conical intersection via a resonance with the probe laser $(800 \mathrm{~nm}, 1.55 \mathrm{eV})$ to a larger energy distance (e.g. $2 \mathrm{eV}$ in $\left.\mathrm{Cr}(\mathrm{CO})_{5}\right)$. Using a $400 \mathrm{~nm}(3.1 \mathrm{eV})$ probe, the oscillations remain invisible. And in $\mathrm{Fe}(\mathrm{CO})_{4}$, where the $\mathrm{S}_{0} \rightarrow \mathrm{S}_{1}$ transition energy is about $0.5 \mathrm{eV}$, no oscillations are detected either [60]. Excitation of the vibrations is plausible since it proceeds along the coordinate that leads with steepest descent from $S_{1}$ to $S_{0}$.

It has repeatedly been assumed that dissociation takes place via a triplet state formed via intersystem crossing (ISC). In particular, this was suggested for the case of $\mathrm{Fe}(\mathrm{CO})_{5}$, where the ground state of the $\mathrm{Fe}(\mathrm{CO})_{4}$ product is a triplet, and for the splitting of the $\mathrm{Mn}-\mathrm{Mn}$ bond in $\mathrm{Mn}_{2}(\mathrm{CO})_{10}$, where only the triplet excited state ${ }^{3} \mathrm{~B}_{2}$ correlates with the ground state of the products $\left.\mathrm{Mn}(\mathrm{CO})_{5}\right)$. In the $\mathrm{Fe}(\mathrm{CO})_{5}$ system, singlet $\mathrm{Fe}(\mathrm{CO})_{4}$ and $\mathrm{Fe}(\mathrm{CO})_{3}$ were observed by IR absorption even after nanoseconds $[107,108]$. This suggests that ISC cannot take place in a time much shorter than $1 \mathrm{~ns}$. Additionally, the times until dissociation (typically $<100$ fs for each step) are too short for ISC. Furthermore, dissociation was found to be slower for the carbonyls of heavier metals in a group than of lighter ones. The opposite would be expected if ISC played a role. After the dissociation, in the group-6 pentacarbonyls, pseudorotation would have no counterpart in the triplet manifold. With ISC thus excluded, the only remaining process for the elimination of a second $\mathrm{CO}$ in the sequential dissociation of metal carbonyls involves the thermal reaction of the hot molecules on the ground state surface $\mathrm{S}_{0}$. If this were the process, the rate should depend on the excess energy and thus on the pump-laser wavelength. Experiments to explore this option remain to be done.

The range of photochemical dynamics phenomena in simple metal carbonyls is surprisingly rich. Although some of the possible steps are not yet definitely identified, it is anticipated that future studies may contribute to a better understanding of the photochemistry of the metal carbonyls and their derivatives, including the stereochemistry (cis-and trans-effect of substituents) or photocatalysis. 
One interesting effect observed at resonance of sufficiently intense IR radiation with the vibrations of polyatomic molecules is their multiphoton excitation until the molecule falls apart, above the dissociation threshold.. Research in IR multiphoton excitation showed that with durations of the IR pulses in the range of 10-100 ns, the randomization of vibrational energy leads to excitement of all vibrations. The subsequent monomolecular reactions (dissociation, isomerization) are statistical in nature. The fast redistribution of energy from the pumped mode to other vibrations of the molecule (intramolecular vibrational redistribution, IVR (see review articles: [109-112]) also limits the possibility of selective vibrational multiphoton excitation of the selected modes of polyatomic molecules above the randomization threshold. Research on intramolecular relaxation, i.e. the measurement of the characteristic time scales, is the subject of a large number of studies. This interest is motivated, in part, by the idea of implementing non-statistical reactions by the use of laser pulses with a duration shorter than the characteristic times of the intramolecular relaxation. A recently released review discusses the research methods used and the results obtained in those studies [112].

Photoprocesses induced by resonant vibrational excitation were studied in free $\mathrm{Fe}(\mathrm{CO})_{5}$ and its molecular clusters [113, 114]. Intense femtosecond pulsed radiation in the region of $5 \mu \mathrm{m}$ was used to excite the intense vibrational bands (the $v_{6}$ and $v_{10}$ modes) of the $\mathrm{CO}$-bonds of $\mathrm{Fe}(\mathrm{CO})_{5}$. Analysis of the results led to the conclusion that the IR pulse selectively excites the $\mathrm{CO}$ vibrational modes. This excitation decreases the multiphoton ionization cross section for the probe pulse, which leads to a reduction of the signal from the molecular ion $\mathrm{Fe}(\mathrm{CO})_{5}{ }^{+}$. A relaxation of the signal was found that is described by two characteristic times, a fast component $\tau_{1}=10 \pm 2$ ps and a slow component $\tau_{2}=670 \pm 40 \mathrm{ps}$. The slow relaxation with $\tau_{2}$ is ascribed to intramolecular energy relaxation that transfers the excitation of the $\mathrm{CO}$ vibrational energy into other vibrations of the molecule. The time $\tau_{1}$ it is probably associated with a Berry-type intramolecular pseudorotation.

In experiments on $\left[\mathrm{Fe}(\mathrm{CO})_{5}\right]_{n}$ clusters, relaxation of vibrational energy stored by individual cluster molecules leads to an increase in the temperature of the clusters and subsequent evaporation of molecules. Free $\mathrm{Fe}(\mathrm{CO})_{5}$ molecules formed as a result of the cluster dissociation were ionized by femtosecond laser radiation at $\lambda=400 \mathrm{~nm}$ and detected with a time-offlight mass-spectrometer. The yield of free molecules from clusters is determined by the magnitude of the energy absorbed by the cluster, and its temporal dependence is described by a sequential evaporation of molecules (Fig. 13) [113].

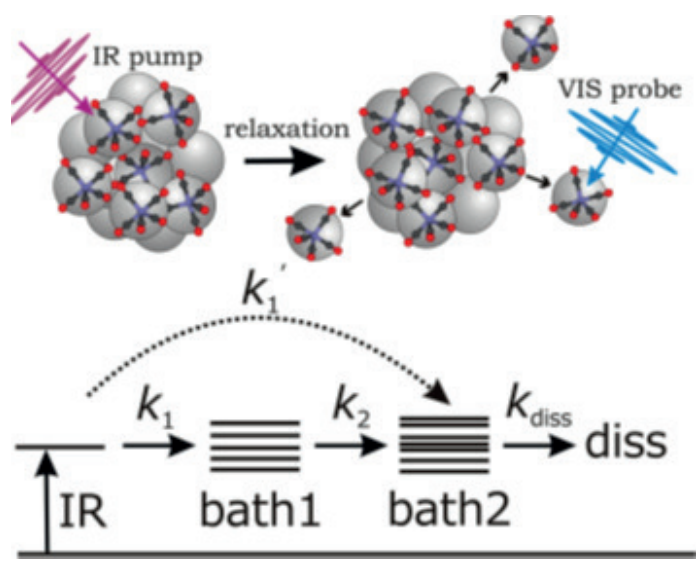

Fig. 13. Schematic diagram of the energy flow during cluster dissociation. Two relaxation schemes are shown: singlebathmode scheme $\left(\mathrm{k}_{1}{ }^{\prime}\right)$ and sequential two-bath-mode scheme $\left(\mathrm{k}_{1}\right.$ and $\left.\mathrm{k}_{2}\right)$. From ref. [113].

\section{STRUCTURE AND NUCLEAR DYNAMICS IN FREE RADICALS: THE JAHN-TELLER EFFECT AND PSEUDOROTATION IN CYCLOPENTADIENYL RADICALS}

Many radicals are sufficiently stable to isolate, handle, and store without any special precautions. The diversity in molecular architectures of these stable radicals is sufficiently large that common factors governing radical stability/persistence, geometric and electronic structure, association/dimerization preferences, and reactivity have generally not been well articulated or appreciated [115]. Techniques such as spin labeling, spin trapping and EPR imaging can provide a wealth of information about systems into which stable radicals have been introduced. There have been widespread efforts aimed at developing new materials with technologically relevant properties (magnetism, conductivity) for which stable radicals are excellent building blocks simply by virtue of having unpaired electrons [115].

Pioneering studies of persistent, long-lived radicals [116] by GED were performed in 1968 by L. Schäfer [117] (please, see also [118]. In these studies, a high temperature nozzle tip was used to decompose diindenylcobalt, $\mathrm{Co}\left(\mathrm{C}_{9} \mathrm{H}_{7}\right)_{2}$ to produce indenyl radicals, $\mathrm{C}_{9} \mathrm{H}_{7}$. An analysis of the experimental data showed the presence of indenyl free radical in the gaseous phase in a purity of at least $80 \%$. This made possible a structural investigation of indenyl which produced the following results: $(\mathrm{C} 1-\mathrm{H} 1)_{\mathrm{av}}=107.2(2.0) \mathrm{pm}$ and $(\mathrm{C} 1-\mathrm{C} 2)_{\mathrm{av}}=$ 141.5(1.0) $\mathrm{pm}$. The $\mathrm{C}-\mathrm{C}$ bond-length average is found in good agreement with quantum chemical calculations. Experimental evidence was found that the molecule possesses different $\mathrm{C}-\mathrm{C}$ bonds, some of which seem to deviate more from the average than is predicted by calculations. Schafer's experiment represents the first example of an investigation of an unstable compound 
by GED. It proves that the method may be expected to be a powerful tool in the study of similar cases. Other achievements in the study of persistent [116] radical structures by GED are described in a review article [35].

The first study of the short-lived $\mathrm{CF}_{3}$ radical by TRED was published in 1983 by A. Ischenko [et al.] The gaseous target of $\mathrm{CF}_{3} \mathrm{I}$ molecules was excited by a TEA $\mathrm{CO}_{2}$ laser. The multiphoton infrared excitation dissociates the $\mathrm{CF}_{3} \mathrm{I}$ molecules,

$$
\mathrm{CF}_{3} \mathrm{I}+\mathrm{nh} v \rightarrow \mathrm{CF}_{3}+\mathrm{I},
$$

and diffraction patterns of $\mathrm{CF}_{3}$ free radicals were recorded. For the experimental integrity of the studies [5, 6] it was important that almost all of the $\mathrm{CF}_{3}$ I molecules dissociated under the effect of a single $10^{-7} \mathrm{~s}$ IR laser pulse [119]. This means that the scattering pattern was recorded from the bulk (inside the IR laser beam) containing no molecular components besides $\mathrm{CF}_{3}$, so that the resulting diffraction pattern was unambiguously associated with $\mathrm{CF}_{3}$ radicals. To record the diffraction pattern with the use of a secondary electron multiplier, the pulse-resonance method was employed [8, 29].

The cyclopentadienyl radical (Cp) plays an important role in different areas of chemistry, and was intensively studied by theoretical [120-128] and experimental methods [129-132].

In 2002 TRED was applied to study the photodissociation reaction of cylcopentadienyl cobalt dicarbonyl, $\mathrm{CpCo}(\mathrm{CO})_{2}$, which proceeds to give product structures (Ihee [et al.], 2002) that were probed by picosecond electron pulses. Three conceivable reaction channels for the dissociation reaction of $\mathrm{CpCo}(\mathrm{CO})_{2}$, are illustrated in Fig. 14 [133]. Femtosecond and nanosecond multi-photon excitation was found to result in a total detachment of all ligands from the cobalt center thereby leaving a bare $\mathrm{Cp}$ ring.

The experimental TRED results were compared with theory to explore the dynamics of the structural changes [133], Figs. 15 and 16. The dynamic nature of the radical was best represented by a pentagonal molecular structure having $\mathrm{D}_{5 \mathrm{~h}}$ symmetry with elevated mean amplitudes of vibration. Comparisons between theory and experiment [133] suggested that the structure of the transition state between the compressed (dienylic) and the elongated (allylic) conformations reflect the dynamics of the pseudorotary surface [133].

To analyze the data, a DFT electronic structure of $\mathrm{D}_{5 \mathrm{~h}} \mathrm{Cp}$ was used as the starting condition for the refinement. The best fit of the data [133] was obtained when the $\mathrm{C}-\mathrm{C}$ bond of the $\mathrm{D}_{5 \mathrm{~h}}$ ring was $r_{\mathrm{e}}=$ 146(3) pm. DFT gave $r_{\mathrm{e}}=142 \mathrm{pm}$, which is consistent with the results from rotationally resolved laser-induced fluorescence spectroscopy [131]. The DFT calculations refer to the bond distance of $142 \mathrm{pm}$ of the $\mathrm{D}_{5 \mathrm{~h}}$ transition

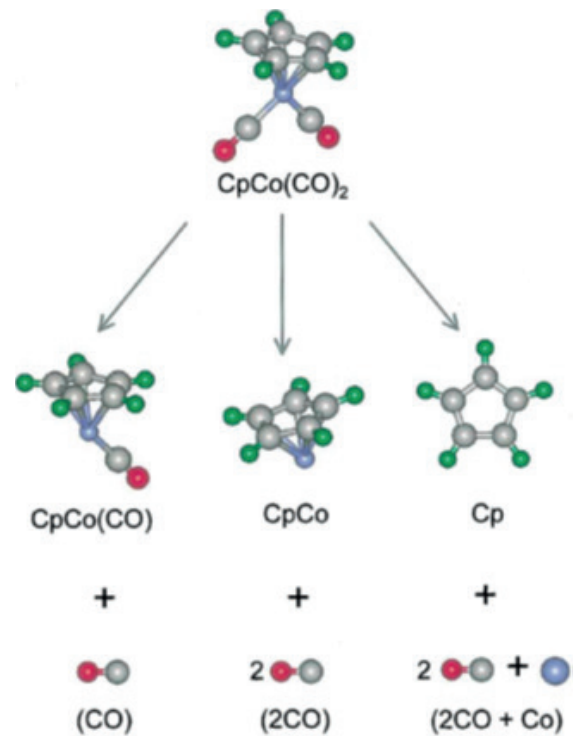

Fig. 14. Three possible fragmentation pathways of $\mathrm{CpCo}(\mathrm{CO})_{2}$. From ref. [133].
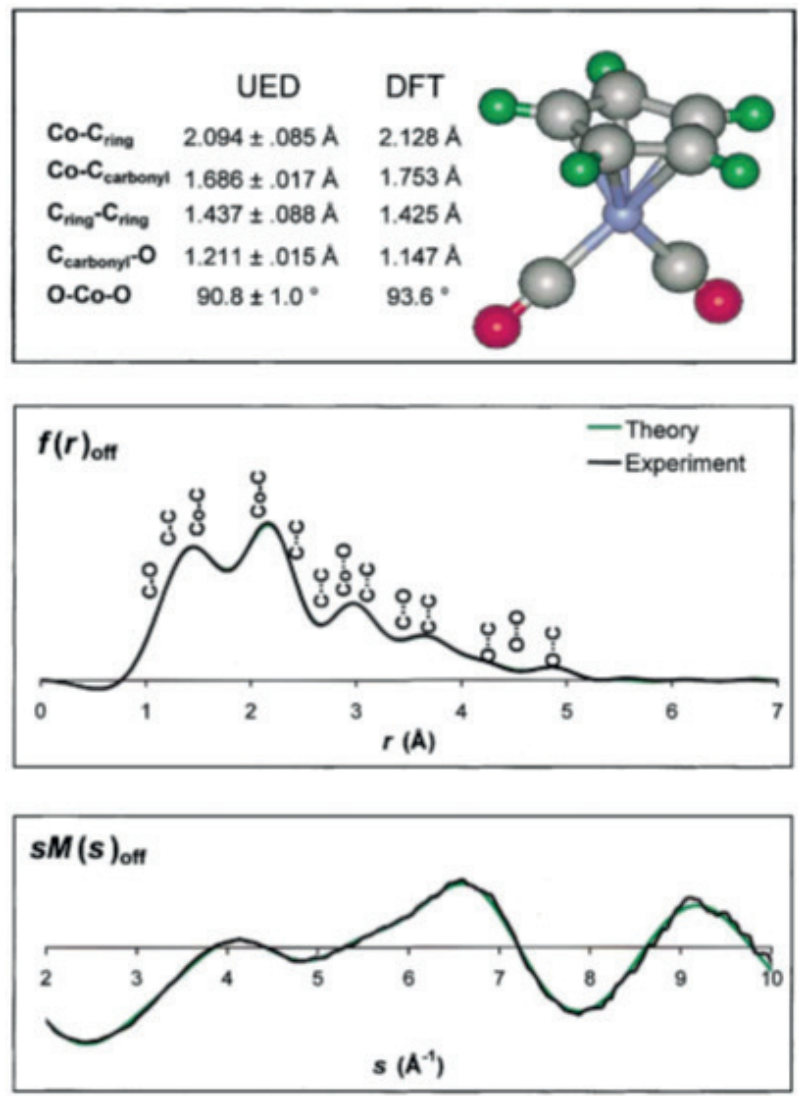

Fig. 15. The refined structure (top) of the parent molecule $\mathrm{CpCo}(\mathrm{CO})_{2}$ along with the modified molecular scattering intensity (bottom) and the radial distribution function (center) obtained with the pump laser off. Black lines are experimental curves, and green lines are the least-squares fits. Shown also at the top are our average refined parameters compared with the average parameters from DFT. From ref. [133]. 

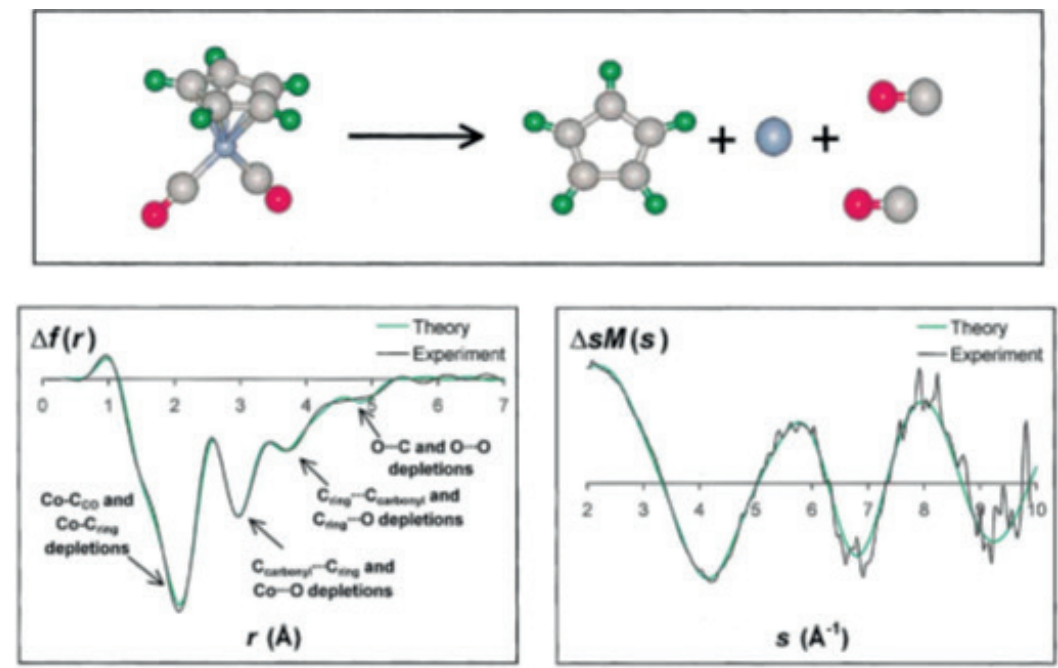

Fig. 16. Refined best fits obtained for the difference curves for the indicated reaction at the top. The bottom-right panel shows the diffraction-difference modified molecular scattering curve, and the bottom-left panel shows the diffraction-difference radial distribution curve. Black lines are experimental curves, and green lines are the least-squares fits. The top panel shows the molecular structures involved in the reaction. From ref. [133].

state (Fig. 17), so that the observed 4 pm extension of the equilibrium bond length was attributed to the pseudorotary dynamics about the $\mathrm{Cp}$ ring [133].
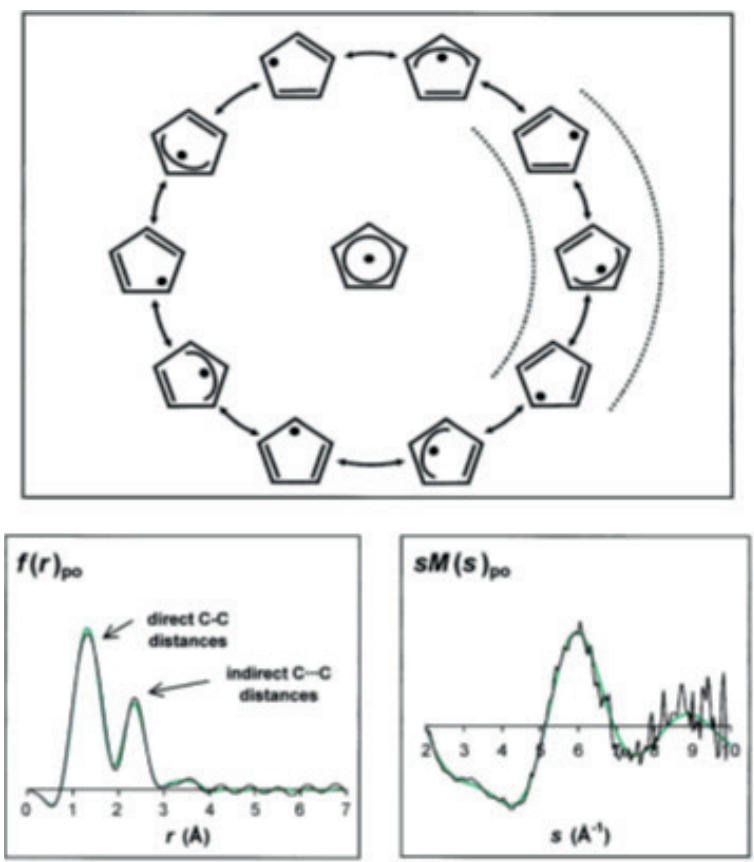

Fig. 17. Top: A representation of pseudorotation in the $\mathrm{Cp}$ radical. In the center is the $\mathrm{D}_{5 \mathrm{~h}}$ transition state $3.5 \mathrm{kcal} / \mathrm{mol}$ (ref. [122]) above the circular pseudorotary surface connecting the elongated and compressed Jahn-Teller isomers of Cp. The transition states along the circular path are estimated to be elevated by energies ranging from zero to $\sim 2 \mathrm{kcal} / \mathrm{mol}$ [130]. The dotted circles indicate two of the many other possible paths. Bottom: The refined best fits obtained for the productonly modified molecular scattering curve $\left(\mathrm{sM}(\mathrm{s})_{\mathrm{po}}\right)$ and radial distribution curve $\left(\mathrm{f}(\mathrm{r})_{\mathrm{po}}\right)$ of the $\mathrm{D}_{5 \mathrm{~h}}$ molecular structure of $\mathrm{Cp}$ at $2600 \mathrm{~K}$. The dynamic nature of the radical was best represented by a stretched structure having $D_{5 h}$ symmetry with elevated mean amplitudes of vibration. From ref. [133].
The $\mathrm{Cp}$ radical has a degenerate electronic ${ }^{2} \mathrm{E}_{1}$ ground state, if it is planar, of $\mathrm{D}_{5 \mathrm{~h}}$ symmetry. The degeneracy is lifted by Jahn-Teller distortion, and the bonds become unequal in length. Due to the near energetic degeneracy of the two Jahn-Teller isomers and the low barrier to pseudorotation on the surface connecting them, the two structures among the many in Fig. 17 are not static. Estimates of the pseudorotary barrier around the circular landscape (not across the center) in $\mathrm{Cp}$ range between zero and $\sim 2 \mathrm{kcal} / \mathrm{mol}$ [130]. If no energy is channeled into the translational energies of the fragments, a maximum of $\sim 104 \mathrm{kcal} / \mathrm{mol}$ in internal energy for the products is available. If this energy is then completely thermalized between and among all modes of $\mathrm{Cp}$, the vibrational ensemble temperature would be $\sim 2900 \mathrm{~K}$. In reality, however, a significant fraction of the available energy would go into translational kinetic energy of the fragments and the equilibrium temperature of $\mathrm{Cp}$ would be lower than this value [133]. A refinement of the molecular temperature, based on the mean-amplitudes of vibration $(l)$ of the bonds, was also performed and the best-fit temperature of the $\mathrm{D}_{5 \mathrm{~h}}$ product was $2600(150)$ $\mathrm{K}$ [133], Fig. 17. This apparent high temperature is a consequence of the highly entropic phase space, which results from the many vibrations involved in the transformations of the structures shown (and not shown) in Fig. 17; note that the arrowed circle represents just one path in the basin of the energy landscape, and a few of the many others are represented by dotted circles. The long bonds of the structure and the high vibrational temperature are in agreement with the dynamic nature of pseudorotation. An active pseudorotary state involves many bonds, changing lengths as the molecule constantly converts between elongated and compressed isomers. The rapid movement of $\mathrm{Cp}$ through these pathways at 
high internal energy is represented by a hot and enlarged $\mathrm{D}_{5 \mathrm{~h}}$ structure as obtained by TRED, from bond lengths and mean amplitudes of vibration [133].

It is tempting to ascribe some of the stability of $\mathrm{Cp}$ radicals to delocalization of the spin around the five positions of the ring (as represented canonically by the structure in Fig. 18, left). However, the fully delocalized, symmetric $\left(\mathrm{D}_{5 \mathrm{~h}}\right)$ structure of the parent cyclopentadienyl radical is known to be unstable with respect to a first order Jahn-Teller distortion. Two possible distorted states both have $\mathrm{C}_{2 \mathrm{v}}$ symmetry (Fig. $18)$; one of these $\left({ }^{2} \mathrm{~B}_{1}\right)$ is essentially a localized radical, while the other $\left({ }^{2} \mathrm{~A}_{2}\right)$ state can be described as an allyltype radical.
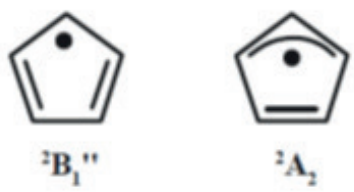

Fig. 18. Electronic states of the cyclopentadienyl radical before (left) and after (right) Jahn-Teller distortion.

The cyclopentadienyl radical consists of essentially (within experimental crystallographic error) symmetric $\left(D_{5 \mathrm{~h}}\right) \mathrm{Cp}$ rings. However, this structure may represent a dynamic average, because the barrier to interconversion between distorted structures is low, and the magnitude of the distortion may just be within the crystallographic error limits. Interestingly, the X-ray structure shows a distinctly localized Cp ring: the two "double bonds" depicted in Fig. 18, average 138.5 pm, the two "single bonds" flanking the radical site are nearly identical at $145 \mathrm{pm}$, and the remaining single bond is $148 \mathrm{pm}$. Computational studies accurately reproduce the X-ray structure and suggest that the radical is in a distorted ${ }^{2} \mathrm{~B}_{1}$ state with the allyl moiety centered at the $t$-butyl substituent position, creating an essentially localized cyclopentadienyl radical $[115,127]$.

The $D_{5 \mathrm{~h}}$ Jahn-Teller crossing and associated $\mathrm{C}_{2 \mathrm{v}}$ minima and saddle points in cyclopentadienyl have been optimized at the CASSCF: cc-pVDZ level of theory. The $\mathrm{C}_{2 \mathrm{v}}$ structures were characterized by computing analytic force constants. Zero point energies calculated for all $\mathrm{C}_{5} \mathrm{H}_{4} \mathrm{D}$ and $\mathrm{C}_{5} \mathrm{HD}_{4}$ isomers of the $\mathrm{C}_{2 \mathrm{~V}}$ minima suggest an alternative interpretation of the experimentally observed degeneracy resolution [131].

The cyclopentadienyl radical provides an example of a conical intersection enforced by symmetry: a JahnTeller crossing [134-136]. The degenerate ${ }^{2} \mathrm{E}_{1}$ ground state at $\mathrm{D}_{5 \mathrm{~h}}$ geometries was predicted to distort along an e'2 coordinate, leading to the alternating $\mathrm{C}_{2 \mathrm{v}}$ minima $\mathrm{M}$ $\left({ }^{2} \mathrm{~B}_{2}\right.$ electronically) and saddle points $\operatorname{TS}\left({ }^{2} \mathrm{~A}_{2}\right)$ illustrated in Fig. 19 [137].

However, early ESR spectra at $120 \mathrm{~K}$ suggested that the spin distribution around the ring was uniform [138], implying that the barrier height for pseudorotation [139] between the five equivalent minima was of the order of $\mathrm{cm}^{-1}$, leading to a time-averaged $D_{5 \mathrm{~h}}$ structure.

Carrington [et al.] [140] predicted that static distorted geometries might be observed as a result of deuterium substitution (e.g. $\mathrm{C}_{5} \mathrm{H}_{4} \mathrm{D}$ or $\mathrm{C}_{5} \mathrm{HD}_{4}$ ): if previously equivalent minima now differed in zero point energy, the time-averaged structure would be biased

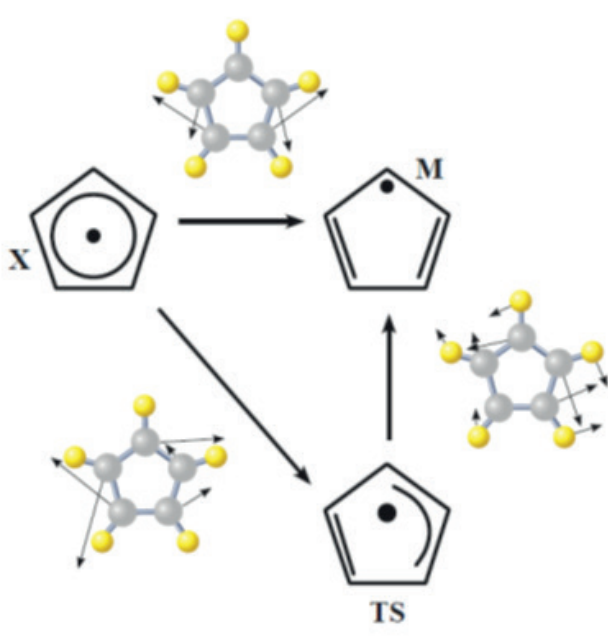

Fig. 19. Cyclopentadienyl D0:D1 surface topology. At the $D_{5 h}$ Jahn-Teller crossing $\mathrm{X}$, there are two vectors - the derivative coupling (top) and gradient difference (left) - which lift the degeneracy. One each of the surrounding five minima M and transition structures TS are shown, linked by the transition vector (right). From ref. [124].

towards those that are most stable. Degenerate vibronic levels would then be split and might be resolved at sufficiently low temperatures. Such an effect has been observed for cyclopentadienyl radicals in matrices [141, $142]$ and for the isolated radical in a supersonic jet [130, $131,143,144]$. The observed splitting is ca. $8-9 \mathrm{~cm}^{-1}$, smaller than the barrier to pseudorotation predicted by previous ab initio studies [120, 145].

From rotational constants derived from spectra recorded at 3 and $10 \mathrm{~K}$ [131] deduced that the most stable isomer of $\mathrm{C}_{5} \mathrm{HD}_{4}$ has a dienylic geometry like that of $\mathrm{M}$ in Fig. 19. By contrast, the most stable isomer of $\mathrm{C}_{5} \mathrm{H}_{4} \mathrm{D}$ was found to have the allylic ring structure of TS), Fig. 20. Used to thinking in terms of APESs - which are unchanged by the H:D substitution - this interpretation did not appear to be consistent with the suggestion of Carrington [et al.] [140]. Furthermore, the size of the $D_{5 \mathrm{~h}}-C_{2 \mathrm{v}}$ distortion calculated from the rotational constants was less than that suggested by ab initio calculations [120, 145]. 

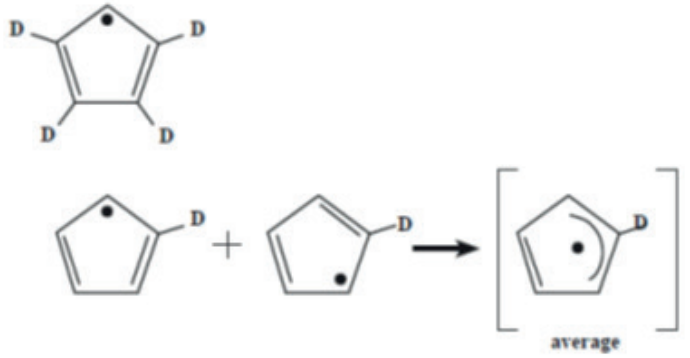

Fig. 20. For $\mathrm{C}_{5} \mathrm{H}_{4} \mathrm{D}$, the two equivalent isotopicallysubstituted minima with the lowest zero point energy lead to a time-averaged $C_{2 \mathrm{~V}}$ structure that resembles the transition structure TS in the moat around the Jahn-Teller intersection (Fig. 19). The unique lowest energy structure $C_{2 \mathrm{~V}}$ for $\mathrm{C}_{5} \mathrm{HD}_{4}$ is also shown. From ref. [124].

Optimized CASSCF/cc-pVDZ structures are shown in Fig. 21. The energy difference between the minima M and the transition structure TS is found to be $3.6 \mathrm{~cm}^{-1}$, much smaller than the $2100 \mathrm{~cm}^{-1}$ stabilization energy due to the static Jahn-Teller distortion from the $D_{5 \mathrm{~h}}$ geometry $\mathrm{X}$, and an order of magnitude smaller than the lowest previous ab initio value of $44 \mathrm{~cm}^{-1}$ [120]. Bearpark [et al.] [124] found a dienylic geometry with electronic symmetry $\mathrm{B}_{2}$ to be the $\mathrm{D}_{0}$ minimum $\mathrm{M}$ in agreement with $[120,145]$. As a test of the method for calculating energy differences, [124] have also optimized the $D_{5 \mathrm{~h}}$ minimum structure (labeled $\mathrm{M}\left(\mathrm{D}_{2}\right)$ ) on $\mathrm{D}_{2}\left({ }^{2} \mathrm{~A}_{2}\right)$. The value for the $0-0$ electronic transition was calculated as $86.6 \mathrm{kcal} \mathrm{mol}^{-1}$, in good agreement with the experimental value of $84.6 \mathrm{kcal} \mathrm{mol}^{-1}$ $\left(29,573 \mathrm{~cm}^{-1}\right)[146,147]$.

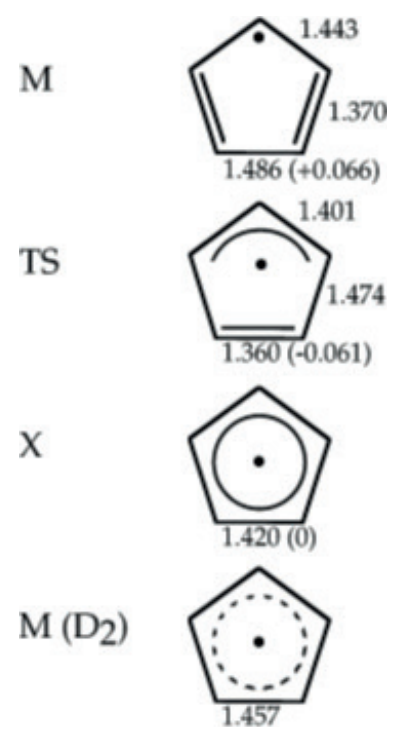

Fig. 21. Cyclopentadienyl structures optimized at the CASSCF: cc-pVDZ level of theory: the diene-like $C_{2 v}$ minimum M (D0); allylic $C_{2 \mathrm{v}}$ transition structure TS $\left(\mathrm{D}_{0}\right)$; $D_{5 \mathrm{~h}}$ Jahn-Teller crossing $\mathrm{X}\left(\mathrm{D}_{0}: \mathrm{D}_{1}\right)$; and $D_{5 \mathrm{~h}}$ minimum on $\mathrm{D}_{2}$ $\mathrm{M}\left(\mathrm{D}_{2}\right)$. Corresponding energies are given in Table 1 of ref. [124]. All bond lengths are in $\AA$. Relative lengths of the basal bond $(\AA)$ are also indicated. From ref. [124].
The interrelationships between $\mathrm{M}, \mathrm{TS}$ and $\mathrm{X}$ are emphasized in Fig. 19. The transition vector determined by the frequency calculation at TS is shown at the right, and in this direction clearly points towards one of the five equivalent M [134], (pp. 48 and 443). One of the five possible pairs of directions that lift the degeneracy at $\mathrm{X}$ are also shown, one leading towards $\mathrm{M}$, the other to TS. For the $D_{5 \mathrm{~h}}$ Jahn-Teller crossing X, the value for the $\mathrm{C}-\mathrm{C}$ bond length of $1.420 \AA$ [124] is almost identical to that of $1.421 \AA$ given by [131]. The corresponding value of $1.457 \AA$ for the $D_{5 \mathrm{~h}}$ minimum on $\mathrm{D}_{2}$ is within $910 \mathrm{~m} \AA$ of the experimental value of $1.449 \AA$, [131]. These results (together with the $92 \mathrm{kcal} \mathrm{mol}^{-1}$ difference between calculated and experimental $\mathrm{O}-\mathrm{O}$ transition energies) suggest that the CASSCF:cc-pVDZ method used is a reliable one for the ${ }^{2} \mathrm{E}$ ', and ${ }^{2} \mathrm{~A}^{\prime}$, states of cyclopentadienyl at these geometries. However, the values for the change of the $\mathrm{C}-\mathrm{C}$ bond length at the base of the pentagon $(\sim 66, \sim 61 \mathrm{~m} \AA$, Fig. 21$)$ are significantly larger than the $937 \mathrm{~m} \AA$ determined experimentally [131].

The $\mathrm{D}_{5 \mathrm{~h}}$ Jahn-Teller intersection is 'peaked': the lowest point on the potential energy surface of the upper state, but one at which the energy gradient does not go to zero overall. At this point there are two directions (Fig. 22 ) that lift the degeneracy (nonzero gradient), and $3 \mathrm{~N}-8$ that preserve it (zero gradient). Since the gradient at the $D_{5 \mathrm{~h}}$ geometry is not zero in the full $3 \mathrm{~N}-6$ coordinates, a conventional frequency calculation is meaningless. However, for those $3 \mathrm{~N}-8$ coordinates that preserve the degeneracy (and along which the gradient is zero) frequencies and normal modes could be calculated in principle by a projection similar to that used for modes orthogonal to a reaction path [124].

Recently, the ionization energy (IE), electron affinity (EA), and heats of formation for cyclopentadienyl radical, cation, and anion, $\mathrm{C}_{5} \mathrm{H}_{5} / \mathrm{C}_{5} \mathrm{H}_{5}{ }^{+} / \mathrm{C}_{5} \mathrm{H}_{5}^{-}$, have been calculated by wave function-based ab initio CCSDT/CBS approach, which involves approximation to a complete basis set (CBS) limit at the coupled-cluster level with up to full triple excitations (CCSDT) [128]. The zero-point vibrational energy correction, core-valence electronic correction, scalar relativistic effect, and higher-order corrections beyond the $\operatorname{CCSD}(\mathrm{T})$ wave function are included in these calculations. The allylic $\left[\mathrm{C}_{5} \mathrm{H}_{5}\left({ }^{2} \mathrm{~A}_{2}\right)\right]$ and dienylic $\left[\mathrm{C}_{5} \mathrm{H}_{5}\left({ }^{2} \mathrm{~B}_{1}\right)\right]$ forms of cyclopentadienyl radical were considered: the ground state structure exists in the dienyl form, and it is about $30 \mathrm{meV}$ more stable than the allylic structure. Both structures are lying closely and are interconvertible along the normal mode of $b_{2}$ in-plane vibration.

The $\mathrm{C}_{5} \mathrm{H}_{5}\left({ }^{2} \mathrm{E}_{1}{ }^{\prime \prime}, \mathrm{D}_{5 \mathrm{~h}}\right)$ normally undergoes JahnTeller distortion along the degenerate $\mathrm{e}_{2}$-type vibration, and its electronic configuration $\left[\ldots\left(\mathrm{a}_{2}{ }^{\prime \prime}\right)^{2}\left(\mathrm{e}_{1}{ }^{\prime \prime}\right)^{2}\left(\mathrm{e}_{1}{ }^{\prime \prime}\right)^{1}\right]$ is split into two nearly degenerate electronic states: ${ }^{2} \mathrm{~B}_{1}[\ldots$ $\left.\left(b_{1}\right)^{2}\left(a_{2}\right)^{2}\left(b_{1}\right)^{1}\right]$ (dienylic form) and ${ }^{2} A_{2}\left[\ldots\left(b_{1}\right)^{2}\left(b_{1}\right)^{2}\left(a_{2}\right)^{1}\right]$ 


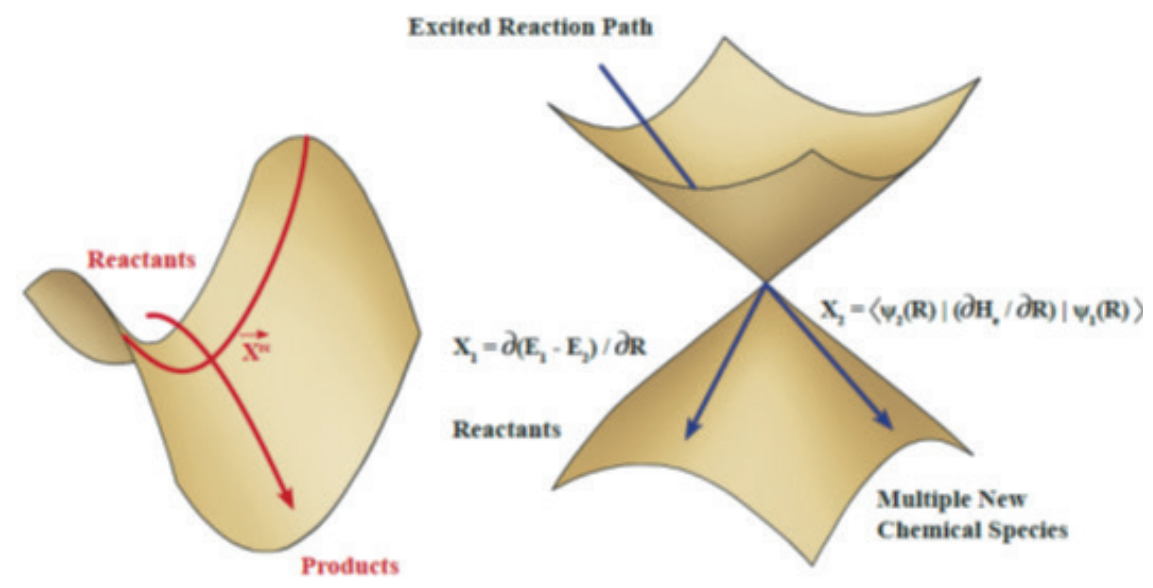

Fig. 22. Comparison of reaction paths through a transition state vs. a conical intersection. $\mathrm{E}_{1}$ and $\mathrm{E}_{2}$ are the two electronic eigenvalues, $\mathrm{H}_{\mathrm{e}}$ is defined as electronic Hamiltonian, $\mathrm{R}$ is a vector of nuclear Cartesian displacements, and $\psi_{1}$ and $\psi_{2}$ are solutions of the electronic Schrödinger equation in a configuration interaction problem, i.e., any standard representation of electronic states expanded in a basis of electron configurations. From ref. [148].

(allylic form), where the doubly degenerate $\mathrm{e}_{1}$ " orbitals (in $\mathrm{D}_{5 \mathrm{~h}}$ symmetry) correspond to $\mathrm{a}_{2}$ and $\mathrm{b}_{1}$ orbitals $\left(\mathrm{C}_{2 \mathrm{v}}\right.$ symmetry). The highest (doubly) occupied molecular orbital (HOMO) in the dienylic form $\left[\mathrm{C}_{5} \mathrm{H}_{5}\left({ }^{2} \mathrm{~B}_{1}\right)\right]$ possesses a symmetry, and the singly occupied molecular orbital (SOMO) is in $b_{1}$ symmetry. The order of HOMO and SOMO are swapped in the allylic form $\left[\mathrm{C}_{5} \mathrm{H}_{5}\left({ }^{2} \mathrm{~A}_{2}\right)\right]$. The SOMOs in $\mathrm{C}_{5} \mathrm{H}_{5}\left({ }^{2} \mathrm{~A}_{2}\right)$ and $\mathrm{C}_{5} \mathrm{H}_{5}\left({ }^{2} \mathrm{~B}_{1}\right)$ have identical orbital energies of -0.199 au, which lie above the HOMOs by $\sim 0.035$ au ( please, see ref. [128]), Fig. 23.

The ground state of cyclopentadienyl radical is found by Lo and Lau [128] to be the $\mathrm{C}_{5} \mathrm{H}_{5}\left({ }^{2} \mathrm{~B}_{1}\right)$ form, and it is about $30 \mathrm{meV}$ more stable than the $\mathrm{C}_{5} \mathrm{H}_{5}\left({ }^{2} \mathrm{~A}_{2}\right)$ structure. Both structures lie very closely on the APES, and they are interconvertible via the normal mode of $b_{2}$ in plane vibration.

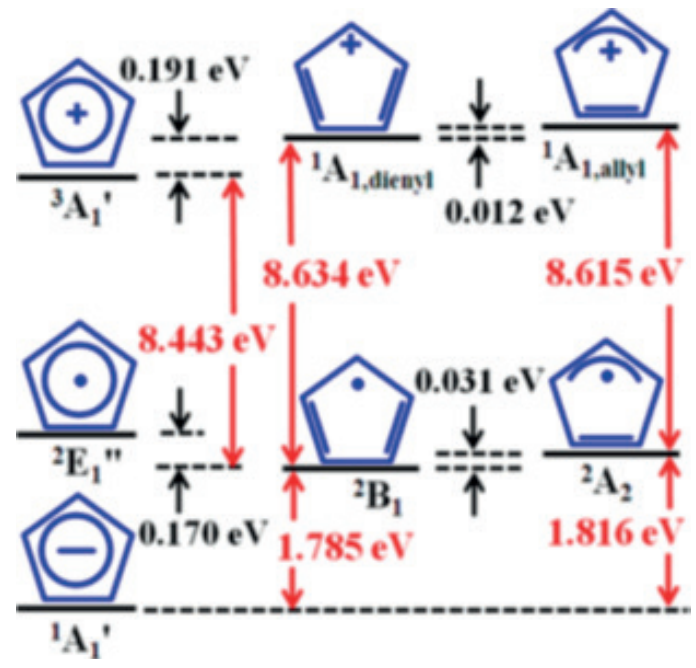

Fig. 23. Schematic illustration of the relative energy levels of $\mathrm{C}_{5} \mathrm{H}_{5}\left({ }^{2} \mathrm{~B}_{1}\right.$ and $\left.{ }^{2} \mathrm{~A}_{2}\right), \mathrm{C}_{5} \mathrm{H}_{5}{ }^{+}\left({ }^{1} \mathrm{~A}_{1}\right.$ and $\left.{ }^{3} \mathrm{~A}_{1}{ }^{\prime}\right)$, and $\mathrm{C}_{5} \mathrm{H}_{5}{ }^{-}\left({ }^{1} \mathrm{~A}_{1}{ }^{\prime}\right)$ at the CCSDT/CBS level. All optimized bond lengths $(\AA)$ are at the CCSD(T)/aug-cc-pVTZ level. From ref. [128].

\section{UNIMOLECULAR PHOTODISSOCIATION OF 1,2-DIIODTETRAFLUORO-ETHANE}

Photofragmentation of haloalkanes are of particular interest, because the final position of the functional groups in the products of reaction are stereochemically controlled to with respect to the formed double bond $\mathrm{C}=\mathrm{C}$ [149]. Halogen radicals, such as $\mathrm{CH}_{2} \mathrm{ICH}_{2}$. and $\mathrm{CF}_{2} \mathrm{ICF}_{2}$, are intermediates in elimination reactions of halogens. There are often made some assumptions about their structures to explain the observed stereoselectivity. In the symmetric bridge structure halogen is connected by the equivalent halogen bonds to two carbon atoms, whereas in the classical structure represented by a mixture of anti and gauche conformers halogen is located predominantly near one carbon atom [150]. Bridge structures of intermediate prevents rotation around the $\mathrm{C}=\mathrm{C}$ bond, and therefore supports the position of functional groups in the final product providing stereochemical control. However, despite numerous experimental and theoretical studies of these reactions, the structure of the intermediates remained to be unknown.

\subsection{Structural dynamics of the elimination reaction of iodine atoms from the free $C_{2} F_{4} I_{2}$ molecules under collisionless conditions}

Ihee [et al.] has investigated the reaction of elimination of two iodine atoms from $\mathrm{C}_{2} \mathrm{~F}_{4} \mathrm{I}_{2}$ using UED (Fig. 24) [151, 152]. Structures of all the intermediates are unknown, and the problem is to determine the structural dynamics of the reaction as a whole.

The molecular structure of the intermediate $\mathrm{C}_{2} \mathrm{~F}_{4} \mathrm{I}$ was determined from the difference curves $\Delta \mathrm{sM}(\mathrm{s}, \mathrm{t})$. The theoretical curves $\Delta \mathrm{sM}(\mathrm{s}, \mathrm{t})$ and $\Delta \mathrm{f}(\mathrm{r}, \mathrm{t})$ for classical structures are in agreement with the experimental data, while the line, provide a theoretical bridge structure (the iodine atom is 


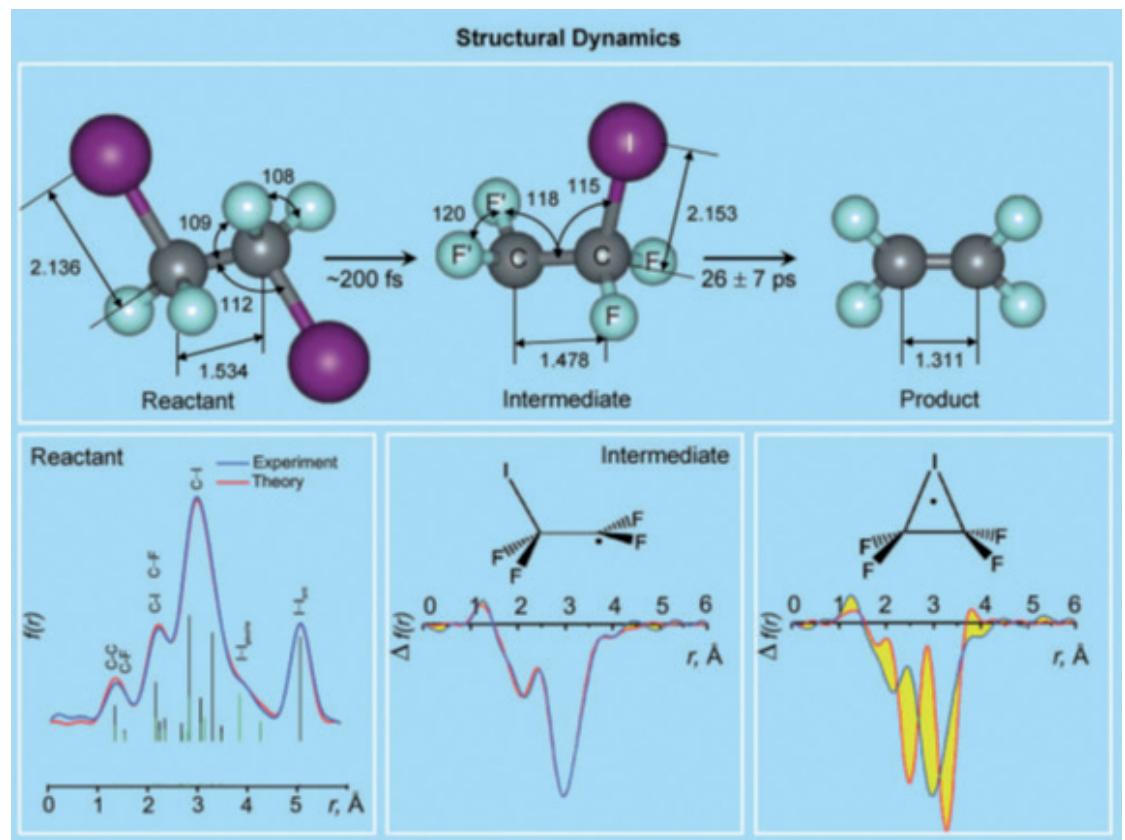

Fig. 24. Structural dynamics of $\mathrm{C}_{2} \mathrm{~F}_{4} \mathrm{I}_{2}$ dissociation reaction: the structure of the reactant, the intermediate and the products of reaction were determined in collisionless environment (upper panel). The values of average interatomic distances $(\AA)$ and bond angles (degrees) are given. UED data for a mixture of anti-gauche conformations of the molecule in their ground states. Internuclear distance for the anti (black) and gauche (green) isomers are shown by vertical lines. The analysis of the diffraction data revealed that the structure of the transition state is not a bridge structure (lower right panel) and corresponds to the classical concepts of structural theory (lower center panel). The mismatch between theoretical and experimental radial distribution curves of internuclear distances, $f(r)$ and given by difference curves, $(\Delta f(r)$ in yellow). From ref. [153]; please, see also ref. [152].

symmetrically connected to two carbon atoms) is not in agreement with experimental data (Fig. 25). Therefore, the structure of the $\mathrm{C}_{2} \mathrm{~F}_{4} \mathrm{I}$ intermediate is classical.

In the intermediate the interatomic distance $\mathrm{C}-\mathrm{I}$ is longer, and $\mathrm{C}-\mathrm{C}$ distance is shorter than those in the reagent, while the internuclear distance $\mathrm{C}-\mathrm{F}^{\prime}$ in the radical $\left(-\mathrm{CF}_{2}^{\prime}\right)$ is shorter than that in $\mathrm{CF}_{2} \mathrm{I}$. These results explain the increased bond multiplicity of $\mathrm{C}-\mathrm{C}$ and reduced bond multiplicity of $\mathrm{C}-\mathrm{I}$ as a result of formation of a transitional structure $\mathrm{CF}_{2} \mathrm{I}$. Moreover, the angles $\mathrm{CCF}^{\prime}$ and $\mathrm{F}^{\prime} \mathrm{CF}^{\prime}$ are larger than the corresponding angles in the reagent (by $\sim 9^{\circ}$ and $\sim 12^{\circ}$, respectively). This suggests that the radical center $\left(-\mathrm{CF}_{2}^{\prime}\right)$ of $\mathrm{C}_{2} \mathrm{~F}_{4} \mathrm{I}$ intermediate relaxes with subsequent loss of the first atom

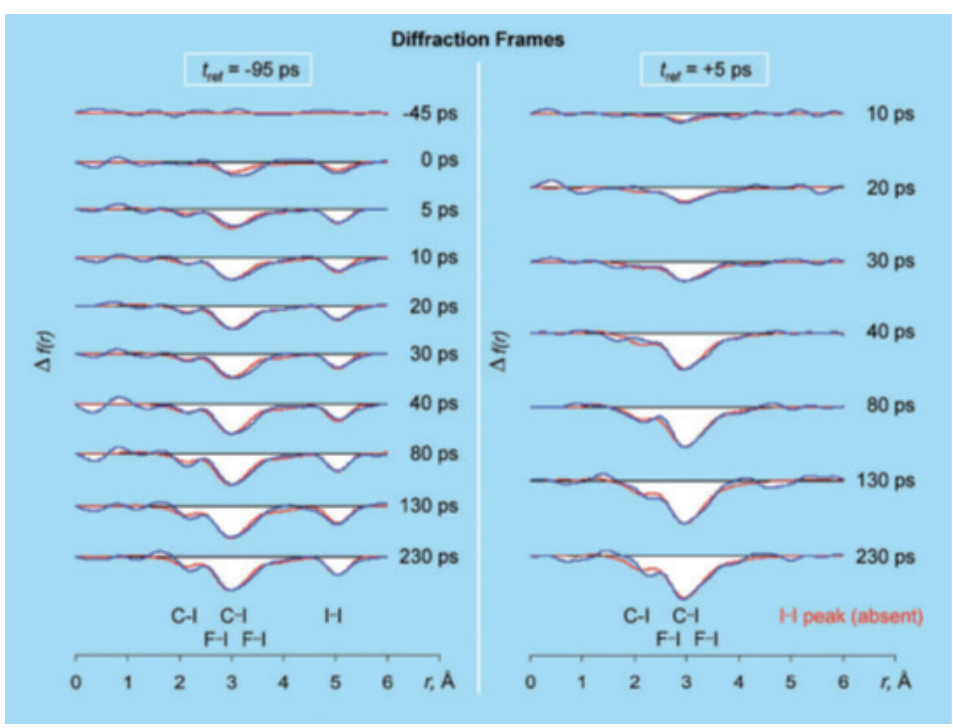

Fig. 25. Time dependence of difference radial distribution curves, $\Delta \mathrm{f}(\mathrm{r}, \mathrm{t})$ for two different starting points: before the arrival of the exciting laser radiation $\left(t_{\text {ref }}=-95 \mathrm{ps}\right.$, left $)$ and after the arrival of the laser pulse $\left(\mathrm{t}_{\mathrm{ref}}=+5 \mathrm{ps}\right.$, right). Peak corresponding to unbound atoms of iodine, I ... I does not exist, as is seen from the right side of the figure. From ref. [153]; please, see also ref. [152]. 
I. Structure and dynamics studied by TRED are required for understanding the conservation of the stereochemistry of this class of reactions $[151,152,154]$, and this is the first example of the determination of these structures.

\subsection{Structural dynamics of iodine cleavage reaction in $\mathrm{C}_{2} \mathrm{H}_{4} \mathrm{I}_{2}$ and $\mathrm{C}_{2} \mathrm{~F}_{4} \mathrm{I}_{2}$ molecules in solution}

As discussed above, cleavage of iodine atoms from the free molecules of 1,2-diiodo-tetrafluoroethane in collisionless environment takes place via two steps and results in formation of tetrafluoroethylene (Fig. 24). Cleavage of the first atom of iodine occurs in $200 \mathrm{fs}$ with formation of an intermediate product - the radical monoiodinetetrafluoroethane which has classical structure. The second stage - the splitting of the second atom of iodine goes up to 25 (7) ps and ends at 26 (7) ps with formation tetrafluoroethylene $[151,152]$.

It would be interesting to study the elimination reaction in solution and compare the results to those obtained for free molecules. This will provide information on the effect of the solvent. Some information may be provided by XANES and EXAFS. However, compared with the data provided by time resolved X-ray diffraction these methods yield much less precise information about the structure of molecules.
Recently, elimination reactions of halogen molecules from haloalkanes were studied using TRXL (TimeResolved X-ray Liquidography) - X-ray diffraction with a time resolution of $\sim 100 \mathrm{ps}$ in solution (see reviews [24, 26]). It was found that as in the gas phase in collisionfree conditions, the elimination reaction of iodine atoms in the solution passes through the intermediate $\mathrm{I}-\mathrm{CF}_{2} \mathrm{CF}_{2}$ which has a classical structure. However, the next stage - the splitting of the second atom of iodine - is about six times slower than that observed for free molecules in collisionless conditions. The authors attribute this result to the influence of a polar solvent - methanol. The presence of solvent molecules environment may lead to increased rate of redistribution of energy, change in the barrier height of the reaction, and/or isolation of the fragments in the solvation shell. Kim [et al.] proposed a mechanism for the elimination iodine atoms in $\mathrm{C}_{2} \mathrm{H}_{4} \mathrm{I}_{2}$, similar to that for isolated $\mathrm{C}_{2} \mathrm{~F}_{4} \mathrm{I}_{2}$ molecules $[24,26]$ : the cleavage of the first atom of iodine leads to the bridge structure of the radical $\mathrm{CH}_{2} \mathrm{ICH}_{2}$. Then atom I joins to $\mathrm{CH}_{2} \mathrm{ICH}_{2}$ resulting in $\mathrm{C}_{2} \mathrm{H}_{4} \mathrm{I}-\mathrm{I}$, an isomer of $\mathrm{C}_{2} \mathrm{H}_{4} \mathrm{I}_{2}$. The next step is the dissociation of $\mathrm{C}_{2} \mathrm{H}_{4} \mathrm{I}-\mathrm{I}$ molecules and formation of $\mathrm{C}_{2} \mathrm{H}_{4}$ and iodine molecules (Fig. 26).
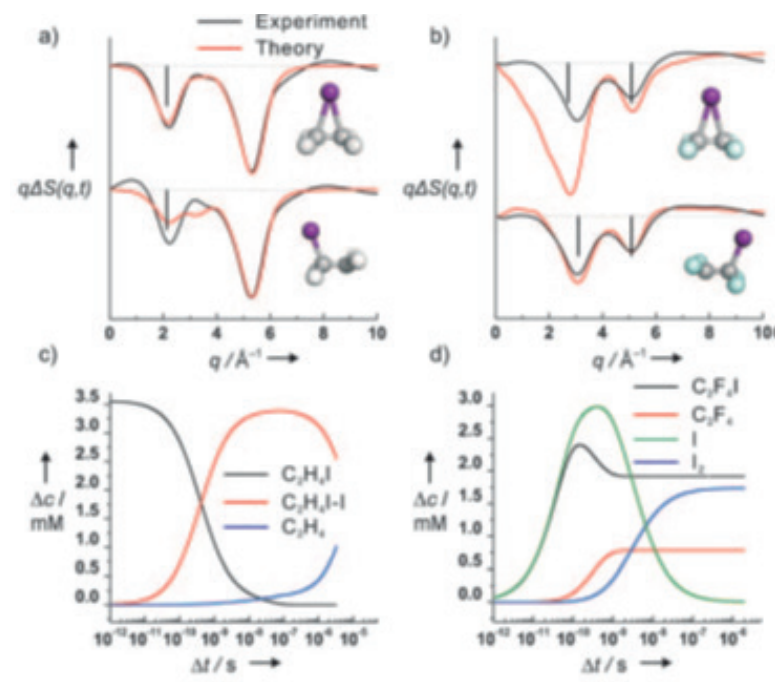

e)

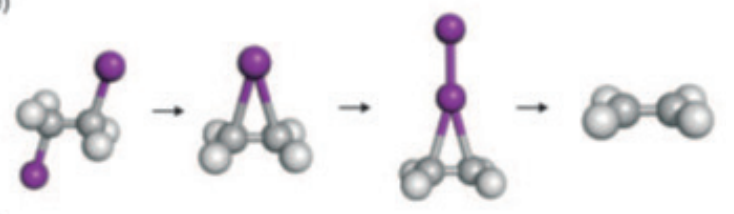

f)

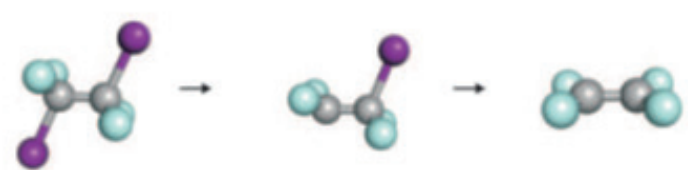

Fig. 26. Structural dynamics of iodine elimination reaction from $\mathrm{C}_{2} \mathrm{H}_{4} \mathrm{I}_{2}$ and $\mathrm{C}_{2} \mathrm{~F}_{4} \mathrm{I}_{2}$ molecules probed using TRXD in methanol solution. The time-dependent diffraction patterns of (a) $\mathrm{C}_{2} \mathrm{H}_{4} \mathrm{I}$ and (b) and $\mathrm{C}_{2} \mathrm{~F}_{4} \mathrm{I}$ radicals. q $\Delta \mathrm{S}$ (q, $\mathrm{t}$ ) were obtained by subtracting the diffraction patterns of $\mathrm{C}_{2} \mathrm{H}_{4} \mathrm{I}_{2}$ and $\mathrm{C}_{2} \mathrm{~F}_{4} \mathrm{I}_{2}$ in electronic state, diffraction patterns of solvent, and accounting for effects caused by heating of solvent by laser radiation. This data representation allowed comparing structural dynamics in solution and in the gas phase for the two configurations of the intermediate $\mathrm{C}_{2} \mathrm{H}_{4} \mathrm{I}$ and $\mathrm{C}_{2} \mathrm{~F}_{4} \mathrm{I}$ - classical and bridged. From ref. [26]. 
The experimental data on Fig. 26 (black) and theoretical (red) show time-dependent differences of the radial distribution curves, RDF (c, d), for two reaction channels and the molecular structures of (I: purple, C: black, H: white, F: green). The upper and lower curves correspond to the bridging and classical structures, respectively. The kinetics of the reactions and the changes in the populations of intermediate particles and the reaction products of the photoelimination of the molecules $\mathrm{C}_{2} \mathrm{H}_{4} \mathrm{I}_{2}$ (c) and $\mathrm{C}_{2} \mathrm{~F}_{4} \mathrm{I}_{2}$ (d) depend on the temporal delay between the excitation pulses and the probe. Figure (c) with the black curve corresponds to the bridged structure $\mathrm{C}_{2} \mathrm{H}_{4} \mathrm{I}$, red - to the isomeric form, and blue - to the final reaction product, $\mathrm{C}_{2} \mathrm{H}_{4}$. The figure (d) with green curve corresponds to the atom I, black - to the classic structure $\mathrm{C}_{2} \mathrm{~F}_{4} \mathrm{I}$, red - to $\mathrm{C}_{2} \mathrm{~F}_{4}$, and blue - to the molecule $\mathrm{I}_{2}$. e) The model of the reaction of $\mathrm{C}_{2} \mathrm{H}_{4} \mathrm{I}_{2}$. After the photoexcitation, one atom splits off from iodine molecules, and the radical $\mathrm{C}_{2} \mathrm{H}_{4} \mathrm{I}$ has a bridging configuration. $\mathrm{C}_{2} \mathrm{H}_{4} \mathrm{I}$ then recombines with the atom I separated from the molecule and forms the isomeric of the ground state: $\mathrm{I} \ldots \mathrm{I}-\mathrm{C}_{2} \mathrm{H}_{4}$. Furthermore, the isomer decays into the molecule $\mathrm{C}_{2} \mathrm{H}_{4}$ and $\mathrm{I}_{2}$. f) The model of the reaction of $\mathrm{C}_{2} \mathrm{~F}_{4} \mathrm{I}_{2}$. After the photoexcitation one iodine atom is cleaved from the molecule, and the intermediate radical $\mathrm{C}_{2} \mathrm{~F}_{4} \mathrm{I}$ has a classical structure. A part of the radicals $\mathrm{C}_{2} \mathrm{~F}_{4} \mathrm{I}$ decay into the molecules $\mathrm{C}_{2} \mathrm{~F}_{4}$, and the atoms of I. Finally, the nongeminal I atoms recombine to form the molecules of $\mathrm{I}_{2}$ [26].

For interpretation of the experimental data Ihee [et al.] [24, 26] reviewed all the previously proposed structures. It was found that the reaction of elimination of iodine molecules from $\mathrm{C}_{2} \mathrm{H}_{4} \mathrm{I}_{2}$ and $\mathrm{C}_{2} \mathrm{~F}_{4} \mathrm{I}_{2}$ have different mechanisms (Fig. 26). Elimination of iodine from $\mathrm{C}_{2} \mathrm{H}_{4} \mathrm{I}_{2}$ results in formation of $\mathrm{C}_{2} \mathrm{H}_{4} \mathrm{I}$ and $\mathrm{I}$ and $\mathrm{C}_{2} \mathrm{H}_{4} \mathrm{I} \ldots \mathrm{I}$ (as measured at a time delay of $100 \mathrm{ps)}$ ) and formation of the final products $-\mathrm{C}_{2} \mathrm{H}_{4}$ and $\mathrm{I}_{2}-$ is not observed. $\mathrm{C}_{2} \mathrm{H}_{4} \mathrm{I}$ does not dissociate into $\mathrm{C}_{2} \mathrm{H}_{4}$ and atom I, but rather reacts with iodine atoms to form $\mathrm{C}_{2} \mathrm{H}_{4} \mathrm{I}$...I. The rate constants of bimolecular reaction leading to formation of isomer was estimated as $k=7.9(3.5) \cdot 10^{11} \mathrm{~m}^{-1} \mathrm{c}^{-1}$, which appeared to be two orders of magnitude higher than the rate of recombination of molecular iodine in a solution of $\mathrm{CCl}_{4}$. This implied that the isomer $\mathrm{C}_{2} \mathrm{H}_{4} \mathrm{I} \ldots \mathrm{I}$ is mainly formed in the "cage" formed by the solvent shell. This isomer dissociates into $\mathrm{C}_{2} \mathrm{H}_{4}+\mathrm{I}_{2}$ on a microsecond time scale with a rate constant of $k=2.0(1.4) \cdot 10^{5} \mathrm{~m}^{-1} \mathrm{c}^{-1}$. On the contrary, $\mathrm{C}_{2} \mathrm{~F}_{4} \mathrm{I}$ and I are the primary particles that are detected after the first $100 \mathrm{ps}$ and apparently formed on a few picosecond time scale, $20(1) \%$ of radicals $\mathrm{C}_{2} \mathrm{~F}_{4} \mathrm{I}$ dissociate into $\mathrm{C}_{2} \mathrm{~F}_{4}$ and I with a time constant of 306 (48) ps. These values can be compared with the data [151, $152]$ for the gas phase: $55(5) \%$ and 26 (7) ps. This clearly illustrates the effect of the solvent molecules, which significantly reduce the rate and the yield of the second stage of the elimination reaction. This is not surprising, since the residual internal energy in the radical $\mathrm{C}_{2} \mathrm{~F}_{4} \mathrm{I}$ after the first stage of molecular decay of $\mathrm{C}_{2} \mathrm{~F}_{4} \mathrm{I}_{2}$ in solution is much lower than that in the gas phase as a result of the transfer of the excess energy to the solvent. Molecular iodine, $\mathrm{I}_{2}$ is formed via recombination of two iodine atoms in $\sim 100 \mathrm{~ns}$ with a rate constant of $4.4(1.2) \cdot 10^{10}$ $\mathrm{m}^{-1} \mathrm{c}^{-1}$, which is comparable with the rate constant for recombination of molecular iodine in the solution. Of particular interest in the study of the structural dynamics is the structure of the transient species. As already noted, the method TRXL can answer the question whether the structure of the radical is bridged or classical? It is possible to make a calculation of the diffraction intensities for the proposed intermediates and compare with experimental data, making correction for the scattering of the solvent. The results of calculation are presented in Figs. 26(a) and 26(b). The intensities of scattering of the intermediate species are determined after subtracting the contribution from the solvent, "cage" of the shell, and other structures and comparing the calculated data of alleged molecules. This "fingerprint method" is similar to the approach used in TRED. Comparison of the data for $100 \mathrm{ps}$ and the alleged intermediates demonstrate that radical $\mathrm{C}_{2} \mathrm{H}_{4} \mathrm{I}$ has bridged structure, while $\mathrm{C}_{2} \mathrm{~F}_{4} \mathrm{I}$ is represented by a mixture of classical and anti-gauche conformers. This conclusion is supported by the results of quantum chemical calculations, which show a significant effect of the fluorine atoms. A large number of photodissociation reactions of free molecules were studied (see review articles [17, 32, 36, 38, 155]. However, it should be noted that the solution of the inverse scattering problem in the determination of intermediate products of both the photo-excitation and the photo-dissociation in the most of the studies carried out to date was conducted using the theoretical counterpart of the scattering intensity of the electrons in the assumption of an equilibrium distribution of the vibrational and rotational degrees of freedom of the molecules. As was shown in the case of the study of the photo-dissociation reaction of $\mathrm{CS}_{2}$, even with nanosecond time resolution this assumption may be inaccurate [35, 36, 38, 156, 157].

\section{Concluding remarks}

In 1927, Davisson and Germer [158] and independently Thomson and Reid [159] discovered the phenomenon of diffraction of electrons on crystals. This finding relates to the "static" diffraction. After the first experiments performed by Mark and Wierl in $1930[1,2]$ the method of electron diffraction remained conceptually unchanged until the early 80 's of the last century. Only 50 years later it became possible to introduce fourth dimension in the technique - time, introducing the concept of structural dynamics and research in 4D 
space - time continuum. Development of the electron diffraction with a time resolution is presented in Fig. 27 (taken from review article [160]), a more detailed description of the history of development is given in the review articles [31,36] and monograph [161].

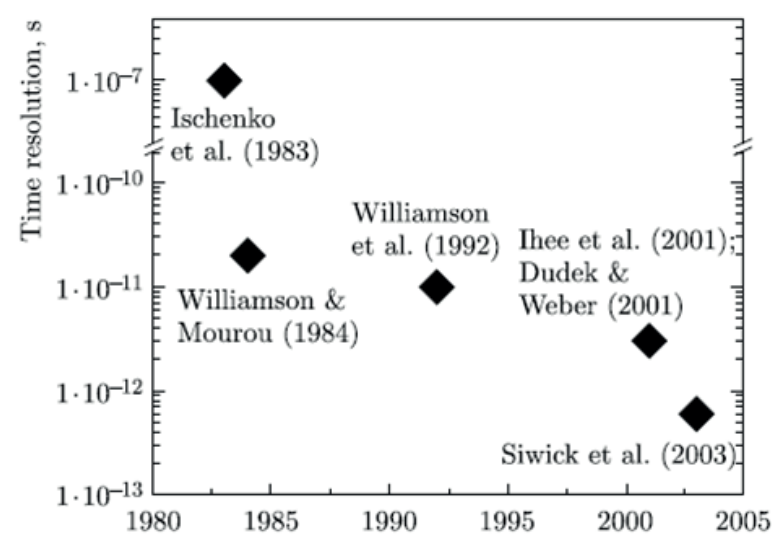

Fig. 27. The development of time resolved electron diffraction. Studies in which structural changes were not observed are not included. The first experimental result and the description of the electron diffraction method with a time resolution (stroboscopic electron diffraction), which recorded the change in the diffraction pattern during the laser dissociation of $\mathrm{CF}_{3} \mathrm{I}$ molecules in the gas phase under the influence of radiation $\mathrm{CO}_{2}-$ laser [5]. The first experiment with subnanosecond temporal resolution: the melting of a thin aluminum film in the laser field [12]. The photo-dissociation of $\mathrm{CF}_{3} \mathrm{I}$ [13]. The process of the photodissociation of $\mathrm{C}_{2} \mathrm{~F}_{4} \mathrm{I}_{2}$ [151]. The disclosure of the cycle in the molecular cyclohexadiene [162]. The investigation of the melting process of $\mathrm{Al}$ exposed to a laser radiation [163]. A more detailed historical overview is presented in the paper [31]. From ref. [160].

The nuclear motion as a chemical reaction unfolds can be probed using TRED (UED). Breaking of chemical bonds, their formation and change in the geometry of the molecule occurs at a rate of $\sim 1000 \mathrm{~m} / \mathrm{s}$ (please, see, e.g., $[164,165])$. Consequently, for the registration of nuclear dynamics the time resolution of $<100 \mathrm{fs}$ is required. Regardless of whether the molecule is isolated or not the ultrafast changes involve coordinated rearrangement of the electron and nuclear subsystems of reacting molecules.

According to the transition state theory [166-169], for the unimolecular reaction we have a frequency factor equal to $k T / h$ - namely with this frequency the transition to the final products occurs through the energy barrier of the chemical reaction [41, 170-173]. At room temperature, its value is $\sim 6 \times 10^{12} \mathrm{~s}^{-1}$, which corresponds to the time of $\sim 150 \mathrm{fs}$. Typical intramolecular vibrations occur in the time interval of the order of hundreds of femtoseconds. That is why to some extent the term "ultrafast electron diffraction" is justified. In this case, it is clear that the diffraction process of electrons is determined by the accelerating voltage, and single scattering event for $100-\mathrm{keV}$-electron occurs in a few attoseconds.

The electron diffraction with a high time resolution has opened the possibility of direct observation of the processes occurring in the transient state of the substance. Here it is necessary to provide a temporary resolution of the order of $100 \mathrm{fs}$, which corresponds to the transition of the system through the energy barrier of the potential surface, which describes the chemical reaction - the process of the breaking and the formation of new bonds between the interacting agents. Thus, the possibility of the investigation of the dynamics of coherent nuclear molecular systems and the condensed matter can be opened [10, 12, 35-38, 161, 174, $175]$. In the past two decades it has been possible to observe the nuclear motion in the temporal interval corresponding to the period of the nuclear oscillation. The observed coherent changes in the nuclear system at such temporal intervals determine the fundamental shift from the standard kinetics to the dynamics of the phase trajectory of a single molecule, the molecular quantum state tomography $[36,38,157,161$, $175,176]$.

At present, the method of ultrafast diffraction is intensively developing. The great opportunities for the study of the structural dynamics are opened by 4D methods of ultrafast electron crystallography and electron microscopy with high temporal resolution from micro- to femtoseconds (please, see review articles $[31,37,160,177,178]$ and the monograph [34]). The recent advances in the formation of ultrashort electron pulses allow us to go to the area of attosecond temporal resolution and to observe the coherent dynamics of the electrons in the molecule $[22,179,180]$.

It is rather impressive that laser alignment of the molecules in the gas phase helps to restore the molecular structure by observing the multiple patterns of the ultrashort electron beam diffraction [181]. In these conditions, in principle, no additional parameters are necessary for the elucidation of complex molecular structures and intermediate states in molecular dynamics. It should be noted that in [181] the first UED experiment with subpicosecond temporal resolution was done in the gas phase. In this experiment the molecules of $\mathrm{CF}_{3}$ I were aligned impulsively with a femtosecond laser pulse and probed with a 500-fs electron pulse two picoseconds later, when the degree of the molecular alignment reaches a maximum.

\section{Acknowledgements}

The authors acknowledge support by RFBR Grant No. 16-29-1167 OFI_m and partial support by Grant No. 14-22-02035 OFI_m. We would like to thank Prof. I.B. Bersuker (Austin University, Texas, USA) and Prof. V.R. Flid (Moscow Technological University, M.V. Lomonosov Institute of Fine Chemical Technologies, Russia) for helpful discussions and valuable comments. 


\section{References:}

1. Mark H., Wierl R. Uber Elektronenbeugung am einzelnen Molekul. Naturwissenschaften. 1930. V. 18, № 9. P. 205-205.

2. Mark H., Wierl R. Die experimentellen und theoretischen grundlagen der electronenbeugung. Berlin: Verlag von Gebruder Borntraeger, 1931.

3. Stereochemical applications of gas-phase electron diffraction. Part A. The electron diffraction technique: book / ed. Hargittai I., Hargittai M. VCH Publishers, 1988.

4. Stereochemical applications of gas-phase electron diffraction. Part B. Structural information for selected classes of compounds: book / ed. Hargittai I., Hargittai M. VCH, 1988.

5. Ischenko A.A. [et al.] A stroboscopical gaselectron diffraction method for the investigation of shortlived molecular species. Appl. Phys. B Photophysics Laser Chem. 1983. V. 32, № 3. P. 161-163.

6. Ischenko A.A. [et al.] The observation of electron diffraction from free radicals - products of the IR multiphoton dissociation of CF3I molecules by stroboscopic gas electron diffraction. Bull. Moscow Univ. Ser 2. Chem. 1985. V. 26, № 2. P. 140-143.

7. Ischenko A.A. [et al.] The study of shortlived intermediate species and structural kinetics of photoexcited molecules by stroboscopic electron diffraction. Interuniversity Collection of Scientific Papers. The Structure and Properties of Molecules. Ivanovo, 1988. P. 63-77.

8. Golubkov V.V. [et al.] New methods for the registration of the signal in gas electron diffraction. Izv. Akad. Nauk SSSR Ser. Fiz. 1983. V. 47. P. 1115-1121. (in Russ.).

9. Akhmanov A.S. [et al.] Pulsed picosecond electron source. VIII-th European Conference on Electron Microscopy. Budapest, September 1984. Abstracts. P. 61-62.

10. Akhmanov S.A. [et al.] Generation of the picosecond electron pulses of fast electrons in the EMR100 electron diffraction apparatus by photoemission in the laser field. Russ. J. Techn. Phys. Lett. 1985. V. 11, № 3. P. 157-161.

11. Rood A.P., Milledge J. Combined flashphotolysis and gas-phase electron-diffraction studies of small molecules. J. Chem. Soc. Faraday Trans. 2. 1984. V. 80, № 9. P. 1145-1153.

12. Williamson S., Mourou G., Li J.C.M. Timeresolved laser-induced phase transformation in aluminum: JOUR. Phys. Rev. Lett. American Physical Society, 1984. V. 52, № 26. P. 2364-2367.

13. Williamson J.C. [et al.] Ultrafast diffraction and molecular structure. Chem. Phys. Lett. 1992. V. 196, № 6. P. 529-534.
14. Williamson J.C. [et al.] Clocking transient chemical changes by ultrafast electron diffraction: JOUR. Nature. 1997. V. 386, № 6621. P. 159-162.

15. Williamson J.C., Zewail A.H. Ultrafast electron diffraction. 4. Molecular structures and coherent dynamics. J. Phys. Chem. 1994. V. 98, № 11. P. 2766-2781.

16. Weber P.M., Carpenter S.D., Lucza T. Reflectron design for femtosecond electron guns. Proc. SPIE 2521, Time-Resolved Electron and X-Ray Diffraction, 23 (September 1, 1995) / ed. Rentzepis P.M. 1995. № 2521. P. 23-30.

17. Srinivasan R. [[et al.]] Ultrafast electron diffraction (UED). A new development for the 4D determination of transient molecular structures. Helv. Chim. Acta. 2003. V. 86, № 6. P. 1761-1799.

18. Dantus M. [et al.] Ultrafast electron diffraction. 5. Experimental time resolution and applications. J. Phys. Chem. American Chemical Society, 1994. V. 98, № 11. P. 2782-2796.

19. Schelev M.Y. 500-fs photoelectron gun for time-resolved electron diffraction experiments. Opt. Eng. 1998. V. 37, № 8. P. 2249-2254.

20. Monastyrski M. [et al.] Dynamics of electron bunches in subpicosecond streak tubes. Nucl. Instruments Methods Phys. Res. Sect. A Accel. Spectrometers, Detect. Assoc. Equip. 1999. V. 427, № 1-2. P. 225-229.

21. Time-resolved diffraction / ed. Helliwell J.R., Rentzepis P.M. Oxford Series on Synchrotron Radiation, No. 2, Clarendon Press, 1997. 454 p.

22. Ben-Nun M., Cao J., Wilson K.R. Ultrafast X-ray and electron diffraction: Theoretical considerations. J. Phys. Chem. A. 1997. V. 101, № 47. P. 8743-8761.

23. Ihee H. [et al.] From the cover: Visualizing reaction pathways in photoactive yellow protein from nanoseconds to seconds. Proc. Natl. Acad. Sci. 2005. V. 102, № 20. P. 7145-7150.

24. Ihee H. [et al.] Ultrafast X-ray scattering: structural dynamics from diatomic to protein molecules. Int. Rev. Phys. Chem. 2010. V. 29, № 3. P. 453-520.

25. Cammarata M. [et al.] Tracking the structural dynamics of proteins in solution using time-resolved wide-angle X-ray scattering. Nat. Methods. 2008. V. 5, № 10. P. 881-886.

26. Kim T.K. [et al.] Spatiotemporal kinetics in solution studied by time-resolved X-Ray liquidography (solution scattering). ChemPhysChem. 2009. V. 10, № 12. P. 1958-1980.

27. Kim J. [et al.] Anisotropic picosecond X-ray solution scattering from photoselectively aligned protein molecules. J. Phys. Chem. Lett. 2011. V. 2, № 5. P. 350-356.

28. Kim T.W. [et al.] Protein structural dynamics of photoactive yellow protein in solution revealed by pump-probe X-ray solution scattering. J. Am. Chem. Soc. 2012. V. 134, № 6. P. 3145-3153.

29. Golubkov V.V. [et al.] Pulse-resonance signal 
method for the recording of signal in a stroboscopic electron microscopy. XII Vsesoyuz. Konf. po Elektronnoi Mikroskopii, Sumy, Oktyabr' 1982. Tezisy Dokladov (XII All-Union Conf. on Electron Microscopy, Sumy, October 1982, Abstracts) (Moscow: Nauka). 1982. P. 62. (in Russ.).

30. Lobastov V.A., Srinivasan R., Zewail A.H. Fourdimensional ultrafast electron microscopy. Proc. Natl. Acad. Sci. U. S. A. 2005. V. 102, № 20. P. 7069-7073.

31. King W.E. [et al.] Ultrafast electron microscopy in materials science, biology, and chemistry. J. Appl. Phys. 2005. V. 97, № 11. P. 111101, 1-27.

32. Zewail A.H. 4D ultrafast electron diffraction, crystallography and microscopy. Annu. Rev. Phys. Chem. 2006. V. 57, № 1. P. 65-103.

33. Zewail A.H. Four-dimensional electron microscopy. Science (80-. ). 2010. V. 328, № 5975. P. 187-193.

34. Zewail A.H., Thomas J.M. 4D electron microscopy. Imaging in space and time. Imperial College Press, 2010. 360 p.

35. Ischenko A.A. [et al.] The stroboscopic gas electron diffraction method for investigation of timeresolved structural kinetics in photoexcitation processes. J. Mol. Struct. Elsevier, 1993. V. 300. P. 115-140.

36. Ewbank J.D., Schäfer L., Ischenko A.A. Structural and vibrational kinetics of photoexcitation processes using time resolved electron diffraction. J. Mol. Struct. 2000. V. 524, № 1. P. 1-49.

37. Sciaini G., Miller R.J.D. Femtosecond electron diffraction: heralding the era of atomically resolved dynamics. Reports Prog. Phys. 2011. V. 74, № 9. P. 096101 (1-36).

38. Ischenko A.A., Bagratashvili V.N., Avilov A.S. Methods for studying the coherent 4D structural dynamics of free molecules and condensed state of matter. Crystallogr. Reports. 2011. V. 56, № 5. P. 751.

39. Ischenko A.A., Schäfer L., Ewbank J.D. Structural kinetics by time-resolved gas electron diffraction: coherent nuclear dynamics in laser excited spatially anisotropic molecular ensembles. J. Mol. Struct. 1996. V. 376, № 1-3. P. 157-171.

40. Hastings J.B. [et al.] Ultrafast time-resolved electron diffraction with megavolt electron beams. Appl. Phys. Lett. 2006. V. 89, № 18. P. 184109.

41. Buchachenko A.L. Chemistry on the border of two centuries - achievements and prospects. Russ. Chem. Rev. 1999. V. 68, № 2. P. 85-102.

42. Ischenko A.A. [et al.] Ultrafast transmission electron microscopy. Fine Chem. Technol. 2017. V. 12, № 1. P. 5-25.

43. Ischenko A.A., Tarasov Y.I., Schäfer L. Structural dynamics of free molecules and condensed state of matter. Part I. Theory and experimental technique. Fine Chem. Technol. 2017. V. 12, № 2. P. 5-33.

44. Rudakov F.M.M. [et al.] Megavolt electron beams for ultrafast time-resolved electron diffraction. AIP Conference Proceedings / ed. M.D. Furnish, M. Elert, T.P. Russell C.T.W. AIP, 2006. V. 845. P. 1287-1292.

45. Kibble T.W.B. Refraction of Electron Beams by Intense Electromagnetic Waves. Phys. Rev. Lett. American Physical Society, 1966. V. 16, № 26. P. 1233-1233.

46. Friedberg E.C. DNA damage and repair. Nature. 2003. V. 421, № 6921. P. 436-440.

47. Crespo-Hernández C.E. [et al.] Ultrafast Excited-State Dynamics in Nucleic Acids. Chem. Rev. 2004. V. 104, № 4. P. 1977-2020.

48. Henry B.R., Kasha M. Radiationless molecular electronic transitions. Annu. Rev. Phys. Chem. 1968. V. 19, № 1. P. 161-192.

49. Robinson G.W., Frosch R.P. Electronic excitation transfer and relaxation. J. Chem. Phys. 1963. V. 38, № 5. P. 1187-1203.

50. Bixon M., Jortner J. Intramolecular Radiationless Transitions. J. Chem. Phys. 1968. V. 48, № 2. P. 715-726.

51. Yarkony D.R. Conical intersections: their description and consequences. Conical intersections: electronic structure, dynamics and spectroscopy / ed. Domcke W., Yarkony D.R., Koppel H. Singapore: World Scientific, 2004. P. 41-127.

52. Kistiakowsky G.B., Parmenter C.S. Effects of pressure on fluorescence and intersystem crossing in benzene vapor. J. Chem. Phys. 1965. V. 42, № 8. P. 2942-2948.

53. Ihee H. [et al.] Direct imaging of transient molecular structures with ultrafast diffraction. Science. American Association for the Advancement of Science, 2001. V. 291, № 5503. P. 458-462.

54. Callomon J.H., Parkin J.E., Lopez-Delgado R. Non-radiative relaxation of the excited $\tilde{\mathrm{A}} 1 \mathrm{~B} 2 \mathrm{u}$ state of benzene. Chem. Phys. Lett. 1972. V. 13, № 2. P. 125-131.

55. Lim E.C. Photophysics of gaseous aromatic molecules: excess vibrational energy dependence of radiationless processes. Advances in Photochemistry, Volume 23 / ed. Neckers D.C., Volman D.H., Von Bünau G. John Wiley \& Sons, Inc., 1997. P. 165-211.

56. Srinivasan R. [et al.] Dark structures in molecular radiationless transitions determined by ultrafast diffraction. Science (80-. ). 2005. V. 307, № 5709. P. 558-563.

57. Zewail A.H. Femtochemistry: atomic-scale dynamics of the chemical bond using ultrafast lasers (Nobel Lecture). Angew. Chem. Int. Ed. Engl. 2000. V. 39, № 15. P. 2586-2631.

58. Wrighton M. Photochemistry of metal carbonyls. Chem. Rev. 1974. V. 74, № 4. P. 401-430.

59. Geoffroy G.L., Wrighton M.S. Organometallic photochemistry. New York: Academic Press, 1979.

60. Fuß W., Trushin S.A., Schmid W.E. Ultrafast photochemistry of metal carbonyls. Res. Chem. Intermed. 2001. V. 27, № 4-5. P. 447-457.

61. Bañares L. [et al.] Femtosecond photodissociation 
dynamics of $\mathrm{Fe}(\mathrm{CO})_{5}$ in the gas phase. Chem. Phys. Lett. 1997. V. 267, № 1-2. P. 141-148.

62. Zewail A.H. Femtochemistry. Past, present, and future. Pure Appl. Chem. 2000. V. 72, № 12. P. 2219-2231.

63. Poliakoff M., Turner J.J. The structure of $\left[\mathrm{Fe}(\mathrm{CO})_{4}\right]$ - an important new chapter in a long-running story. Angew. Chemie Int. Ed. 2001. V. 40, № 15. P. 2809-2812.

64. Apostolova E.S., Tikhonov A.P., Sendyurev O.A. Studies of $\mathrm{Fe}_{2}(\mathrm{CO})_{9}$ formation in the thermolysis of $\mathrm{Fe}(\mathrm{CO})_{5}$ using $\mathrm{ab}$ initio calculations of $\mathrm{Fe}(\mathrm{CO})_{5}$ and $\mathrm{Fe}(\mathrm{CO})_{4}$. Russ. J. Coord. Chem. 2002. V. 28, № 1. P. 38-45.

65. Trushin S.A. [et al.] Femtosecond dynamics of $\mathrm{Fe}(\mathrm{CO})_{5}$ photodissociation at $267 \mathrm{~nm}$ studied by transient ionization. J. Phys. Chem. A. 2000. V. 104, № 10. P. 1997-2006.

66. Shorokhov D., Park S.T., Zewail A.H. Ultrafast electron diffraction: Dynamical structures on complex energy landscapes. ChemPhysChem. 2005. V. 6, № 11. P. 2228-2250.

67. Portius P. [et al.] Unraveling the photochemistry of $\mathrm{Fe}(\mathrm{CO})_{5}$ in solution: Observation of $\mathrm{Fe}(\mathrm{CO})_{3}$ and the conversion between ${ }^{3} \mathrm{Fe}(\mathrm{CO})_{4}$ and ${ }^{1} \mathrm{Fe}(\mathrm{CO})_{4}$ (solvent). J. Am. Chem. Soc. 2004. V. 126, № 34. P. 10713-10720.

68. Ewens R.V.G., Lister M.W. The structure of iron pentacarbonyl, and of iron and cobalt carbonyl hydrides. Trans. Faraday Soc. 1939. V. 35. P. 681-691.

69. Donohue J., Caron A. The crystal structure of iron pentacarbonyl: Space group and refinement of the structure. Acta Crystallogr. 1964. V. 17, № 6. P. 663-667.

70. Davis M.I., Hanson H.P. Reply to bond lengths in iron pentacarbonyl. J. Phys. Chem. 1967. V. 71, № 3. P. 775-777.

71. Beagley B. [et al.] The molecular structure of $\mathrm{Fe}(\mathrm{CO})_{5}$ in the gas phase. Acta Crystallogr. Sect. B Struct. Crystallogr. Cryst. Chem. 1969. V. 25, № 4. P. 737-744.

72. Beagley B., Schmidling D.G. A re-evaluation of the molecular structure of iron pentacarbonyl. J. Mol. Struct. 1974. V. 22, № 3. P. 466-468.

73. McClelland B.W. [et al.] Iron pentacarbonyl: Are the axial or the equatorial iron-carbon bonds longer in the gaseous molecule? Inorg. Chem. 2001. V. 40, № 6. P. $1358-1362$.

74. Jang J.H. [et al.] Molecular structures and vibrational frequencies of iron carbonyls: $\mathrm{Fe}(\mathrm{CO})_{5}$, $\mathrm{Fe}_{2}(\mathrm{CO})_{9}$, and $\mathrm{Fe}_{3}(\mathrm{CO})_{12}$. J. Phys. Chem. A. 1998. V. 102, № 27. P. 5298-5304.

75. Pierloot K. The CASPT2 method in inorganic electronic spectroscopy: from ionic transition metal to covalent actinide complexes. Mol. Phys. 2003. V. 101, № 13. P. 2083-2094.

76. Radius U. [et al.] Is $\mathrm{CO}$ a special ligand in organometallic chemistry? Theoretical investigation of $\mathrm{AB}, \mathrm{Fe}(\mathrm{CO})_{4} \mathrm{AB}$, and $\mathrm{Fe}(\mathrm{AB})_{5}\left(\mathrm{AB}=\mathrm{N}_{2}, \mathrm{CO}, \mathrm{BF}, \mathrm{SiO}\right)$. Inorg. Chem. 1998. V. 37, № 5. P. 1080-1090.
77. Ihee H., Cao J., Zewail A.H. Ultrafast electron diffraction of transient $\left[\mathrm{Fe}(\mathrm{CO})_{4}\right]$ : determination of molecular structure and reaction pathway. Angew. Chem. Int. Ed. Engl. 2001. V. 40, № 8. P. 1532-1536.

78. McKinlay R.G., Paterson M.J. The Jahn-Teller effect in binary transition metal carbonyl complexes. The Jahn-Teller effect: Fundametals and implications for physics and chemistry / ed. Köppel H., Yarkony D.R., Barentzen H. Heidelberg: Springer, 2009. P. 311-344.

79. Kim S.K., Pedersen S., Zewail A.H. Femtochemistry of organometallics: dynamics of metalmetal and metal-ligand bond cleavage in $\mathrm{M}_{2}(\mathrm{CO})_{10}$. Chem. Phys. Lett. 1995. V. 233, № 5-6. P. 500-508.

80. Trushin S.A. [et al.] Femtosecond dynamics and vibrational coherence in gas-phase ultraviolet photodecomposition of $\mathrm{Cr}(\mathrm{CO})_{6}$. J. Phys. Chem. A. 1998. V. 102, № 23. P. 4129-4137.

81. Trushin S.A., Fuß W., Schmid W.E. Conical intersections, pseudorotation and coherent oscillations in ultrafast photodissociation of group-6 metal hexacarbonyls. Chem. Phys. 2000. V. 259, № 2-3. P. 313-330.

82. Turro N.J., Ramamurthy V., Scaiano J.C. Principles of molecular photochemistry: An introduction: book / ed. Turro N.J., Ramamurthy V., Scaiano J.C. Sausalito, CA: University Science Books, 2009. 495 p.

83. Roos B.O. [et al.] Multiconfigurational perturbation theory: Applications in electronic spectroscopy. Advances in chemical physics: New methods in computational quantum mechanics. Volume 93 / ed. Prigogine I., Rice S.A. 1996. P. 219-331.

84. Roos B.O. Multiconfigurational quantum chemistry. Theory and applications of computational chemistry: The first forty years. Elsevier, 2005. P. 725-764.

85. Worth G.A., Cederbaum L.S. Beyond BornOppenheimer: Molecular dynamics through a conical intersection. Annu. Rev. Phys. Chem. 2004. V. 55, № 1. P. 127-158.

86. McKinlay R.G., Żurek J.M., Paterson M.J. Vibronic coupling in inorganic systems: Photochemistry, conical intersections, and the Jahn-Teller and pseudoJahn-Teller effects. Advances in Inorganic Chemistry. Theoretical and Computational Inorganic Chemistry. 2010. P. 351-390.

87. Jean Y., Marsden C.T. Molecular orbitals of transition metal complexes: book. OUP Oxford, 2005. $288 \mathrm{p}$.

88. Persson B.J., Roos B.O., Pierloot K. A theoretical study of the chemical bonding in $\mathrm{M}(\mathrm{CO})_{\mathrm{x}}(\mathrm{M}$ $=$ Cr, Fe, and Ni). J. Chem. Phys. 1994. V. 101, № 8. P. 6810-6821.

89. Pierloot K., Tsokos E., Vanquickenborne L.G. Optical spectra of $\mathrm{Ni}(\mathrm{CO})_{4}$ and $\mathrm{Cr}(\mathrm{CO})_{6}$ revisited. J. Phys. Chem. 1996. V. 100, № 41. P. 16545-16550.

90. Paterson M.J. [et al.] Non-adiabatic direct dynamics study of chromium hexacarbonyl 
photodissociation. J. Phys. Chem. A. 2002. V. 106, № 44. P. 10494-10504.

91. Worth G.A., Welch G., Paterson M.J. Wavepacket dynamics study of $\mathrm{Cr}(\mathrm{CO})_{5}$ after formation by photodissociation: relaxation through an $(\mathrm{E} \oplus \mathrm{A}) \otimes$ e JahnTeller conical intersection. Mol. Phys. 2006. V. 104, № 5-7. P. 1095-1105.

92. Leadbeater N. Enlightening organometallic chemistry: the photochemistry of $\mathrm{Fe}(\mathrm{CO})_{5}$ and the reaction chemistry of unsaturated iron carbonyl fragments. Coord. Chem. Rev. 1999. V. 188, № 1. P. 35-70.

93. Rubner O. [et al.] A CASSCF/MR-CCI study of the excited states of $\mathrm{Fe}(\mathrm{CO})_{5}$. Chem. Phys. Lett. 1999. V. 302, № 5-6. P. 489-494.

94. Jackson R.L. Mechanisms of metal atom formation in the multiphoton dissociation of organometallic molecules. Acc. Chem. Res. 1992. V. 25, № 12. P. 581-586.

95. Longuet-Higgins H.C. The intersection of potential energy surfaces in polyatomic molecules. Proc. R. Soc. A Math. Phys. Eng. Sci. 1975. V. 344, № 1637. P. 147-156.

96. Manthe U., Köppel H. Dynamics on potential energy surfaces with a conical intersection: Adiabatic, intermediate, and diabatic behavior. J. Chem. Phys. 1990. V. 93, № 3. P. 1658-1669.

97. Ceulemans A., Vanquickenborne L.G. The epikernel principle. Stereochemistry and Bonding. Structure and Bonding, Vol 71. Berlin, Heidelberg: Springer, 1989. P. 125-159.

98. Bersuker I.B. [et al.] Pseudo Jahn-Teller origin of instability of molecular high-symmetry configurations: Novel numerical method and results. J. Chem. Phys. 2002. V. 117, № 23. P. 10478-10486.

99. Neumann von J., Wigner E.P. Uber das Verhalten von Eigenwerten bei adiabatischen Prozessen. Phys. Zeitschr. 1929. V. 30. P. 467-470.

100. Ihee H., Cao J., Zewail A. Ultrafast electron diffraction: structures in dissociation dynamics of $\mathrm{Fe}(\mathrm{CO})_{5}$. Chem. Phys. Lett. 1997. V. 281, № 1-3. P. 10-19.

101. Poliakoff M., Ceulemans A. IR laser induced isomerization of iron tetracarbonyl $\left(\mathrm{Fe}(\mathrm{CO})_{4}\right)$ : a unique example of the Jahn-Teller effect. J. Am. Chem. Soc. 1984. V. 106, № 1. P. 50-54.

102. Poliakoff M., Weitz E. Shedding light on organometallic reactions: the characterization of tetracarbonyliron $\left(\mathrm{Fe}(\mathrm{CO})_{4}\right)$, a prototypical reaction intermediate. Acc. Chem. Res. 1987. V. 20, № 11. P. 408-414.

103. Demkov Y.N., Kurasov P.B. Von NeumannWigner theorem: Level repulsion and degenerate eigenvalues. Theor. Math. Phys. 2007. V. 153, № 1. P. 1407-1422.

104. Guillaumont D., Vlček, A., Daniel C. Photoreactivity of $\mathrm{Cr}(\mathrm{CO})_{4}$ (2,2'-bipyridine): Quantum chemistry and photodissociation dynamics. J. Phys. Chem. A. 2001. V. 105, № 7. P. 1107-1114.
105. Costa P.J. [et al.] Photochemistry of methyltrioxorhenium revisited: A DFT/TD-DFT and CASSCF/MS-CASPT2 theoretical study. Organometallics. 2006. V. 25, № 22. P. 5235-5241.

106. Ben Amor N. [et al.] Photodissociation dynamics of trimethyltin iodide. Chem. Phys. 2007. V. 338, № 2-3. P. 81-89.

107. Ryther R.J., Weitz E. Reaction kinetics of coordinatively unsaturated iron carbonyls formed on gasphase excimer laser photolysis of iron pentacarbonyl. J. Phys. Chem. 1991. V. 95, № 24. P. 9841-9852.

108. Ryther R.J., Weitz E. Diode laser probes of the product distribution of coordinatively unsaturated iron carbonyls produced following excimer laser photolysis of iron pentacarbonyl in the gas phase. J. Phys. Chem. 1992. V. 96, № 6. P. 2561-2567.

109. Laser spectroscopy of highly vibrationally excited molecules: book / ed. Letokhov V.S. Bristol: Adam Hilger, 1989. 396 p.

110. Lehmann K.K., Scoles G., Pate B.H. Intramolecular dynamics from eigenstate-resolved infrared spectra. Annu. Rev. Phys. Chem. 1994. V. 45, № 1. P. 241-274.

111. Nesbitt D.J., Field R.W. Vibrational energy flow in highly excited molecules: Role of intramolecular vibrational redistribution. J. Phys. Chem. 1996. V. 100, № 31. P. 12735-12756.

112. Makarov A.A., Malinovsky A.L., Ryabov E.A. Intramolecular vibrational redistribution: from high-resolution spectra to real-time dynamics. PhysicsUspekhi. 2012. V. 55, № 10. P. 977-1007.

113. Poydashev D.G. [et al.] Ultrafast dissociation dynamics of $\left[\mathrm{Fe}(\mathrm{CO})_{5}\right]$ n clusters induced by femtosecond IR radiation. J. Phys. Chem. A. 2014. V. 118, № 47. P. $11177-11184$.

114. Kompanets V.O. [et al.] Dynamics of photoprocesses induced by femtosecond infrared radiation in free molecules and clusters of iron pentacarbonyl. J. Exp. Theor. Phys. 2016. V. 122, № 4. P. 621-632.

115. Hicks R.G. What's new in stable radical chemistry? Org. Biomol. Chem. 2007. V. 5, № 9. P. 1321-1338.

116. Griller D., Ingold K.U. Persistent carbon-centered radicals. Acc. Chem. Res. 1976. V. 9, № 1. P. 13-19.

117. Schäfer L. Electron diffraction studies of free radicals. I. Indenyl. J. Am. Chem. Soc. 1968. V. 90, № 15. P. 3919-3925.

118. Southern J.F. [et al.] Structural comparison of indene and indenyl using electron diffraction. J. Chem. Phys. 1971. V. 55, № 5. P. 2418-2421.

119. Bagratashvili V.N. [et al.] Isotopic selectivity of IR laser photodissociation of $\mathrm{CF}_{3} \mathrm{I}$ molecules. Appl. Phys. 1979. V. 20, № 3. P. 231-235.

120. Borden W.T., Davidson E.R. Potential surfaces for the planar cyclopentadienyl radical and cation. J. Am. 
Chem. Soc. 1979. V. 101, № 14. P. 3771-3775.

121. Ha T.-K., Meyer R., Günthard H.H. Ab initio ci potential surface and vibronic states of the $\mathrm{C}_{5} \mathrm{H}_{5}$ radical. Chem. Phys. Lett. 1980. V. 69, № 3. P. 510-513.

122. PierlootK., Persson B.J., Roos B.O. Theoretical study of the chemical bonding in $\left[\mathrm{Ni}\left(\mathrm{C}_{2} \mathrm{H}_{4}\right)\right]$ and ferrocene. J. Phys. Chem. 1995. V. 99, № 11. P. 3465-3472.

123. Wang H., Brezinsky K. Computational study on the thermochemistry of cyclopentadiene derivatives and kinetics of cyclopentadienone thermal decomposition. J. Phys. Chem. A. 1998. V. 102, № 9. P. 1530-1541.

124. Bearpark M., Robb M., Yamamoto N. A CASSCF study of the cyclopentadienyl radical: conical intersections and the Jahn-Teller effect. Spectrochim. Acta Part A Mol. Biomol. Spectrosc. 1999. V. 55, № 3. P. 639-646.

125. Zhou X., Hrovat D.A., Borden W.T. Calculations of the effects of substituents on bond localization in annelated cyclopentadienyl radicals. J. Am. Chem. Soc. 2007. V. 129, № 35. P. 10785-10794.

126. Zeng T. [et al.] Effects of spin-orbit coupling on covalent bonding and the Jahn-Teller effect are revealed with the natural language of spinors. J. Chem. Theory Comput. 2011. V. 7, № 9. P. 2864-2875.

127. Zou W., Filatov M., Cremer D. Bondpseudorotation, Jahn-Teller, and pseudo-JahnTeller effects in the cyclopentadienyl cation and its pentahalogeno derivatives. Int. J. Quantum Chem. 2012. V. 112, № 20. P. 3277-3288.

128. Lo P.-K., Lau K.-C. High-level ab initio predictions for the ionization energy, electron affinity, and heats of formation of cyclopentadienyl radical, cation, and anion, $\mathrm{C}_{5} \mathrm{H}_{5} / \mathrm{C}_{5} \mathrm{H}_{5}^{+} / \mathrm{C}_{5} \mathrm{H}_{5}^{-}$. J. Phys. Chem. A. 2014. V. 118, № 13. P. 2498-2507.

129. Liebling G.R., McConnell H.M. Study of molecular orbital degeneracy in $\mathrm{C}_{5} \mathrm{H}_{5}$. J. Chem. Phys. 1965. V. 42, № 11. P. 3931-3934.

130. Yu L. [et al.] Rotationally resolved electronic spectrum of jet-cooled cyclopentadienyl radical. J. Phys. Chem. 1988. V. 92, № 15. P. 4263-4266.

131. Yu L. [et al.] High resolution laser spectroscopy of asymmetrically deuterated cyclopentadienyl radicals: A study of vibronic degeneracy resolution and JahnTeller distortion. J. Chem. Phys. 1993. V. 98, № 4. P. 2682-2698.

132. Korolev V.A., Nefedov O.M. Direct IR spectroscopic study of the cyclopentadienyl radical. Russ. Chem. Bull. 1993. V. 42, № 8. P. 1436-1437.

133. Ihee H. [et al.] Ultrafast electron diffraction of transient cyclopentadienyl radical: A dynamic pseudorotary structure. Chem. Phys. Lett. 2002. V. 353, № 5-6. P. 325-334.

134. Herzberg G. Molecular spectra and molecular structure. III. Electronic spectra and electronic structure of polyatomic molecules: book. Van Nostrand, 1966. 784 p.
135. Jahn H.A., Teller E. Stability of degenerate electronic states in polyatomic molecules. Phys. Rev. 1936. V. 49. P. 874-880.

136. Jahn H.A., Teller E. Stability of polyatomic molecules in degenerate electronic states. I. Orbital degeneracy. Proc. R. Soc. A Math. Phys. Eng. Sci. 1937. V. 161, № 905. P. 220-235.

137. Salem L. The molecular orbital theory of conjugated systems: book. W.A. Benjamin, 1966. 576 p.

138. Ohnishi S., Nitta I. ESR study of free radicals produced in irradiated cyclopentadiene and cyclohexene: The cyclopentadienyl and cyclohexenyl radicals. J. Chem. Phys. 1963. V. 39, № 11. P. 2848-2849.

139. Liehr A.D. Topological aspects of the conformational stability problem. Part I. Degenerate electronic states. J. Phys. Chem. 1963. V. 67, № 2. P. 389-471.

140. Carrington A. [et al.] Isotope effects in electron spin resonance: the negative ion of cyclo-octatetraene1-d. Mol. Phys. 1965. V. 9, № 2. P. 187-190.

141. Kira M., Watanabe M., Sakurai H. Chemistry of organosilicon compounds. 131. Substituent effects by deuterium and alkyl groups and carbon-13 hyperfine coupling constants of cyclopentadienyl radicals as studied by electron spin resonance. J. Am. Chem. Soc. 1980. V. 102, № 16. P. 5202-5207.

142. Barker P.J., Davies A.G., Tse M.-W. The photolysis of cyclopentadienyl compounds of tin and mercury. Electron spin resonance spectra and electronic configuration of the cyclopentadienyl, deuteriocyclopentadienyl, and alkylcyclopentadienyl radicals. J. Chem. Soc. Perkin Trans. 2. 1980. № 6. P. 941-948.

143. Yu L., Williamson J.M., Miller T.A. Rotationally resolved electronic spectrum of jet-cooled deuterated cyclopentadienyl radical. Chem. Phys. Lett. 1989. V. 162, № 6. P. 431-436.

144. Cullin D.W. [et al.] High-resolution spectroscopy of jet-cooled substituted cyclopentadienyl radicals. J. Phys. Chem. 1992. V. 96, № 1. P. 89-94.

145. Meyer R. [et al.] Jahn-teller effect in cyclopentadienyl radical: delocalized vibronic valence isomerisation. Chem. Phys. Lett. 1979. V. 66, № 1. P. 65-71.

146. Engleman Jr. R., Ramsay D.A. Electronic absorption spectrum of the cyclopentadienyl radical $\left(\mathrm{C}_{5} \mathrm{H}_{5}\right)$ and its deuterated derivatives. Can. J. Phys. 1970. V. 48, № 8. P. 964-969.

147. Sun S., Bernstein E.R. Vibronic structure of the cyclopentadienyl radical and its nonrigid van der Waals cluster with nitrogen. J. Chem. Phys. 1995. V. 103, № 11. P. 4447-4454.

148. Almeida N.M.S., McKinlay R.G., Paterson M.J. Computation of excited states of transition metal complexes. Computational Studies in Organometallic Chemistry. Springer Verlag: Berlin, Heidelberg, 2014. P. 107-138. 
149. Fossey J., Lefort D., Sorba J. Free radicals in organic chemistry. Wiley, 1995. 322 p.

150. Skell P.S., Tuleen D.L., Readio P.D. Stereochemical evidence of bridged radicals. J. Am. Chem. Soc. 1963. V. 85, № 18. P. 2849-2850.

151. Ihee $\mathrm{H}$. [et al.] $\mathrm{CF}_{2} \mathrm{XCF}_{2} \mathrm{X}$ and $\mathrm{CF}_{2} \mathrm{XCF}_{2}$. radicals $(\mathrm{X}=\mathrm{Cl}, \mathrm{Br}, \mathrm{I})$ : $\mathrm{ab}$ initio and DFT studies and comparison with experiments. J. Phys. Chem. A. 2001. V. 105, № 14. P. 3623-3632.

152. Ihee H. [et al.] Ultrafast electron diffraction and structural dynamics: transient intermediates in the elimination reaction of $\mathrm{C}_{2} \mathrm{~F}_{4} \mathrm{I}_{2}$. J. Phys. Chem. A. 2002. V. 106, № 16. P. 4087-4103.

153. Shorokhov D., Zewail A.H. 4D electron imaging: principles and perspectives. Phys. Chem. Chem. Phys. 2008. V. 10, № 20. P. 2879-2893.

154. Ihee H., Zewail A.H., Goddard W.A. Conformations and barriers of haloethyl radicals $\left(\mathrm{CH}_{2} \mathrm{XCH}_{2}, \mathrm{X}=\mathrm{F}, \mathrm{Cl}, \mathrm{Br}, \mathrm{I}\right): \mathrm{Ab}$ initio studies. J. Phys. Chem. A. 1999. V. 103, № 33. P. 6638-6649.

155. Baskin J.S., Zewail A.H. Ultrafast electron diffraction: oriented molecular structures in space and time. ChemPhysChem. 2005. V. 6, № 11. P. 2261-2276.

156. Ischenko A.A., Ewbank J.D., Schäfer L. Structural and vibrational kinetics by time-resolved gas electron diffraction: stochastic approach to data analysis. J. Phys. Chem. 1995. V. 99, № 43. P. 15790-15797.

157. Ischenko A.A., Schäfer L., Ewbank J.D. Manifestation of chaotic nuclear dynamics of highly excited polyatomic molecules in time-resolved electron diffraction data. J. Phys. Chem. A. 1998. V. 102, № 37. P. 7329-7332.

158. Davisson C.J., Germer L.H. Reflection of electrons by a crystal of nickel: JOUR. Proc. Natl. Acad. Sci. U.S.A. 1928. V. 14, № 4. P. 317-322.

159. Thomson G.P., Reid A. Diffraction of cathode rays by a thin film. Nature. 1927. V. 119, № 3007. P. 890-890.

160. Dwyer J.R. [et al.] Femtosecond electron diffraction: "making the molecular movie". Philos. Trans. R. Soc. A Math. Phys. Eng. Sci. 2006. V. 364, № 1840. P. 741-778.

161. Ischenko A.A., Girichev G.V., Tarasov Y.I. Electron diffraction: structure and dynamics of free molecules and condensed matter. Moscow: FIZMATLIT, 2013. 616 p.

162. Dudek R.C., Weber P.M. Ultrafast diffraction imaging of the electrocyclic ring-opening reaction of 1,3-cyclohexadiene. J. Phys. Chem. A. American Chemical Society, 2001. V. 105, № 17. P. 4167-4171.

163. Siwick B.J. [et al.] An atomic-level view of melting using femtosecond electron diffraction. Science. American Association for the Advancement of Science, 2003. V. 302, № 5649. P. 1382-1385.

164. Ischenko A.A. [et al.] Structural and vibrational kinetics by stroboscopic gas electron diffraction: the 193 nm photodissociation of $\mathrm{CS}_{2}$. J. Phys. Chem. 1994. V. 98, № 35. P. 8673-8678.

165. Ischenko A.A., Schäfer L., Ewbank J. Timeresolved electron diffraction: a method to study the structural vibrational kinetics of photoexcited molecules. Timeresolved diffraction. Ch. 13 / ed. Helliwell J.R., Rentzepis P.M. Oxford University Press, 1997. P. 323-390.

166. Polanyi M., Wigner E. Über die Interferenz von Eigenschwingungen als Ursache von Energieschwankungen und chemischer Umsetzungen. Zeitschrift für Phys. Chemie. 1928. V. 139A, № 1. P. 439-451.

167. Evans M.G., Polanyi M. Some applications of the transition state method to the calculation of reaction velocities, especially in solution. Trans. Faraday Soc. 1935. V. 31. P. 875-894.

168. Evans M.G., Polanyi M. Further considerations on the thermodynamics of chemical equilibria and reaction rates. Trans. Faraday Soc. 1936. V. 32. P. 1333-1360.

169. Evans M.G., Polanyi M. On the introduction of thermodynamic variables into reaction kinetics. Trans. Faraday Soc. 1937. V. 33. P. 448-452.

170. Arrhenius S. Zur Theorie der Chemischen Reaktionsgeschwindigkeit. Z. Phys. Chem. 1899. V. 28. P. 317-335.

171. Emmanuel N.M., Knorre D.G. Kurs khimicheskoi kinetiki (A course in chemical kinetics). Moscow: Higher School, 1984. 462p. (in Russ.).

172. Levine R.D. Chemical reaction dynamics. Looks to the understanding of complex systems. Chemistry for the 21st Century / ed. Keinan E., Schechter I. Weinheim, Germany: Wiley-VCH Verlag $\mathrm{GmbH}$, 2001. P. 209-218.

173. Levine R.D. Molecular reaction dynamics: book. Cambridge University Press, 2009. 555 p.

174. Lobastov V.A. [et al.] Instrumentation for timeresolved electron diffraction spanning the time domain from microseconds to picoseconds. Rev. Sci. Instrum. 1998. V. 69, № 7. P. 2633-2643.

175. Ischenko A.A. Molecular tomography of the quantum state by time-resolved electron diffraction. Phys. Res. Int. 2013. V. 2013. P. 1-8.

176. Ischenko A.A. The study of coherent dynamics of the nuclei by time-resolved electron diffraction. III. Molecular quantum state tomography. Russ. J. Chem. Chem. Technol. 2009. V. 52, № 9. P. 62-66.

177. Schäfer L. [et al.] Ultrafast electron crystallography and nanocrystallography: for chemistry, biology and material science. Part I. Ultrafast electron crystallography. Russ. J. Chem. Chem. Technol. 2017. V. 60, № 5. P. 3.

178. Schäfer L. [et al.] Ultrafast electron crystallography and nanocrystallography: for chemistry, biology and material science. Part II. Ultrafast electron nanocrystallography. Russ. J. Chem. Chem. Technol. 2017. V. 60, № 6. P. 3. 
179. Shao H.-C., Starace A.F. Detecting electron motion in atoms and molecules. Phys. Rev. Lett. American Physical Society, 2010. V. 105, № 26. P. 263201 (1-4).

180. Shao H.-C., Starace A., Madsen L. Ultrafast electron pulse (e,2e) processes. Bull. Am. Phys. Soc. 43rd Annu. Meet. APS Div. At. Mol. Opt. Phys. 2012. V. 57, № 5. P. Abstract: N3.00008.

181. Hensley C.J., Yang J., Centurion M. Imaging of isolated molecules with ultrafast electron pulses. Phys. Rev. Lett. 2012. V. 109, № 13. P. 133202.

\section{About the authors:}

Anatoly A. Ischenko, Dr.Sci. (Chemistry), Professor, Head of Alimarin Department of Analytical Chemistry, Lomonosov Institute of Fine Chemical Technologies, Moscow Technological University (86, Vernadskogo pr., Moscow 119571, Russia).

Yury I. Tarasov, Dr.Sci. (Phys.-Mathematics), Professor, Head of Department of Physics and Technical Mechanics, Lomonosov Institute of Fine Chemical Technologies, Moscow Technological University (86, Vernadskogo pr., Moscow 119571, Russia).

Lothar Schäfer, Professor, Department of Chemistry and Biochemistry, University of Arkansas (Fayetteville, AR, U.S.A., AR72701).

\section{Об авторах:}

ниенко Анатолий Александрович, доктор химических наук, профессор, заведующий кафедрой аналитической химии им. И.П. Алимарина Института тонких химических технологий им. М.В. Ломоносова ФГБОУ ВО «Московский технологический университет» (119571, Россия, Москва, пр-т Вернадского, д. 86).

Tарасов Юрий Нгоревич, доктор физико-математических наук, профессор, заведующий кафедрой физики и технической механики Института тонких химических технологий им. М.В. Ломоносова ФГБОУ ВО «Московский технологический университет» (119571, Россия, Москва, пр-т Вернадского, д. 86).

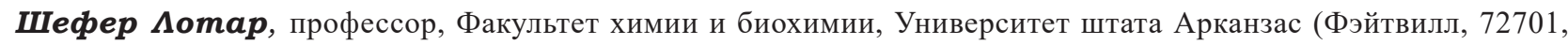
Арканзас, США). 